Prendes-Espinosa, Maria Paz; Castañeda-Quintero, Linda; Solano-Fernández, Isabel María; Roig-Vila, Rosabel; Aguiar-Perera, $\mathrm{M}^{\mathrm{a}}$ Victoria \& Serrano-Sánchez, José Luis (2016). Validación de un cuestionario sobre hábitos de trabajo y aprendizaje para futuros profesionales: explorar los Entornos Personales de Aprendizaje. RELIEVE, 22(2), art. 6. doi: http://dx.doi.org/10.7203/relieve.22.2.7228

\title{
Validación de un cuestionario sobre hábitos de trabajo y aprendizaje para futuros profesionales: Explorar los Entornos personales de Aprendizaje
}

\author{
Validation of a Questionnaire on Work and Learning Habits for Future Professionals: \\ Exploring Personal Learning Environments
}

\author{
Prendes-Espinosa, María Paz ${ }^{(1)}$; Castañeda-Quintero, Linda ${ }^{(1)}$; Solano-Fernández, Isabel \\ María $^{(1)}$; Roig-Vila, Rosabel ${ }^{(2)}$; Aguiar-Perera, M $^{\text {a }}$ Victoria $^{(3)}$; Serrano-Sánchez, José Luis ${ }^{(1)}$ \\ (1) Universidad de Murcia (2) Universidad de Alicante (3) Universidad de las Palmas de Gran Canaria
}

\begin{abstract}
Resumen
Este artículo describe el proceso completo de validación del instrumento de recogida de información del proyecto CAPPLE. La validación del instrumento - un cuestionario onlinepretende garantizar la fiabilidad, validez, pertinencia y la funcionalidad del proceso de recogida. Se ha optado por un método de validación basado en tres procedimientos sucesivos y complementarios: 1) un juicio de expertos realizado por 8 profesionales en tres rondas consecutivas; 2) una ronda de entrevistas cognitivas a 24 sujetos con 10 ítems cruciales; y 3) una prueba piloto con una muestra invitada de 400 sujetos, de los que 224 se consideran muestra productora de datos. Tras la realización de los tres procedimientos se ha conseguido un instrumento conformado por cuatro dimensiones básicas (autopercepción, gestión de la información, gestión del proceso de aprendizaje y comunicación) y que resulta de gran utilidad en el estudio de los Entornos Personales de Aprendizaje de los estudiantes de Educación Superior.
\end{abstract}

\section{Palabras clave:}

Entornos Personales de Aprendizaje, validación de cuestionario, PLE, autopercepción, gestión de la información, gestión del proceso de aprendizaje y comunicación.

\footnotetext{
Abstract

This article describes the entire process of validating the data collection instrument of the CAPPLE project.

The validation of the instrument (an online survey) aims to ensure the reliability, validity, relevance and functionality of the collection process. Hence, a validation method based on three complementary procedures has been chosen: expert judgement by eight experts in three consecutive rounds; a round of cognitive interviews with 24 subjects on 10 critical items, and a pilot study with 400 invited subjects, of which 224 are considered the final sample.

Following the completion of the three methods described, we get an instrument that meets the validation criteria, configured by four basic dimensions (self-perception, information management, management of the learning process and communication) and that could be considered as a very useful tool in the study of Personal Learning Environments of university students.
}

Fecha de recepción 2015 Noviembre 03

Fecha de aprobación 2016 Septiembre 01

Fecha de publicación 2016 Septiembre 03

\section{Keywords:}

Personal Learning Environments, questionnaire validity, PLE, self-perception, information management, management of the learning process, communication.

Este artículo describe el proceso completo de validación del instrumento de recogida de información del proyecto CAPPLE -un cuestionario para ser administrado online-, que pretende garantizar la fiabilidad, validez, pertinencia y la funcionalidad del proceso de 
Prendes-Espinosa, Maria Paz; Castañeda-Quintero, Linda; Solano-Fernández, Isabel María; Roig-Vila, Rosabel; Aguiar-Perera, Ma Victoria \& Serrano-Sánchez, José Luis (2016). Validación de un cuestionario sobre hábitos de trabajo y aprendizaje para futuros profesionales: explorar los Entornos Personales de Aprendizaje. RELIEVE, 22(2), art. 6. doi: http://dx.doi.org/10.7203/relieve.22.2.7228

recogida. La validación del instrumento que describimos en este artículo es en sí misma un proceso de interés (García, Ferrández, Sales \& Moliner, 2006; Jaramillo \& Oses, 2012), pero a ello se añade el valor de presentar una herramienta útil para el estudio de los Entornos Personales de Aprendizaje de los estudiantes de Educación Superior que entendemos podría ser utilizado en el futuro en otros ámbitos de acción o servir como base de estudios más profundos.

\section{La exploración de los entornos personales de aprendizaje (PLE)}

Los Entornos Personales de Aprendizaje en adelante PLE (Personal Learning Environment) - son uno de los temas que ha despertado mayor interés en los últimos tiempos en el ámbito de la tecnología educativa, la didáctica y la educación en general.

Se entiende por PLE el "conjunto de herramientas, fuentes de información, conexiones y actividades que una persona usa de forma asidua para aprender" (Adell \& Castañeda, 2010 p. 20), en el que se incluyen también los procesos cognitivos, las estrategias $\mathrm{y}$ actitudes personales que promueven ese aprendizaje (Castañeda \& Adell, 2013), entendidos de forma holística, dinámica $\mathrm{e}$ interrelacionada.

$\mathrm{Su}$ formulación, como un enfoque para entender cómo aprende la gente -más allá de con qué aprende (tecnología) -, ha estimulado una línea de trabajo que incide en casi todos los aspectos de la pedagogía y que plantea numerosos desafíos, tanto en términos de investigación teórica como de implementación práctica.

La investigación centrada en el estudio de PLE en los últimos años ha experimentado una tendencia alcista (Buchem, Attwell \& TorresKompen, 2011; Gallego-Arrufat \& ChavesBarboza, 2014; Llorente, 2013) en la que los estudios han estado especialmente dirigidos a conceptualizarlos, a difundir el término, a ubicarlos y a ayudar a construirlos en situaciones concretas -especialmente en situaciones de educación informal- (Attwell, Castañeda \& Buchem, 2013). La investigación empírica sobre el uso del concepto de PLE como fundamento para planteamientos más formales ha tenido que esperar más.

Como subrayan Castañeda y Adell (2014: 756) la mayoría de las investigaciones sobre PLE hasta el momento centran su interés en el análisis de tres cuestiones clave: a) "cómo las personas integran las distintas tecnologías en sus PLE y cómo las usan", b) "los mecanismos psicológicos ligados a ciertos elementos de los PLE, como el sentido de propiedad de los artefactos construidos por los aprendices", y c) "la relación entre algún rasgo de autorregulación del aprendizaje y el uso de herramientas que forman parte del PLE", aunque estas perspectivas siguen ofreciendo sobre todo una representación tecnológica de los PLE. Coincidiendo con Attwell et al. (2013), Gallego-Arrufat y Chaves-Barboza (2014:14) destacan que "sería importante favorecer la realización de un mayor número de investigaciones empíricas en las que se asocie el análisis del PLE con la mejora del aprendizaje; se investigue la capacitación tecnológica que tienen los docentes y los estudiantes (en los centros, en las universidades y otras) en herramientas que pueden conformar sus PLE y se analice el reto docente que supone poner en acción la idea de PLE en su práctica didáctica".

El proyecto CAPPLE (www.um.es/ple) tiene como objetivo precisamente estudiar cómo son los PLE de los futuros profesionales universitarios en España (estudiantes de último curso de las universidades españolas). Se trata de una apuesta por ir más allá de la definición o discusión teórica y la exploración prospectiva en entornos pequeños, para hacer un análisis de la realidad educativa de la educación en general, y de la educación universitaria en particular desde una perspectiva que entiende que uno de los principales retos de la educación actual es formar personas - profesionales en este casoque sepan aprender eficientemente, y conocer su PLE nos puede dar una idea de hasta qué 
Prendes-Espinosa, Maria Paz; Castañeda-Quintero, Linda; Solano-Fernández, Isabel María; Roig-Vila, Rosabel; Aguiar-Perera, Ma Victoria \& Serrano-Sánchez, José Luis (2016). Validación de un cuestionario sobre hábitos de trabajo y aprendizaje para futuros profesionales: explorar los Entornos Personales de Aprendizaje. RELIEVE, 22(2), art. 6. doi: http://dx.doi.org/10.7203/relieve.22.2.7228

punto es así. No en vano se parte de que el PLE es una idea que nos ayuda a entender "cómo aprendemos las personas usando eficientemente las tecnologías que tenemos a disposición" (Castañeda y Adell, 2013:15).

Conseguir la información pertinente para realizar ese análisis en profundidad en una muestra suficientemente representativa que nos permita hacer inferencias sobre la población y plantear propuestas y discusiones relevantes a nuestros contextos educativos es el objetivo último del diseño del instrumento CAPPLE y su validación es el reto que proponemos en este documento.

\section{Un instrumento para describir PLE en el proyecto CAPPLE}

El proyecto "Competencias para el aprendizaje permanente basado en el uso de PLE (entornos personales de aprendizaje): análisis de los futuros profesionales $y$ propuestas de mejora" -CAPPLE- (referencia EDU2012-33256), es una investigación financiada por el Ministerio español de Economía y Competitividad que pretende la descripción y el análisis prospectivo, tanto en términos técnicos como en términos funcionales, de los entornos personales de aprendizaje (PLE) de los futuros profesionales españoles de todas las áreas de conocimiento (estudiantes de último año de carrera universitaria) de España (http://www.um.es/ple).

En otras palabras, el proyecto CAPPLE pretende describir cómo perciben los estudiantes de último curso la forma en la que aprenden $\mathrm{y}$ cómo podría traducirse en características de su PLE. A partir de tales descripciones podremos realizar inferencias sobre su formación $\mathrm{y}$ sus competencias, especialmente algunas referidas de modo específico a su formación como profesionales universitarios que esperamos puedan ser realmente interesantes para nuestras instituciones y sus planteamientos transversales.

Para conseguirlo, como ya hemos descrito en algunas publicaciones anteriores (Prendes y
Castañeda, 2013; Prendes, Castañeda, Ovelar y Carreras, 2014), se diseñó un proyecto basado en 4 fases claramente definidas y coincidentes con los objetivos del proyecto:

(1) Diseño y validación de los instrumentos de recogida de información sobre PLE, estrategia de recolección de datos.

(2) Recogida de información sobre PLE y análisis de datos.

(3) Análisis descriptivo y comparativo de los modelos de PLE subyacentes.

(4) Análisis y prospección de las implicaciones educativas e institucionales de los resultados obtenidos. Propuestas prácticas pedagógicas y organizativas.

Sin embargo, si algo es evidente en todas ellas, es que la recogida de datos y el instrumento con el que se pretenden recoger dichos datos resulta de una importancia central. Por ello, la creación y validación del cuestionario de CAPPLE tenía como reto responder inequívocamente al primero de los objetivos del proyecto:

Describir las estrategias y herramientas concretas utilizadas de forma habitual por estudiantes universitarios de último curso de todas las áreas de conocimiento para enriquecer $\mathrm{y}$ gestionar $\mathrm{su}$ proceso de aprendizaje, dentro y fuera de las aulas, especialmente aquellas que tienen lugar en contextos electrónicos.

Ese objetivo y la naturaleza del proyecto determinan aspectos que actúan como condicionantes del proceso de recogida de datos que han de tenerse en cuenta a la hora de crear y validar un instrumento idóneo. Por un lado, pretende hacerse una recogida muy amplia ya que se trata de un proyecto nacional que pretende tener una muestra representativa -en torno a 1000 - de los estudiantes de último curso de la universidad española y eso justifica más si cabe el uso de un cuestionario validado (Best y Kahn, 2006); pero, por otro lado, se trata de una recogida de datos que pretende ser exhaustiva con el fin de que el objeto observado pueda ser descrito $\mathrm{y}$ detallado en toda su extensión, aunque resulte 
Prendes-Espinosa, Maria Paz; Castañeda-Quintero, Linda; Solano-Fernández, Isabel María; Roig-Vila, Rosabel; Aguiar-Perera, Ma Victoria \& Serrano-Sánchez, José Luis (2016). Validación de un cuestionario sobre hábitos de trabajo y aprendizaje para futuros profesionales: explorar los Entornos Personales de Aprendizaje. RELIEVE, 22(2), art. 6. doi: http://dx.doi.org/10.7203/relieve.22.2.7228

extenso. Además el cuestionario ha de ser una herramienta que recoja la auto-percepción de los estudiantes sobre su entorno personal de aprendizaje, pero sin explicitar el concepto de PLE ni las dimensiones que lo configuran.

Tomamos como núcleo de partida la definición de Adell y Castañeda (2010: 23) que define los PLE como "el conjunto de herramientas, fuentes de información, conexiones y actividades que cada persona utiliza de forma asidua para aprender". Se entiende que incluyen "procesos, experiencias y estrategias que el aprendiz puede $-\mathrm{y}$ debeponer en marcha para aprender, en las actuales condiciones sociales y culturales" (Castañeda \& Adell, 2013:15).

Para la construcción de este instrumento se partió de la revisión bibliográfica y documental de otros proyectos y de la literatura científica relacionada con los PLE, con los procesos de autorregulación (estrategias cognitivas y de motivación) y con el uso de herramientas telemáticas para el aprendizaje (autodirigido o dirigido por otros). Utilizamos como base los principales instrumentos sobre estrategias de aprendizaje y aprendizaje autorregulado (Pintrich et al., 1991; Midgley et al., 2000; Martín et al., 2007), así como el instrumento sobre el conocimiento y uso de las herramientas telemáticas de Prendes (2010). A partir del procedimiento seguido se concretaron cuatro dimensiones -con subdimensiones que las definen y describen- que configurarían el centro de nuestra recogida de datos, así:
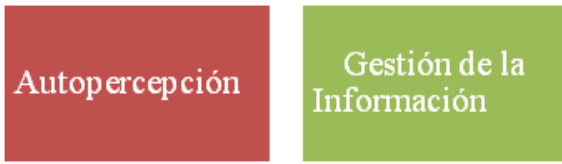

Gestión del

Proceso de Aprendizaje

Figura 1. Dimensionas básicas proyecto proyecto CAPPLE (Prendes et al. 2014:8)

Se hizo un esfuerzo importante por no incluir sólo conceptos, sino asociar conceptos a indicadores y escalas ya validadas en otras investigaciones anteriores $\mathrm{y}$, tras un proceso de recogida y depuración de dos vueltas consecutivas, se obtuvo la primera versión del cuestionario (el proceso de construcción del instrumento se describe más detalladamente en Prendes et al., 2014).

\section{Método: el proceso de validación del instrumento CAPPLE}

El proceso de validación de este instrumento responde en general a la necesidad de garantizar la fiabilidad, validez, pertinencia y la funcionalidad del proceso de recogida, garantizando que el instrumento realmente mide lo que debe medir (Knapp y Mueller, 2010). No se trata sólo de la validación de una escala que evalúe un aspecto acotado del proceso de aprendizaje de los individuos, sino de la validación de un instrumento que pueda describir con detalle cómo nuestros estudiantes de último curso aprenden usando $-\mathrm{O}$ notecnología.

Por la complejidad del instrumento y los condicionantes a los que se aludía en el apartado anterior se ha estructurado en tres procedimientos consecutivos y complementarios en los que, a su vez, se han combinado procedimientos cualitativos $\mathrm{y}$ cuantitativos - con sus debilidades- (Utkin, 2006) que han aportado una mayor robustez al cuestionario que se refleja en la validez denotada en la investigación. Al tratarse de etapas sucesivas, cada vez que se terminaba uno de los procedimientos se generaba una nueva versión del cuestionario que era la que se sometía al siguiente proceso de validación.

En primer lugar, partiendo del primer borrador del cuestionario (Anexo 1) se hizo una validación de constructo a través de juicio de expertos; posteriormente se llevaron a cabo entrevistas cognitivas para la validación de procedimiento y contenido del instrumento (los cambios incluidos tras los procedimientos 
Prendes-Espinosa, Maria Paz; Castañeda-Quintero, Linda; Solano-Fernández, Isabel María; Roig-Vila, Rosabel; Aguiar-Perera, Ma Victoria \& Serrano-Sánchez, José Luis (2016). Validación de un cuestionario sobre hábitos de trabajo y aprendizaje para futuros profesionales: explorar los Entornos Personales de Aprendizaje. RELIEVE, 22(2), art. 6. doi: http://dx.doi.org/10.7203/relieve.22.2.7228

de juicio de expertos y entrevistas cognitivas pueden apreciarse en el borrador de cuestionario incluido en el anexo 4); y, finalmente, se realizó una prueba piloto para hacer las pruebas de fiabilidad interna y cerrar algunos aspectos metodológicos.

El juicio de expertos es uno de los procedimientos recogidos por Crocker y Algina (1986) para la construcción y validación de un instrumento de investigación, entendiendo que puede ayudar a calificar el instrumento en términos de la eficacia con que muestra aspectos significativos de su propósito y proporcionar estimaciones de la validez de contenido (Best \& Kahn, 2006). Teniendo en cuenta las dificultades de realizar este procedimiento presencialmente $\mathrm{y}$ con el objetivo además de evitar la influencia entre expertos, se decidió realizar un juicio de expertos por el método de agregados individuales.

En el caso de las entrevistas cognitivas, se trata de un procedimiento basado en métodos cognitivos que permiten obtener evidencias sobre la validez de los ítems formulados en el cuestionarios a través de la información aportada por algunos sujetos durante el proceso de respuesta del cuestionario (Snijkers, 2002; Willis, 2005; Wolley, Bowen \& Bowen, 2006; Dilman, 2007).

El tipo de entrevista empleada ha sido la entrevista cognitiva de sondeo concurrente (Smith y Molina, 2011) que consistió en solicitarle a los alumnos que fueran respondiendo en voz alta a las preguntas que les planteaban, manifestando en ese momento sus dudas, problemas o inquietudes. Para el desarrollo de la entrevista, se siguieron las recomendaciones de Snijkers, (2002), referidas a elegir de entre el total de ítems del cuestionario aquellos que se consideraran diferentes o especialmente problemáticos por su contenido (target test questions), de manera que se garantizase la inclusión de al menos un elemento con cada tipo de escala utilizada y con núcleos temáticos que abarcaran el espectro completo del cuestionario. A esas preguntas utilizadas en el procedimiento se consideró preguntas diana.

Así, los investigadores del proyecto fueron preguntados por cuáles consideraban que eran las 10 preguntas del cuestionario susceptibles de ser incluidas en el proceso, y aquellas que seleccionadas por un mayor número de investigadores, fueron elegidas preguntas diana,y en torno a ellas se fueron planteando una serie de cuestiones (pruebas generales y específicas) que aportarían información sobre la forma en la que el sujeto afrontaba la respuesta a la pregunta del cuestionario. El protocolo de entrevista cognitiva (incluido en el Anexo 2) fue elaborado en el mes de mayo de 2013 y repartido entre todos los investigadores que habrían de estar involucrados en la recogida, de manera que pudieran solventarse las dudas que surgieran antes de su administración. El proceso de recogida de información se inició en junio de 2013.

Los entrevistadores fueron seleccionados de entre los miembros del equipo de investigación de las Universidades del País Vasco, Oviedo, Las Palmas de Gran Canaria y Murcia. La selección de los participantes fue realizada directamente por los entrevistadores, siguiendo los criterios que previamente fueron establecidos: se seleccionó un alumno de último curso de titulación (Grado, Licenciatura o Diplomatura) por área de especialización en cada una de las universidades mencionadas (o de universidades ubicadas en la misma zona geográfica), a excepción de la de Murcia, que seleccionó dos alumnos por área de especialización.

Las entrevistas fueron grabadas $y$ posteriormente transcritas. El procedimiento de tratamiento y análisis de la información se realizó por áreas de especialización, de modo que finalmente dispusimos de recomendaciones y propuestas de mejora de cada una de las preguntas en función de cada rama de especialización. La matriz de datos cualitativos realizada a partir de los datos seleccionados tenía tres categorías básicas: Resultados generales; Comentarios de los 
Prendes-Espinosa, Maria Paz; Castañeda-Quintero, Linda; Solano-Fernández, Isabel María; Roig-Vila, Rosabel; Aguiar-Perera, Ma Victoria \& Serrano-Sánchez, José Luis (2016). Validación de un cuestionario sobre hábitos de trabajo y aprendizaje para futuros profesionales: explorar los Entornos Personales de Aprendizaje. RELIEVE, 22(2), art. 6. doi: http://dx.doi.org/10.7203/relieve.22.2.7228

participantes; Recomendaciones y propuestas de mejora. La categoría de resultados generales aporta información sobre la inteligibilidad del enunciado y las opciones de respuesta. Por otro lado, en los comentarios se han recogido información específica sobre algunas de las propuestas, dudas o comentarios recogidos por los participantes. A partir de estos comentarios, se elaboró la última categoría referida a recomendaciones, en la que se sintetizaron, en función de la frecuencia de aparición de los comentarios, dudas o propuestas, los principales cambios que había que realizar en el instrumento.

A partir de los resultados, se rediseñó el cuestionario y con él se realizó el último procedimiento más usado en Ciencias Sociales para la medida de la fiabilidad de un instrumento, es decir, la combinación de análisis descriptivo (estadísticos descriptivos básicos), confirmatorio (análisis de tallos y hojas) y finalmente correlacional basado en el Alpha de Cronbach de cada uno de los ítems (Knapp \& Mueller, 2010).

Para la selección de la muestra de esta prueba piloto se siguieron las recomendaciones de autores como Nunnally (1978), Cohen (1988), Kline (1994), Osborne y Costello (2004), Morales (2012 y 2013) y se realizó con una muestra invitada de 400 alumnos de diferentes universidades participantes en el proyecto y se utilizó un cuestionario en línea que se aplicó entre diciembre de 2013 y enero de 2014.

Es importante destacar que los resultados de este último procedimiento solo se aplican a las preguntas del cuestionario que corresponden con variables de tipo escalar, y que los resultados fueron discutidos en función de las necesidades de información del proyecto para tomar decisiones sobre si incluirlas o no en cuestionario final. Así, las preguntas nominales o abiertas, o aquellas que no han podido ser incluidas en el informe del tercer mecanismo de validación por ser único ítem de categoría o similar, se incluyeron o no en el cuestionario final en función de su utilidad para la recogida de información del proyecto, siempre que hubiesen superado los dos mecanismos de validación anteriores.

Procedimiento de validación 1: Juicio de Expertos

Una vez construida la primera versión del instrumento a partir del trabajo del equipo de investigación, para una primera evaluación se envió a un grupo diferente de expertos que estuvieron implicados en el procedimiento de construcción del mismo. Se seleccionó a un grupo de 8 expertos, uno por cada universidad implicada en el proyecto -dos por aquellas donde había más de 3 investigadores implicados-, que no estuvieron implicados directamente en la realización de la primera versión del cuestionario y que por su categoría de expertos en educación, en educación superior $y$ en tecnología educativa, se consideraban idóneos para la validación del instrumento.

Los expertos debían juzgar de manera independiente la relevancia y congruencia de los ítems con el contenido teórico y también la claridad en la redacción y el sesgo o tendenciosidad en la formulación de los ítems. Como se ha dicho antes, se usó el método de agregados individuales y se pidió individualmente a cada experto que diese una estimación directa de los ítems del instrumento.

Cada experto recibió el instrumento de validación en una tabla que identificaba cada pregunta e ítem con la dimensión a la que pertenecía y con otra en la que debía indicar su acuerdo o desacuerdo en relación a la pregunta y el contenido, la claridad de la misma y su formulación (incluyendo enunciado y escala), si se observa tendenciosidad o sesgo y un espacio abierto para las observaciones.

Teniendo en cuenta que en la primera versión del cuestionario enviada a los jueces incluía 66 preguntas con un total de más de 360 ítems, es evidente que el cuestionario necesitaba reducirse, así que se decidió asumir en la primera ronda un criterio restrictivo respecto al acuerdo de los jueces: sólo habrían de conservarse aquellas preguntas en las que 
Prendes-Espinosa, Maria Paz; Castañeda-Quintero, Linda; Solano-Fernández, Isabel María; Roig-Vila, Rosabel; Aguiar-Perera, Ma Victoria \& Serrano-Sánchez, José Luis (2016). Validación de un cuestionario sobre hábitos de trabajo y aprendizaje para futuros profesionales: explorar los Entornos Personales de Aprendizaje. RELIEVE, 22(2), art. 6. doi: http://dx.doi.org/10.7203/relieve.22.2.7228

coincidiesen plenamente los jueces (preguntas congruentes, claras en su redacción y no tendenciosas).

En una segunda ronda se preguntó a los jueces si consideraban que alguna de las preguntas podían combinarse en una y que hicieran su propuesta de enunciación. Las propuestas de enunciación se reorganizaron y se volvieron a enviar a todos los expertos para hacer un juicio como el de la primera ronda y que seguiría el mismo criterio de selección.

El resultado de este procedimiento de validación, aunque incluyendo los matices incluidos por el procedimiento siguiente (las entrevistas cognitivas), se pueden apreciar en el Anexo 4 de este documento.

\section{Procedimiento de validación 2: entrevistas cognitivas}

La técnica de selección de los participantes en las entrevistas cognitivas fue no probabilística por cuotas, es decir, se ha realizado atendiendo a la organización de las diferentes titulaciones por áreas de especialización, encontrando 7 alumnos de Ciencias Sociales y Jurídicas, 4 alumnos de Ciencias, 4 alumnos de Ciencias de la Salud, 5 alumnos de Ingeniería y Arquitectura y 4 alumnos de Letras y Humanidades (Tabla 1). El 90\% de los alumnos que han participado en esta fase de la investigación tienen una edad comprendida entre 20 a 26 años.

Tabla1. Participantes en las entrevistas cognitivas.

\begin{tabular}{|c|c|c|}
\hline TITULACIÓN & UNIVERSIDAD & EDAD \\
\hline \multicolumn{3}{|c|}{ CIENCIAS SOCIALES Y JURÍDICAS } \\
\hline Grado en Publicidad y Relaciones Públicas & Universidad del País Vasco (EHU) & 23 \\
\hline Licenciatura en Psicopedagogía & U. de Las Palmas de Gran Canaria (ULPGC) & 21 \\
\hline Grado en Educación Primaria & \multirow[t]{3}{*}{ Universidad de Oviedo (UNIOVI) } & - \\
\hline Diplomatura en Educación Primaria & & - \\
\hline Diplomatura en Educación Infantil & & - \\
\hline Grado en Educación Social & \multirow[t]{2}{*}{ Universidad de Murcia (UM) } & 35 \\
\hline Grado en Relaciones Laborales y Recursos Humanos & & 24 \\
\hline \multicolumn{3}{|c|}{$\begin{array}{ll} & \text { CIENCIAS }\end{array}$} \\
\hline Grado en Biología & EHU & 23 \\
\hline Grado en Ciencias del Mar & ULPGC & 23 \\
\hline Grado en Biología & \multirow[t]{2}{*}{ UM } & 20 \\
\hline Grado en Matemáticas & & 21 \\
\hline \multicolumn{3}{|c|}{ CIENCIAS DE LA SALUD } \\
\hline Grado en Medicina & EHU & 24 \\
\hline Grado en Enfermería & ULPGC & 23 \\
\hline Grado en Psicología & UM & 22 \\
\hline Grado en Actividad Física y del Deporte & Universidad Católica de San Antonio (UCAM) & 31 \\
\hline \multicolumn{3}{|c|}{ INGENIERÍA Y ARQUITECTURA } \\
\hline Grado en Ingeniería Industrial & EHU & 23 \\
\hline Grado en Ingeniería Informática & ULPGC & 23 \\
\hline Grado en Ingeniería Industrial & UNIOVI & - \\
\hline Grado en Ingeniería Industrial & Universidad Politécnica de Cartagena (UPCT) & 24 \\
\hline Grado en Ingeniería Informática & UM & 22 \\
\hline \multicolumn{3}{|c|}{ LETRAS Y HUMANIDADES } \\
\hline Grado en Bellas Artes & EHU & 23 \\
\hline Grado en Geografía & ULPGC & 26 \\
\hline Grado en Lengua y Literatura & UM & 21 \\
\hline Grado en Historia & & 26 \\
\hline
\end{tabular}


Prendes-Espinosa, Maria Paz; Castañeda-Quintero, Linda; Solano-Fernández, Isabel María; Roig-Vila, Rosabel; Aguiar-Perera, Ma Victoria \& Serrano-Sánchez, José Luis (2016). Validación de un cuestionario sobre hábitos de trabajo y aprendizaje para futuros profesionales: explorar los Entornos Personales de Aprendizaje. RELIEVE, 22(2), art. 6. doi: http://dx.doi.org/10.7203/relieve.22.2.7228

Una vez codificados y analizados los datos obtenidos de la entrevista cognitiva, presentamos en este apartado las recomendaciones y propuestas de mejora que los participantes realizaron para cada una de las preguntas target del cuestionario.

A nivel metodológico, las recomendaciones realizadas por los participantes hacen referencia tanto a la presentación de la escala de medida utilizada en el instrumento, como a la formulación de los ítems.

Las preguntas 7, 11 y 12 no presentan la escala de medida utilizada en el resto de ítems. Los participantes manifestaron que esto les provocaba inseguridad a la hora de responder. En este sentido, se recomienda el uso de esta escala en todos los ítems que sean claves para definir las dimensiones y subdimensiones que subyacen al modelo teórico planteado en el cuestionario.

Es preciso revisar la formulación de los ítems que están en negativo. Los participantes detectaron que en las preguntas 6 y 10 existen dos opciones de respuestas formuladas en negativo. En este sentido, se recomienda reformular estas opciones ya que existen dos opciones en la escala de medida que nos pueden aportar la información que necesitamos: "No se aplica o no lo uso" y "Nunca o casi nunca". Asimismo, se sugiere que sean revisados el resto de ítems del instrumento general para detectar la posible reformulación de preguntas $\mathrm{u}$ opciones de respuesta que están en negativo.

A nivel de contenido, las recomendaciones y propuestas de mejora han sido recogidas en la tabla 3. En líneas generales, es preciso indicar que la única pregunta en la que no se proponen mejoras ni cambios es la 7, referida al procedimiento de búsqueda en Internet. Las preguntas que han resultado más ininteligibles para los participantes, o que les ha suscitado más dudas, han sido la 6,8 y 12 , esta última destacada por la práctica totalidad de los estudiantes.

A nivel ortográfico $y$ de estilo, los participantes también han destacado términos que no se encuentran bien escritos, por aparición inadecuada u omisión de tildes, por uso inadecuado de tiempos verbales, por un uso inadecuado del plural, etc. Estos cambios han sido incorporados directamente en la nueva formulación de los ítems.

Tabla 2. Recomendaciones de mejora arrojadas por la entrevista cognitiva a nivel de contenido

PREGUNTAS RECOMENDACIONES

La mención de herramientas o servicios específicos dentro de algunas categorías puede dificultar que la información se entienda correctamente.

Se aprecia que, al poner Youtube como ejemplo de información multimedia en red en el

PREGUNTA 4: cuestionario, los participantes consideran que son vídeos.

Se sugiere que la cuestión de medios de comunicación en red y medios convencionales se formulen una a continuación de la otra.

Se recomienda revisar el número de opciones, pues parece que hay muchas opciones de respuesta en el ítem, y puede llevar a confusión.

Se recomienda hacer el enunciado más entendible en relación a la expresión "cuando aprendes en Internet" y el verbo "fijar".

PREGUNTA 5 En cuanto a las opciones, se recomienda eliminar o reformular las opciones "me ajusto a las

Cuando aprendes en Internet, ¿cómo fijas lo que debes aprender?

PREGUNTA 6

A la hora de organizar mi tiempo en cuanto a trabajo y tareas necesidades laborales", o reformularla, por ejemplo, poniendo "me ajusto a lo que me exigirán en mi futuro laboral", y "me ajusto a lo que me exigirán mis colegas"; se considera pertinente sustituir "colegas" por compañeros.

Se recomienda reformular o eliminar las opciones de "me ajusto a mis capacidades académicas".

Se recomienda eliminar o completar el término "herramienta agregador" porque no se entiende. Se podría decir "usar herramientas que permitan recibir información actualizada (RSS, feeds...), es decir, un agregador de información, noticias o contenidos".

Las herramientas mencionadas generan confusión, por tanto habrá que redactarlo de modo que sea más entendible y claro. El hecho de que aparezcan herramientas que no se conocen ni 
Prendes-Espinosa, Maria Paz; Castañeda-Quintero, Linda; Solano-Fernández, Isabel María; Roig-Vila, Rosabel; Aguiar-Perera, Ma Victoria \& Serrano-Sánchez, José Luis (2016). Validación de un cuestionario sobre hábitos de trabajo y aprendizaje para futuros profesionales: explorar los Entornos Personales de Aprendizaje. RELIEVE, 22(2), art. 6. doi: http://dx.doi.org/10.7203/relieve.22.2.7228

\section{PREGUNTAS RECOMENDACIONES}

utilizan provoca inseguridad a la hora de responder.

Valorar si es pertinente incluir una categoría que haga referencia a "otra forma de organizarte".

\begin{tabular}{|c|c|}
\hline $\begin{array}{c}\text { PREGUNTA 7 } \\
\text { Para acceder a la } \\
\text { información realizo... }\end{array}$ & No se proponen modificaciones. \\
\hline $\begin{array}{c}\text { PREGUNTA } 8 \\
\text { Cuando quiero } \\
\text { aprender algo nuevo } \\
\text { acudo a: }\end{array}$ & $\begin{array}{l}\text { Revisar la correspondencia del enunciado con las opciones. Se recomienda reformular el } \\
\text { enunciado porque la expresión "acudo a" no se corresponde con todas las opciones. Valorar la } \\
\text { posibilidad de reformular el enunciado y modificar u omitir algunas de las opciones. } \\
\text { Se recomienda suprimir la categoría "me vienen a la mente espontáneamente". Otra opción es } \\
\text { reformularla: "Las ideas vienen espontáneamente, sin un referente previo", "hablo en voz baja" } \\
\text { y "hablo mentalmente". }\end{array}$ \\
\hline $\begin{array}{c}\text { PREGUNTA } 9 \\
\text { Cuando quiero hacer } \\
\text { algo creativo y nuevo: }\end{array}$ & $\begin{array}{l}\text { Se recomienda reformular las opciones "Creo algo nuevo" y "Creo algo un poco diferente". } \\
\text { Valorar la posibilidad de no poner que se crea nada nuevo sin partir de algún referente. }\end{array}$ \\
\hline $\begin{array}{l}\text { PREGUNTA } 10 \\
\text { Para elaborar } \\
\text { informaciones que } \\
\text { deseo alojar en la red, } \\
\text { me ayudo de: }\end{array}$ & $\begin{array}{l}\text { Se recomienda sustituir el término alojar por publicar, subir o colgar en Internet. } \\
\text { Valora la posibilidad de incluir una opción referida a recurrir a un experto. } \\
\text { Valorar si es recomendable eliminar la opción de borradores elaborados en papel. } \\
\text { Se recomienda unificar las opciones tercera (compañeros con quienes hablo) y cuarta opción } \\
\text { (compañeros quienes revisan) } \\
\text { Se recomienda reformular el enunciado sustituyendo el término "alojar" por subir, guardar o } \\
\text { colgar. }\end{array}$ \\
\hline $\begin{array}{l}\text { PREGUNTA } 11 \\
\text { Para favorecer la } \\
\text { colaboración e } \\
\text { interacción con otros } \\
\quad \text { prefiero: }\end{array}$ & $\begin{array}{l}\text { Se recomienda unificar la opción de "Otros medios" con "otras estrategias" pues los } \\
\text { participantes no entienden la diferenciación entre estos términos. } \\
\text { Se debe hacer referencia en el enunciado a que se sitúen en un contexto académico o piensen en } \\
\text { actividades educativas. } \\
\text { Se recomienda hacer referencia en el enunciado a que se refiere a un uso académico o en un } \\
\text { contexto escolar. } \\
\text { No se considera pertinente añadir la opción de la presencialidad, porque ya se pregunta en otras } \\
\text { dimensiones y categorías del instrumento. }\end{array}$ \\
\hline $\begin{array}{c}\text { PREGUNTA } 12 \\
\text { Para realizar proyectos } \\
\text { colaborativos prefiero } \\
\text { utilizar: }\end{array}$ & $\begin{array}{l}\text { Se recomienda reformular el enunciado en lo referente a "prefiero utilizar". } \\
\text { Se recomienda reformular el enunciado y hacer más claras las opciones de respuesta. } \\
\text { "proyectos colaborativos y/o en grupo". } \\
\text { Se recomienda reformular las opciones de respuesta, e incluso reordenarlas, poniendo quizás } \\
\text { primero la del grado de cohesión e indicando quién exige la implicación y la libertad. }\end{array}$ \\
\hline $\begin{array}{l}\text { PREGUNTA } 13 \\
\text { Ajusto la cantidad y } \\
\quad \text { variedad de } \\
\text { herramientas en red que } \\
\text { utilizo para aprender en } \\
\quad \text { función de: }\end{array}$ & $\begin{array}{l}\text { Se recomienda añadir en la tercera opción quién valorará ese aprendizaje "Valoración } \\
\text { académica que va a tener ese aprendizaje", o "valoración que los docentes van a hacer de ese } \\
\text { aprendizaje", o "La valoración que otras personas van a hacer de ese aprendizaje". } \\
\text { Se recomienda reformular el enunciado, eliminado el verbo ajustar. } \\
\text { Se recomienda matizar el concepto de aprendizaje, delimitando a qué tipo se refiere (Proyecto, } \\
\text { trabajo, tarea, etc.) } \\
\text { Se recomienda reformular el enunciado y reformular el término del prestigio en red, ya que no } \\
\text { es una opción clara para los participantes. }\end{array}$ \\
\hline
\end{tabular}

Tras la obtención de las recomendaciones de diseño del cuestionario a partir de los resultados que arrojaron las entrevistas cognitivas, se procedió al nuevo diseño del cuestionario, quedando finalmente conformado por 256 ítems reunidos en 51 preguntas.

\section{Procedimiento de validación 3: Prueba Piloto}

Para realizar la prueba piloto en esta investigación se trabajó con una muestra invitada no probabilística de 406 alumnos universitarios de último curso de licenciatura o grado de diferentes áreas de especialización de ocho universidades españolas: Valencia, Las Palmas de Gran Canaria, Alicante, Lleida, 
Prendes-Espinosa, Maria Paz; Castañeda-Quintero, Linda; Solano-Fernández, Isabel María; Roig-Vila, Rosabel; Aguiar-Perera, Ma Victoria \& Serrano-Sánchez, José Luis (2016). Validación de un cuestionario sobre hábitos de trabajo y aprendizaje para futuros profesionales: explorar los Entornos Personales de Aprendizaje. RELIEVE, 22(2), art. 6. doi: http://dx.doi.org/10.7203/relieve.22.2.7228

Rovira i Virgili, País Vasco, Murcia y Oviedo. El cuestionario se administró en red (a través de la herramienta Survey Monkey) durante los meses de noviembre y diciembre de 2013 y enero de 2014. Esta muestra inicial tiene una media de edad de 24,9 años, con una desviación estándar de 6,22.

En la primera exploración de los datos se comprobó que 61 alumnos tan sólo respondieron a las 4 primeras preguntas del cuestionario y 25 más dejaron de hacer el cuestionario a partir de la pregunta 7 . Esto estableció nuestra muestra productora de datos en 314 sujetos. Asimismo, en diferentes momentos de realización del instrumento, los alumnos dejaron de responder al mismo, encontrándonos que, a partir de la pregunta 50, solo quedaban 224 sujetos que llegaron al final del instrumento. Asimismo, algunos ítem no fueron respondidos durante el desarrollo del instrumento, $\mathrm{y}$ esto ha sido fundamental para constituir la muestra válida para realizar las correlaciones en cada una de las dimensiones. La participación de la muestra quedó finalmente constituida como se indica en la tabla 3 .

Tabla 3. Muestra participante en la validación de cada uno de los ítems

\begin{tabular}{|c|c|}
\hline DIMENSIÓN & Muestra participante \\
\hline \multicolumn{2}{|l|}{ DIMENSIÓN AUTOPERCEPCIÓN } \\
\hline Motivación intrínseca & 301 \\
\hline Conocimientos previos & 313 \\
\hline Autopercepción & 277 \\
\hline Retroalimentación & - \\
\hline \multicolumn{2}{|c|}{ DIMENSIÓN GESTIÓN DE LA INFORMACIÓN } \\
\hline Procesamiento de la información & 162 \\
\hline Gestión de la información & 286 \\
\hline Organización de la Información & 110 \\
\hline Recuperación de la Información & 186 \\
\hline Procesamiento ético de la información & 278 \\
\hline Descodificación & 154 \\
\hline Creación de la información & 154 \\
\hline \multicolumn{2}{|c|}{ DIMENSIÓN GESTIÓN DEL PROCESO DE APRENDIZAJE } \\
\hline Regulación y planificación del aprendizaje & 168 \\
\hline Pensamiento crítico & 174 \\
\hline Aprendizaje abierto & - \\
\hline Atención selectiva & 286 \\
\hline Representación mental & 167 \\
\hline Resolución de problemas & 224 \\
\hline \multicolumn{2}{|l|}{ DIMENSIÓN COMUNICACIÓN } \\
\hline Comunicación & 277 \\
\hline Participación/trabajo en equipo & 169 \\
\hline
\end{tabular}

En cuanto a las áreas de especialización, se recogió un número mayor de cuestionarios de Ciencias Sociales y Jurídicas $(35,2 \%)$, seguido de Ingeniería y Arquitectura (18,5\%), Ciencias $(17,2 \%)$, Arte y Humanidades $(17 \%) \mathrm{y}$, por último, Ciencias de la Salud (12\%), coincidiendo en gran medida con la distribución actual de los estudiantes de las universidades españolas por áreas de conocimiento.
El análisis de los resultados consistió en un análisis descriptivo (estadísticos descriptivos básicos), un análisis exploratorio (diagramas de tallo y hojas (steam y leaf), orientados a conocer la distribución de los datos) y, por último, un análisis correlacional en el que, a partir de la obtención del Alpha de Cronbach (a) para cada uno de los ítems estructurados en las diferentes dimensiones, podemos conocer si cada uno de ellos contribuye a dar respuesta 
Prendes-Espinosa, Maria Paz; Castañeda-Quintero, Linda; Solano-Fernández, Isabel María; Roig-Vila, Rosabel; Aguiar-Perera, Ma Victoria \& Serrano-Sánchez, José Luis (2016). Validación de un cuestionario sobre hábitos de trabajo y aprendizaje para futuros profesionales: explorar los Entornos Personales de Aprendizaje. RELIEVE, 22(2), art. 6. doi: http://dx.doi.org/10.7203/relieve.22.2.7228

a la dimensión o no, en cuyo caso realizaremos la propuesta pertinente de eliminación o modificación de ítem.

Así, por ejemplo, tras el primer análisis descriptivo de la composición de la subdimensión Gestión de la Información (incluida en la dimensión del mismo nombre), tiene un alpha de 0,33 con los 3 ítems que la componen (los alphas iniciales y finales se incluyen en la tabla 4. Los datos de ese análisis exploratorio ponen de manifiesto que el ítem
139 puede estar en la base del problema, indicando incluso que si se excluye este ítem, el Alpha total puede subir al 0,662, pudiendo por tanto validar la dimensión. Así pues, en el caso de este ítem se recurre al diagrama de Tallos y Hojas (figura 2) en el que los datos descriptivos $\mathrm{y}$ exploratorios para este ítem evidencian no es un ítem discriminativo (Mediana 1), pues agrupa mayoritariamente las respuestas entre 1 y 2.

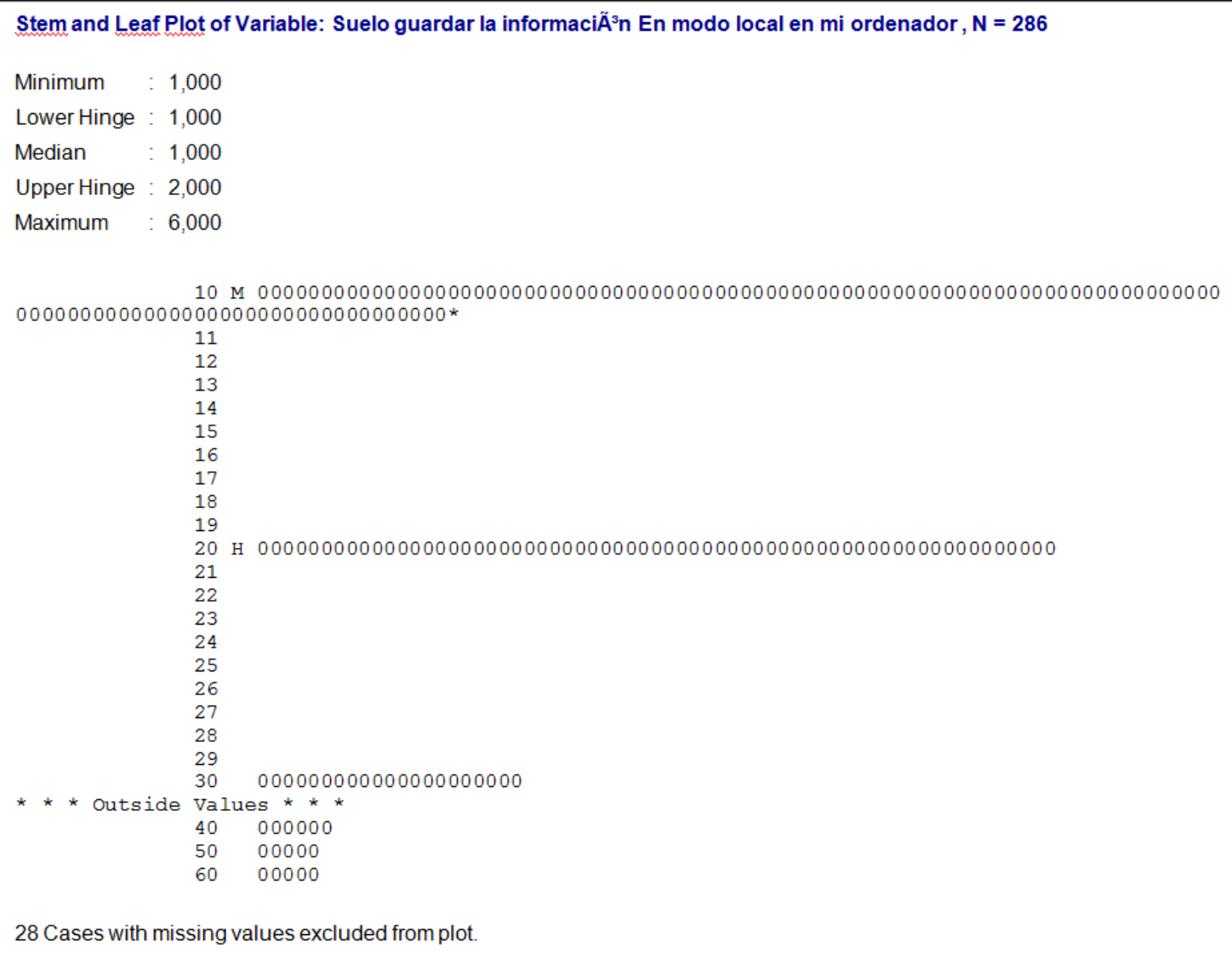

Figura 2. Gráfico de Tallo y Hojas del ítem 139

Tras el primer análisis basado en los diagramas de tallo y hojas (del cual se aporta un ejemplo en la figura 2), se decidió retirar todos los ítems en los que el análisis de los descriptivos indicaba que no aportaban información en la gran mayoría de los sujetos.

Así, uno de los genéricos que se retiró fue el ítem "otros" que aparecía como última opción de respuesta en muchas de las preguntas.
Como es evidente, sólo podemos validar la fiabilidad de las categorías y subcategorías con base en los ítems de variables ordinales; los ítems de variables nominales entendemos que quedan validados por el procedimiento anterior. Así, de las dimensiones Autopercepción y retroalimentación no se ha podido obtener el valor Alpha, en el primer caso porque la dimensión estaba formada por un solo ítem, y en el segundo caso porque la 
Prendes-Espinosa, Maria Paz; Castañeda-Quintero, Linda; Solano-Fernández, Isabel María; Roig-Vila, Rosabel; Aguiar-Perera, Ma Victoria \& Serrano-Sánchez, José Luis (2016). Validación de un cuestionario sobre hábitos de trabajo y aprendizaje para futuros profesionales: explorar los Entornos Personales de Aprendizaje. RELIEVE, 22(2), art. 6. doi: http://dx.doi.org/10.7203/relieve.22.2.7228

escala de medida de la dimensión retroalimentación es nominal.

Fiabilidad de las escalas en categorías y subcategorías:

Para el análisis de la fiabilidad de los ítems del cuestionario organizados en cada uno de dimensiones y subdimensiones presentamos una tabla inicial (tabla 4) en la que se recoge la información sobre la categoría o subcategoría analizada (subdimensión), el Alpha total obtenido por la dimensión $(\alpha)$, el rango de valores obtenidos por los ítems que componen la dimensión ( $\mathrm{R}$ Range), la media de los valores $\alpha$ ( $\mathrm{R}$ Mean), el número de ítems incluidos en la subdimensión y el tamaño de la muestra. A partir de ahí, indicaremos las subdimensiones y los ítems dentro de estas que han sido validados, esto es, las subdimensiones en las que los ítems incluidos responden a esta dimensión, y por tanto, no debería ser eliminado o modificado ningún ítem incluido en esta escala.

Los resultados del presente estudio han sido obtenidos utilizando los paquetes estadísticos IBM SPSS v.20 junto con la SYSTAT v. 13.

Tabla 4. Primera ronda de alphas del estudio piloto

\begin{tabular}{|c|c|c|c|c|c|c|}
\hline Dimensión & Subdimensión & R RANGE I & R MEAN & $\begin{array}{c}\mathrm{N} . \\
\text { ítems } \\
\end{array}$ & $\begin{array}{c}\text { Muestra } \\
\text { participante }\end{array}$ & $\begin{array}{c}\text { Alpha } \\
\text { final }\end{array}$ \\
\hline \multirow{4}{*}{$\begin{array}{l}\text { Auto- } \\
\text { percepción }\end{array}$} & Motivación intrínseca $(\mathrm{n}=301)$ & $.47-.72$ & .64 & 7 & 301 & .744 \\
\hline & Conocimientos previos $(n=313)$ & $.56-.75$ & .68 & 5 & 313 & .705 \\
\hline & Autopercepción $(n=277)$ & & 0 & 1 & 277 & .0 \\
\hline & Retroalimentación & & & & & \\
\hline \multirow{7}{*}{$\begin{array}{l}\text { Gestión de la } \\
\text { información }\end{array}$} & Procesamiento de la información $(n=162)$ & $.43-.69$ & .56 & 15 & 287 & .843 \\
\hline & Gestión de la información $(n=286)$ & $.10-.67$ & .48 & 19 & 162 & .823 \\
\hline & Organización de la Información $(n=110)$ & $.27-.81$ & .62 & 3 & 286 & .332 \\
\hline & Recuperación de la Información (n=186) & $.07-.73$ & .42 & 19 & 110 & .778 \\
\hline & $\begin{array}{l}\begin{array}{c}\text { Procesamiento ético de la información } \\
(\mathrm{n}=278)\end{array} \\
\end{array}$ & $.41-.67$ & .56 & 7 & 186 & .630 \\
\hline & Descodificación $(n=154)$ & $.10-.81$ & .56 & 4 & 278 & .199 \\
\hline & Creación de la información $(n=154)$ & $.28-.73$ & .53 & 12 & 154 & .776 \\
\hline \multirow{6}{*}{$\begin{array}{l}\text { Gestión del } \\
\text { proceso de } \\
\text { aprendizaje }\end{array}$} & $\begin{array}{l}\text { Regulación y planificación del aprendizaje } \\
(\mathrm{n}=168)\end{array}$ & $.16-.72$ & .47 & 17 & 168 & .766 \\
\hline & $\underline{\text { Pensamiento crítico }(\mathrm{n}=174)}$ & $.02-.60$ & .40 & 32 & 174 & .838 \\
\hline & Aprendizaje abierto & & & & & \\
\hline & Atención selectiva $(\mathrm{n}=286)$ & $.53-.57$ & .59 & 7 & 286 & .695 \\
\hline & Representación mental $(\mathrm{n}=167)$ & $.45-.75$ & .69 & 7 & 167 & .764 \\
\hline & Resolución de problemas $(\mathrm{n}=224)$ & $.22-.75$ & .54 & 22 & 224 & .894 \\
\hline \multirow{2}{*}{ Comunicación } & Comunicación $(\mathrm{n}=277)$ & $.60-.83$ & .73 & 5 & 277 & .784 \\
\hline & Participación/trabajo en equipo $(n=169)$ & $.59-.76$ & .69 & 4 & 169 & .546 \\
\hline
\end{tabular}

De la dimensión autopercepción se han validado las subdimensiones motivación intrínseca (compuesta por los ítems 26 a 38) y conocimientos previos (compuesta por los ítems 33 a 37). La motivación intrínseca ha obtenido un valor $\alpha$ de 0,744 y todos sus ítems han tenido un valor $\alpha$ total del ítems superior a
0,3. Lo mismo ha ocurrido con la subdimensión conocimientos previos, con un valor $\alpha$ de 0,705 .

De la dimensión gestión de la información se ha validado la subdimensión de Recuperación de la información, formada por 
Prendes-Espinosa, Maria Paz; Castañeda-Quintero, Linda; Solano-Fernández, Isabel María; Roig-Vila, Rosabel; Aguiar-Perera, Ma Victoria \& Serrano-Sánchez, José Luis (2016). Validación de un cuestionario sobre hábitos de trabajo y aprendizaje para futuros profesionales: explorar los Entornos Personales de Aprendizaje. RELIEVE, 22(2), art. 6. doi: http://dx.doi.org/10.7203/relieve.22.2.7228

los ítems 75 a 81 , obteniendo un $\alpha$ total de 0,63 .

De la dimensión gestión del proceso de aprendizaje, se ha validado la subdimensión de atención selectiva, formada por los ítems 129 a 135 , obteniendo un $\alpha$ total de 0,695 . También se ha validado la subdimensión representación mental (compuesta por los ítems 170-176) y con un $\alpha$ total de 0,764. En esta dimensión ha sido imposible obtener información sobre la subdimensión de aprendizaje abierto al no contar con una muestra lo suficientemente consistente para realizar el análisis de correlaciones.

De la dimensión comunicación se ha validado la subdimensión de comunicación, compuesta por los ítems 228-232 con un $\alpha$ total de 0,546 .

En segundo lugar destacaremos aquellas subdimensiones que no han sido validadas. En este caso, analizaremos qué ítems están condicionando estos resultados, analizaremos los ítems desde los datos descriptivos y exploratorios que poseemos $\mathrm{y}$, por último, volveremos a realizar el análisis correlacional para comprobar si al eliminarlo se obtiene un $\alpha$ total superior a 0,6 , en cuyo caso se validará la subdimensión y los ítems que la componen.

Las subdimensiones de gestión de la información $(\alpha 0,33)$ y procesamiento ético de la información $(\alpha$ 0,199), ambas incluidas en la dimensión gestión de la información, no obtienen el valor $\alpha$ mínimo requerido para proceder a su validación. Los datos obtenidos ponen de manifiesto que el ítem 139 puede estar en la base del problema, indicando incluso que si se excluye este ítem, el $\alpha$ total puede subir al 0,662 , pudiendo por tanto validar la dimensión.

En cuanto a la subdimensión de procesamiento ético de la información, el ítem que no responde a los requisitos de la dimensión es el ítem 185, que previsiblemente si se quitara permitiría que la dimensión fuera validada con un $\alpha$ de 0,740 .

Tras realizar un segundo análisis excluyendo los ítem 139 y 185 de estas subdimensiones, comprobamos que el $\alpha$ aumenta a 0,662 en la subdimensión gestión de la información y 0,74 en la subdimensión procesamiento ético de la información. Por tanto, damos por válida la dimensión con la supresión de dichos ítems.

En tercer lugar destacaremos aquellos ítems que, a pesar de haber obtenido un $\alpha$ total superior a 0,6 , han obtenido un $\alpha$ total de algunos de sus ítems inferior a 0,3 (límite para considerar válido el $\alpha$ total $\mathrm{R}$ del ítem). En este caso, teniendo en cuenta la recomendación realizada anteriormente de reducir el número total del instrumento, eliminaremos los ítems que se consideran que no dan respuesta a la subdimensión, y se volverá a realizar el análisis correlacional para volver conocer el valor $\alpha$. En este caso, también realizaremos un análisis de los ítems desde los datos descriptivos y correlaciónales que tenemos.

Una vez realizada la segunda ronda de evaluación y eliminando los ítems conflictivos, la tabla resumen del análisis quedaría del siguiente modo (Tabla 5). 
Prendes-Espinosa, Maria Paz; Castañeda-Quintero, Linda; Solano-Fernández, Isabel María; Roig-Vila, Rosabel; Aguiar-Perera, Ma Victoria \& Serrano-Sánchez, José Luis (2016). Validación de un cuestionario sobre hábitos de trabajo y aprendizaje para futuros profesionales: explorar los Entornos Personales de Aprendizaje. RELIEVE, 22(2), art. 6. doi: http://dx.doi.org/10.7203/relieve.22.2.7228

Tabla 5. Segunda ronda de alphas del estudio piloto

\begin{tabular}{|c|c|c|c|c|c|c|}
\hline Dimensión & Subdimensión & R RANGE & R MEAN & $\begin{array}{l}\text { N. ítems } \\
\text { final }\end{array}$ & $\begin{array}{c}\text { Muestra } \\
\text { participante }\end{array}$ & $\begin{array}{l}\text { Alpha } \\
\text { final }\end{array}$ \\
\hline \multirow{4}{*}{ Autopercepción } & Motivación intrínseca $(\mathrm{n}=301)$ & $.47-.72$ & .64 & 7 & 301 & .744 \\
\hline & Conocimientos previos $(\mathrm{n}=313)$ & $.56-.75$ & .68 & 5 & 313 & .705 \\
\hline & Autopercepción $(\mathrm{n}=277)$ & & 0 & 1 & 277 & .0 \\
\hline & Retroalimentación & & & & & \\
\hline \multirow{7}{*}{$\begin{array}{l}\text { Gestión de la } \\
\text { información }\end{array}$} & Procesamiento de la información ( $\mathrm{n}=162)$ & $.43-.69$ & .56 & 15 & 287 & .843 \\
\hline & Gestión de la información ( $\mathrm{n}=286)$ & $.85-.88$ & .87 & 2 & 286 & 662 \\
\hline & Organización de la Información $(\mathrm{n}=110)$ & $.06-.80$ & .55 & 14 & 150 & .846 \\
\hline & Recuperación de la Información $(\mathrm{n}=186)$ & $.41-.67$ & .56 & 7 & 186 & .630 \\
\hline & Procesamiento ético de la información $(\mathrm{n}=278)$ & $.70-.88$ & .81 & 3 & 278 & .740 \\
\hline & Descodificación (n=154) & $.44-.77$ & .60 & 10 & 158 & .80 \\
\hline & Creación de la información $(n=154)$ & $.15-.76$ & .53 & 28 & 154 & 908 \\
\hline \multirow{6}{*}{$\begin{array}{l}\text { Gestión del } \\
\text { proceso de } \\
\text { aprendizaje }\end{array}$} & $\begin{array}{c}\text { Regulación y planificación del aprendizaje } \\
(\mathrm{n}=168)\end{array}$ & $.32-.73$ & .51 & 15 & 168 & .788 \\
\hline & Pensamiento crítico $(\mathrm{n}=174)$ & $.32-.61$ & .45 & 26 & 176 & .845 \\
\hline & Aprendizaje abierto & & & & & \\
\hline & Atención selectiva $(\mathrm{n}=286)$ & $.53-.57$ & .59 & 7 & 286 & 695 \\
\hline & $\underline{\text { Representación mental }(\mathrm{n}=167)}$ & $.45-.75$ & .69 & 7 & 167 & .764 \\
\hline & Resolución de problemas (n=224) & $.49-.77$ & .67 & 16 & 224 & .920 \\
\hline \multirow{2}{*}{ Comunicación } & Comunicación $(\mathrm{n}=277)$ & $.60-.83$ & .73 & 5 & 277 & .784 \\
\hline & Participación/trabajo en equipo $(n=169)$ & $.59-.76$ & .69 & 4 & 169 & .546 \\
\hline
\end{tabular}

Además, hemos realizado un análisis del alpha de las dimensiones genéricas con base en los datos finales y con ellos:

- La autopercepción: ha quedado validada con un Alpha de ,861 y compuesto por 6 preguntas con 39 ítems.

- La gestión de la información: ha quedado validada con un Alpha de ,946, y compuesto por 17 preguntas con 92 ítems.

- La gestión del proceso de aprendizaje: ha quedado validada con un Alpha de ,885 y compuesto por 11 preguntas con 88 ítems.

- La comunicación: ha quedado validada con un Alpha de ,772 compuesto por 4 preguntas con 11 ítems

\section{Resultados: el Instrumento definitivo}

Como se ha dicho más arriba, el instrumento definitivo que se presenta incluye, además de los ítems validados en el tercer proceso de validación, aquellos que habiendo pasado los dos procesos anteriores no han podido incluirse en el tercero (p.e. nominales).

Así, finalmente el cuestionario consta de 48 preguntas: 4 de caracterización demográfica (Sexo, Edad, Universidad, Área de Conocimiento); 8 preguntas nominales, de las que 2 presentan categorías dicotómicas; 35 son preguntas que responden a una escala de 5 niveles más una opción de "No usa/ No aplicable", de las que 30 responden a frecuencia y 5 a nivel de acuerdo o desacuerdo con la afirmación. 
Prendes-Espinosa, Maria Paz; Castañeda-Quintero, Linda; Solano-Fernández, Isabel María; Roig-Vila, Rosabel; Aguiar-Perera, Ma Victoria \& Serrano-Sánchez, José Luis (2016). Validación de un cuestionario sobre hábitos de trabajo y aprendizaje para futuros profesionales: explorar los Entornos Personales de Aprendizaje. RELIEVE, 22(2), art.

6. doi: http://dx.doi.org/10.7203/relieve.22.2.7228

\section{Cuestionario CAPPLE sobre hábitos de trabajo y aprendizaje}

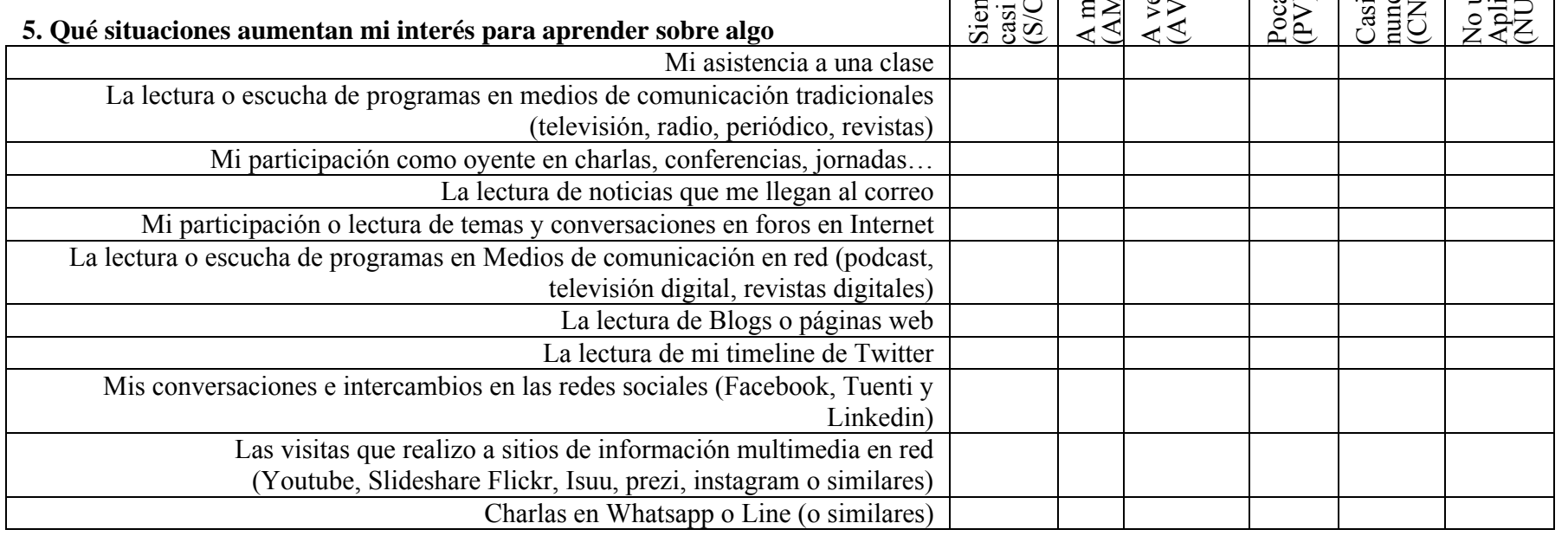

6. Mi motivación en el desempeño de tareas se incrementa si (marca tantos como corresponda):

Conozco la finalidad de las mismas

Conozco los requerimientos "a priori"

Conozco las dificultades previsibles

Dispongo de los recursos necesarios para desarrollar la tarea
Hay DIMENSIÓNes externos que me animan a realizarla

Me apasiona poder realizarla

Tengo intereses personales claros en la tarea Estoy comprometido y soy responsable de su realización

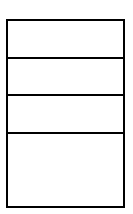

7. Principalmente, ¿con qué finalidad accedes a Internet?:

\begin{tabular}{|c|c|c|c|c|c|c|}
\hline & 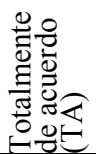 & 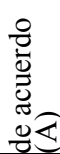 & 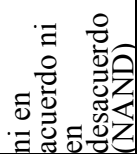 & 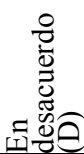 & 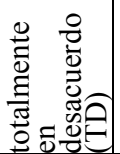 & 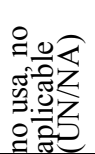 \\
\hline \multicolumn{7}{|l|}{ Comunicación } \\
\hline \multicolumn{7}{|l|}{ Información } \\
\hline \multicolumn{7}{|l|}{ Trabajo } \\
\hline \multicolumn{7}{|l|}{ Ocio } \\
\hline \multicolumn{7}{|l|}{ Organización } \\
\hline Formación & & & & & & \\
\hline Relaciones Sociales & & & & & & \\
\hline
\end{tabular}

8. Cuando aprendes en internet ¿Cómo decides lo que debes aprender?

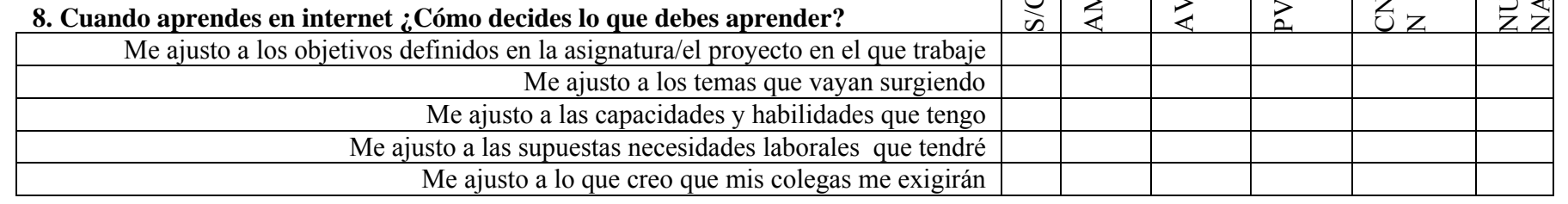

\begin{tabular}{|c|c|c|c|c|c|c|}
\hline & 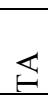 & $\ll$ & 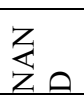 & D & $\theta$ & 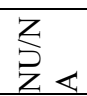 \\
\hline 9. Establecer objetivos me ayuda a aprovechar el tiempo que dedico a Interne & & & & & & \\
\hline $\begin{array}{l}\text { 10. Analizo mis puntos fuertes y débiles con objeto de valorar el esfuerzo que } \\
\text { necesito para llevar a cabo una tarea }\end{array}$ & & & & & & \\
\hline
\end{tabular}

11. A la hora de planificar y organizar mi estudio y trabajo...

Organizo mis ideas-tareas en un gestor de tareas tipo Evernote, Remember The Milk.

Organizo mi tiempo utilizando una agenda en papel

Organizo mi tiempo utilizando un calendario en red

Utilizo algún tipo de herramienta para organizar mis recursos y herramientas en red

tipo Symbaloo, Netvibes.

\begin{tabular}{|l|l|l|l|l|l|}
\hline \multirow{2}{N}{} & $\sum$ & $Z$ & $Z$ & $Z$ & $Z$ \\
出 & & & & & $Z$ \\
\hline & & & & & \\
\hline & & & & & \\
\hline & & & & & \\
\hline
\end{tabular}


Prendes-Espinosa, Maria Paz; Castañeda-Quintero, Linda; Solano-Fernández, Isabel María; Roig-Vila, Rosabel; Aguiar-Perera, Ma Victoria \& Serrano-Sánchez, José Luis (2016). Validación de un cuestionario sobre hábitos de trabajo y aprendizaje para futuros profesionales: explorar los Entornos Personales de Aprendizaje. RELIEVE, 22(2), art.

6. doi: http://dx.doi.org/10.7203/relieve.22.2.7228

Utilizo algún contador de tiempo de aprendizaje para organizar mis tiempos en red (Tipo "pomodoro").

12. El número y la variedad de herramientas en red que utilizo para aprender dependen de...

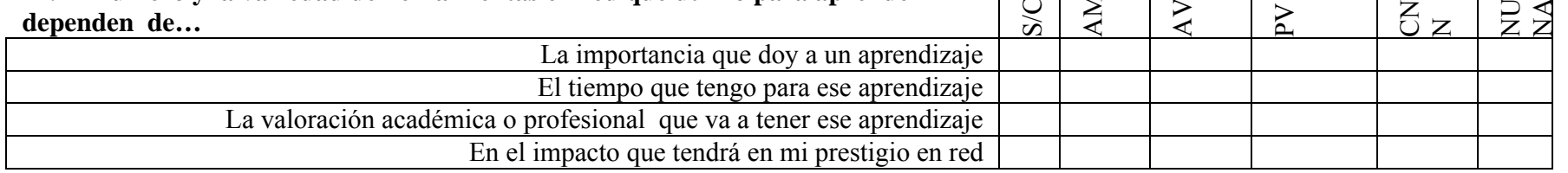

13. Cuando quiero aprender algo nuevo acudo a:...

\begin{tabular}{|r|r|}
\hline Colegas y amigos presenciales \\
\hline Medios de comunicación en red \\
Blogs o páginas webs \\
\hline Wikipedia o enciclopedias en red \\
Redes sociales \\
Foros \\
\hline Colegas y amigos contactando por mail o mensajes privados en otras plataformas \\
\hline Aplicaciones móviles espé́ficas del tema
\end{tabular}

(FB, DM en Twitter, Whatsapp)

14. Cuando busco información lo hago en (marca una única respuesta)

Un único motor de búsqueda generalista (google, yahoo...)

Varios buscadores generalistas

Buscadores temáticos, especializados

Motores de búsqueda específicos, temáticos

\begin{tabular}{|c|c|c|c|c|c|}
\hline$\frac{n}{n}$ & $\sum$ & 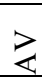 & z & $z_{z}$ & 之艺 \\
\hline & & & & & \\
\hline & & & & & \\
\hline & & & & & \\
\hline & & & & & \\
\hline & & & & & \\
\hline & & & & & \\
\hline & & & & & \\
\hline & & & & & \\
\hline
\end{tabular}

Bibliotecas y bases de datos en red

Redes sociales

Foros de debate

15. Para acceder a la información realizo...(marca una única respuesta)

Búsquedas "de tanteo" en manuales, libros de texto,

Enciclopedias

Búsquedas "de tanteo" en buscadores web.

Búsquedas sistematizadas en revistas especializadas

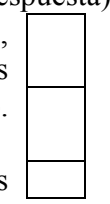

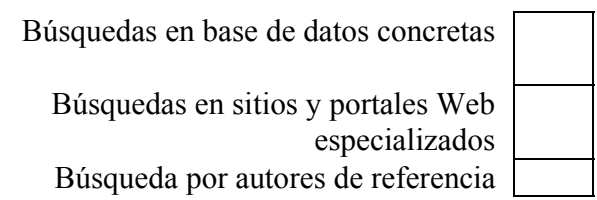

16. Cuando quiero aprender algo nuevo, utilizo las siguientes estrategias de acceso al conocimiento:

\begin{tabular}{|r|}
\hline Las ideas me vienen a la mente espontáneamente \\
\hline Llego a los nuevos conocimientos a través de otras ideas, conocimientos previos \\
\hline Repito mentalmente o en voz baja las ideas \\
\hline Utilizo un papel para escribir o representar las ideas o los conocimientos \\
\hline Recurro a materiales que he elaborado y que tienen relación directa con dichos \\
conocimientos
\end{tabular}

\begin{tabular}{|c|c|c|c|c|c|}
\hline$\frac{\infty}{\infty}$ & $\sum$ & 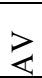 & z & $Z_{z}$ & 之艺 \\
\hline & & & & & \\
\hline & & & & & \\
\hline & & & & & \\
\hline & & & & & \\
\hline & & & & & \\
\hline & & & & & \\
\hline
\end{tabular}

17. Cuando trabajo con información, para comprenderla mejor, prefiero que sea:

\begin{tabular}{|c|c|c|c|c|c|c|}
\hline 17. Cuando trabajo con información, para comprenderla mejor, prefiero que sea: & $\stackrel{U}{2}$ & $\sum$ & $\gtrless$ & 文 & $\bar{z}_{z}$ & 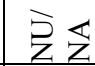 \\
\hline Icónica (fotografía o imágenes) & & & & & & \\
\hline Vídeo & & & & & & \\
\hline Audio & & & & & & \\
\hline Multimedia & & & & & & \\
\hline Hipermedia & & & & & & \\
\hline
\end{tabular}

18. Me planteo realizar actividades que, a través de la red, supongan::

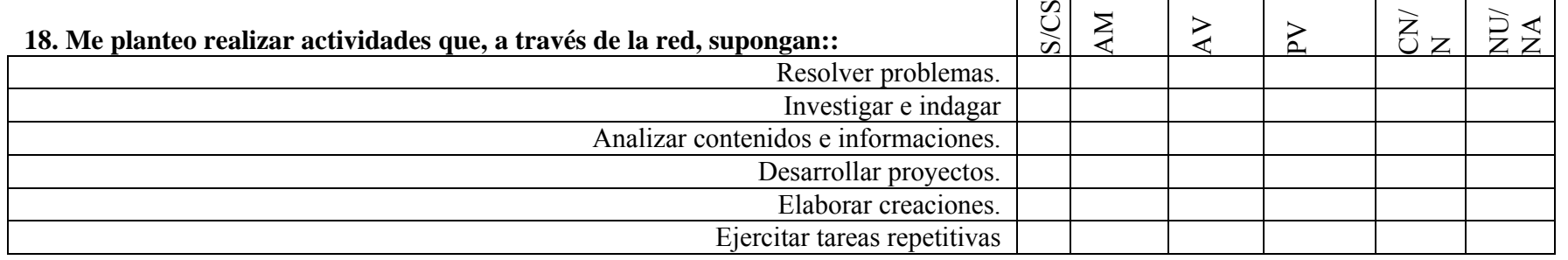


Prendes-Espinosa, Maria Paz; Castañeda-Quintero, Linda; Solano-Fernández, Isabel María; Roig-Vila, Rosabel; Aguiar-Perera, Ma Victoria \& Serrano-Sánchez, José Luis (2016). Validación de un cuestionario sobre hábitos de trabajo y aprendizaje para futuros profesionales: explorar los Entornos Personales de Aprendizaje. RELIEVE, 22(2), art.

6. doi: http://dx.doi.org/10.7203/relieve.22.2.7228

19. Cuestiono la información que recibo de...

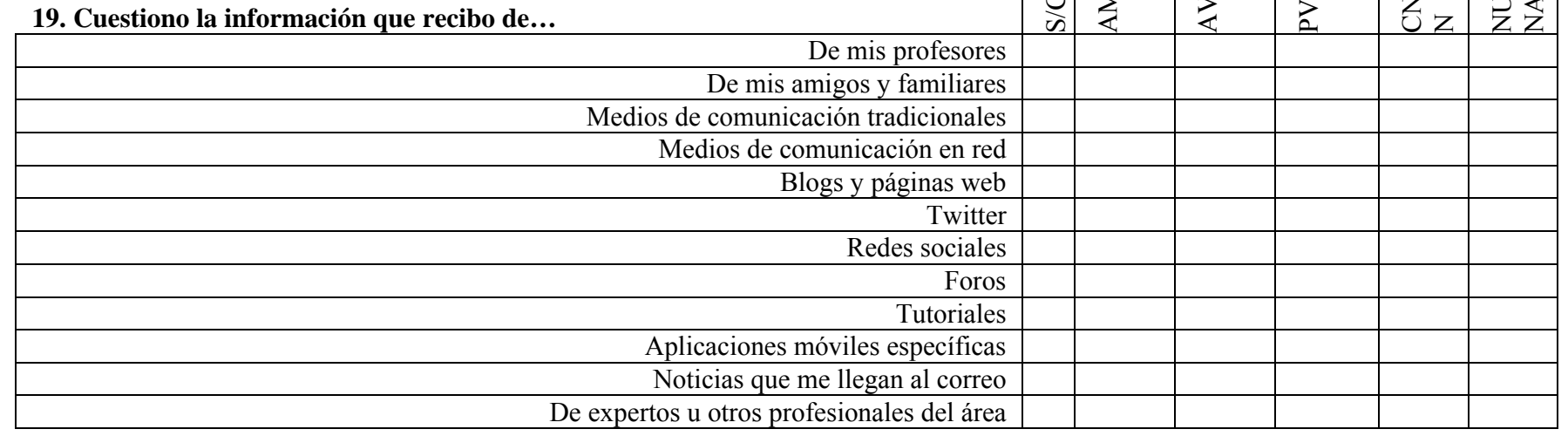

20. ¿Qué añade credibilidad a la información que recibo?:

Que me lo recomienden mis colegas, amigos y familiares Que sea recomendado en las redes sociales Que aparezca en un sistema de recomendación en red ("meneame", "tripavisor") Que sea una de las primeras posiciones de la búsqueda en google Que sea trending topic en twitter Que aparezca en varios recursos (artículos, libros, vídeos) en red Que lo recomiende un experto

\section{Ante la información que recibo}

Soy consciente de que la interpreto según mis propios puntos de vista

La interpreto de manera reflexiva en base a argumentos que me ayuden a comprenderla Valoro la opinión dada por el grupo de usuarios Pienso que no siempre es veraz o se corresponde con la realidad Considero que no debo cuestionarla, sea cual sea su origen

La contrasto

\section{De la información que localizo, selecciono:}

La que es estéticamente más atractiva La que es más actual La que utilice un lenguaje más sencillo La que utiliza formato audiovisual

La que parte de un esquema claro La que más me han recomendado La que es obligatorio que revise

\begin{tabular}{|c|c|c|c|c|c|}
\hline$\frac{\tilde{U}}{\omega}$ & $\sum$ & z & a & $z_{Z}^{Z}$ & $\mathrm{Z}_{\mathrm{Z}}$ \\
\hline & & & & & \\
\hline & & & & & \\
\hline & & & & & \\
\hline & & & & & \\
\hline & & & & & \\
\hline & & & & & \\
\hline & & & & & \\
\hline
\end{tabular}

\begin{tabular}{|c|c|c|c|c|c|}
\hline$\frac{\tilde{U}}{n}$ & $\sum$ & $\gtreqless$ & a & $Z_{Z}^{Z}$ & $\mathrm{Z}_{\mathrm{Z}}$ \\
\hline & & & & & \\
\hline & & & & & \\
\hline & & & & & \\
\hline & & & & & \\
\hline & & & & & \\
\hline & & & & & \\
\hline
\end{tabular}

\begin{tabular}{|r|}
\hline La que es estéticamente más atractiva \\
\hline La que es más actual \\
\hline La que utilice un lenguaje más sencillo \\
\hline La que utiliza formato audiovisual \\
La que parte de un esquema claro \\
\hline La que más me han recomendado \\
La que es obligatorio que revise
\end{tabular}

\begin{tabular}{|c|c|c|c|c|c|}
\hline$\frac{\omega}{\omega n}$ & $\sum$ & 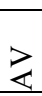 & $z$ & $Z_{\text {Z }}$ & $\begin{array}{l}Z \\
Z \\
Z\end{array}$ \\
\hline & & & & & \\
\hline & & & & & \\
\hline & & & & & \\
\hline & & & & & \\
\hline & & & & & \\
\hline & & & & & \\
\hline & & & & & \\
\hline
\end{tabular}

\section{Cuándo abordo un nueva información, considero necesario establecer una} conexión y/asociación entre los diferentes conceptos

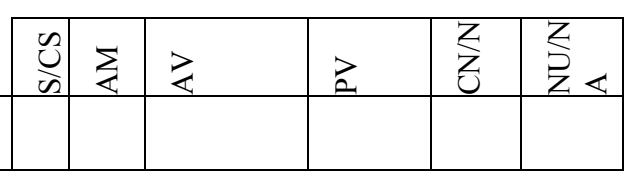

24. Suelo guardar la información

\begin{tabular}{rr|}
\hline En mi ordenador y en Internet ( la nube) \\
\hline Sólo en Internet ( la nube)
\end{tabular}

25. Para organizar y gestionar la información prefiero

\begin{tabular}{|r|}
\hline Organizar mi información en carpetas (jerárquicas) \\
\hline Organizar mi información en una línea de tiempo \\
\hline Usar Marcadores sociales (Diigo, delicious...) \\
\hline Usar Wikis / Usar Blogs \\
\hline Usar herramientas con red social (Twitter, facebook...) \\
\hline
\end{tabular}

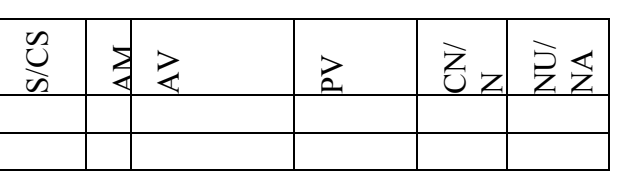

\begin{tabular}{|c|c|c|c|c|}
\hline$\sum_{\infty}^{\infty}$ & $\sum>$ & a & Z & $\stackrel{Z}{Z}_{z}$ \\
\hline & & & & \\
\hline & & & & \\
\hline & & & & \\
\hline & & & & \\
\hline & & & & \\
\hline
\end{tabular}


Prendes-Espinosa, Maria Paz; Castañeda-Quintero, Linda; Solano-Fernández, Isabel María; Roig-Vila, Rosabel; Aguiar-Perera, Ma Victoria \& Serrano-Sánchez, José Luis (2016). Validación de un cuestionario sobre hábitos de trabajo y aprendizaje para futuros profesionales: explorar los Entornos Personales de Aprendizaje. RELIEVE, 22(2), art.

6. doi: http://dx.doi.org/10.7203/relieve.22.2.7228

26. ¿Qué hago con mis notas/información relevante que he encontrado?:

La guardo cuidadosamente

Hago un esquema/mapa conceptual para relacionarla: en papel/en un documento de texto/en una herramienta específica en red

Me hago un resumen: en papel/en un documento de texto/en una entrada en mi página personal/en una entrada que comparto en mi red social

27. Cuando encuentro un documento interesante...:

Lo leo en red y tomo notas en una herramienta online específica (tipo diigo)

Lo incluyo en una herramienta específica de gestión de bibliografía (tipo mendeley, RefWorks) y tomo notas del mismo en esa misma herramienta

Me bajo el documento a mi ordenador y tomo notas en una herramienta específica mientras lo leo en pantalla.

Uso metadatos para incorporarlo en mis propios recursos

Lo leo impreso en papel, lo subrayo y tomo notas en el mismo papel, las notas las paso a un documento de texto para guardarlas

28. Cuando encuentro un vídeo o un audio interesante...

Lo escucho/veo en red y tomo notas en papel Lo escucho/veo en red y tomo notas en un documento de texto Lo escucho/veo en red y tomo notas en un programa específico para ello
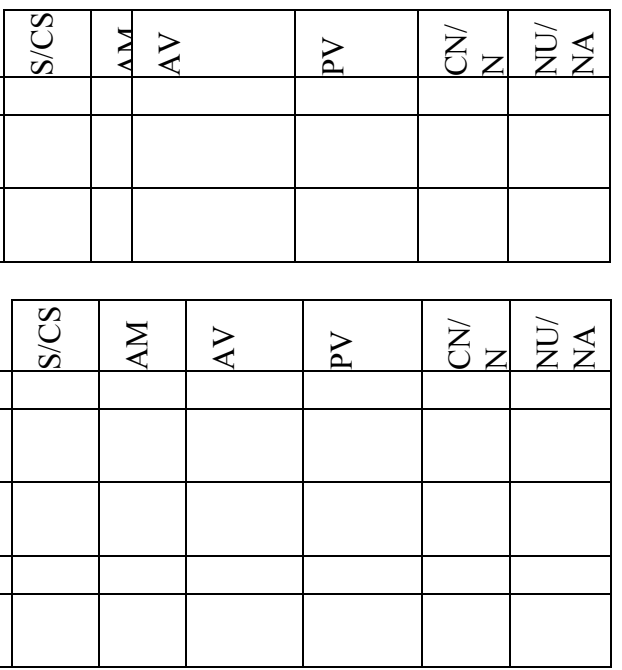

$\begin{array}{r}\text { Lo escucho/veo en red y tomo notas en papel } \\ \hline \text { Lo escucho/veo en red y tomo notas en un documento de texto } \\ \hline \text { Lo escucho/veo en red y tomo notas en un programa específico para ello } \\ \hline\end{array}$

\begin{tabular}{|c|c|c|c|c|c|}
\hline$\sum_{\infty}^{\infty}$ & $\sum$ & 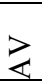 & z & $Z_{Z}^{Z}$ & 引 $\varangle$ \\
\hline & & & & & \\
\hline & & & & & \\
\hline
\end{tabular}

29. Cuando recibo información nueva que me interesa...

\begin{tabular}{|r|}
\hline La analizo \\
\hline La interpreto \\
\hline La contrasto con lo que sé \\
\hline La relaciono con lo que sé \\
\hline Me surgen preguntas / dudas \\
\hline Busco contrastarla con otras fuentes \\
\hline
\end{tabular}

\begin{tabular}{|c|c|c|c|c|c|}
\hline$\bigcup_{n}^{n}$ & & $z$ & B & $z_{z}$ & 引 \\
\hline & & & & & \\
\hline & & & & & \\
\hline & & & & & \\
\hline & & & & & \\
\hline & & & & & \\
\hline & & & & & \\
\hline
\end{tabular}

30. Cuando utilizo información de terceros lo hago:

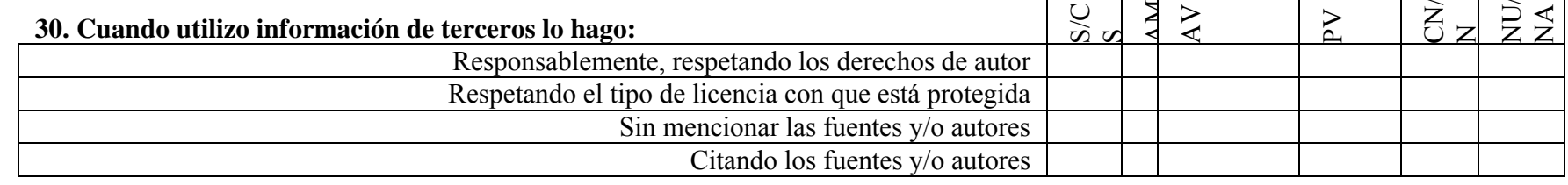

31. Cuando quiero generar nueva información para publicarla en la Red::

\begin{tabular}{|r|}
\hline Publico la información en una red social que utilizo habitualmente. \\
\hline Utilizo una herramienta específica (tipo blog). \\
\hline Según el tipo de información utilizo una herramienta u otra (blog, red social, Googlesites,
\end{tabular}

Según el tipo de información utilizo una herramienta u otra (blog, red social, Googlesites,

etc.)

32. Los contenidos digitales que produzco para compartir en red son:

Texto (wikis, blog)

Icónica (fotografia o imágenes en flickr, instagram, etc.) Vídeo (youtube, vimeo...) Audio (podcast)

Multimedia (slideshare, animoto, etc.)

Hipermedia (Exelearning, páginas web en Wix u otras)

\begin{tabular}{|c|c|c|c|c|c|}
\hline$\sum_{i s}^{n}$ & $\sum$ & 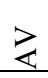 & z & $z_{z}$ & 之艺 \\
\hline & & & & & \\
\hline & & & & & \\
\hline & & & & & \\
\hline & & & & & \\
\hline
\end{tabular}

\begin{tabular}{|c|c|c|c|c|c|}
\hline$\sum_{\infty}^{\infty}$ & $\sum$ & 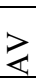 & 2 & $\bar{u}_{z}$ & 之吕 \\
\hline & & & & & \\
\hline & & & & & \\
\hline & & & & & \\
\hline & & & & & \\
\hline & & & & & \\
\hline & & & & & \\
\hline
\end{tabular}

33. Cuando quiero hacer algo creativo y nuevo...

Selecciono información que considero relevante y a partir de ahí creo algo nuevo.

Creo algo nuevo sin buscar referentes

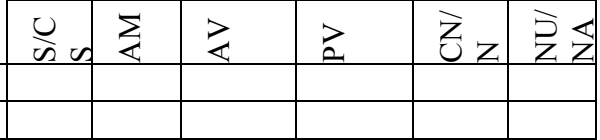


Prendes-Espinosa, Maria Paz; Castañeda-Quintero, Linda; Solano-Fernández, Isabel María; Roig-Vila, Rosabel; Aguiar-Perera, Ma Victoria \& Serrano-Sánchez, José Luis (2016). Validación de un cuestionario sobre hábitos de trabajo y aprendizaje para futuros profesionales: explorar los Entornos Personales de Aprendizaje. RELIEVE, 22(2), art.

6. doi: http://dx.doi.org/10.7203/relieve.22.2.7228

34. Para elaborar informaciones que deseo subir a Internet me ayudo de:

Borradores elaborados en papel Borradores elaborados en soporte digital Compañeros, con quienes hablo sobre lo que estoy elaborando Compañeros, quienes revisan lo que estoy elaborando antes de publicarlo Profesores o expertos que revisan lo que he elaborado No utilizo ayudas, edito y publico directamente la información)

\begin{tabular}{|c|c|c|c|c|c|}
\hline$\frac{U}{\infty} \backsim$ & $\sum$ & $\frac{8}{4}$ & z & $\bar{z}_{z}$ & 之吕 \\
\hline & & & & & \\
\hline & & & & & \\
\hline & & & & & \\
\hline & & & & & \\
\hline & & & & & \\
\hline & & & & & \\
\hline
\end{tabular}

35. Suelo reflejar la reflexión sobre lo que voy aprendiendo:

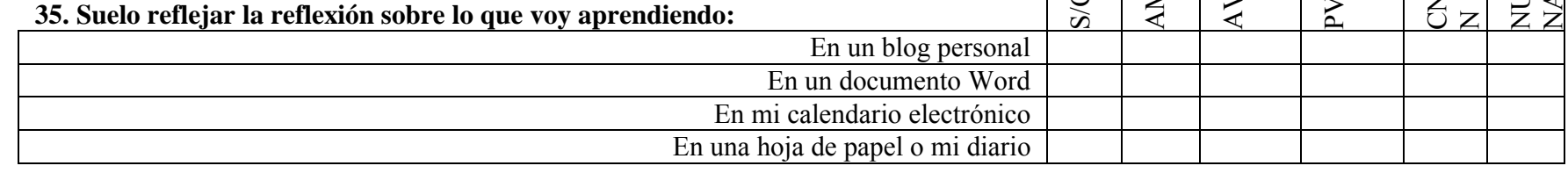

36. Cuando necesito comunicarme a través de la Red:

\begin{tabular}{|c|c|c|c|c|c|c|}
\hline 36. Cuando necesito comunicarme a través de la Red: & $\underset{\omega}{\omega}$ & $\sum$ & $\geqslant$ & z & $\bar{z}_{z}$ & 之艺 \\
\hline Apenas me comunico. & & & & & & \\
\hline Utilizo herramientas básicas (correo electrónico) & & & & & & \\
\hline Utilizo herramientas con red social (Facebook, Twitter) & & & & & & \\
\hline
\end{tabular}

\section{7. ¿Valoras las aportaciones y críticas de los usuarios?}

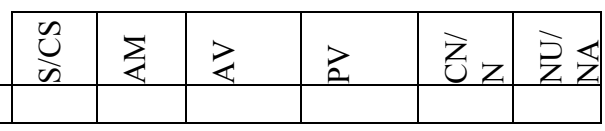

38. Para favorecer la colaboración e interacción con otros prefiero: (marca una única respuesta)

Redes sociales (Twitter, Facebook...)

Correo electrónico

Bibliotecas y bases de datos en red

Chats

Redes sociales

39. Para realizar proyectos en grupo prefiero utilizar (marca una única respuesta)

Google Docs/Google Drive

Wikis

Blogs
Redes sociales (Twitter, Facebook...) Entornos virtuales como Moodle, Sakai, etc.

40. Para la resolución de problemas prefiero

\begin{tabular}{|c|c|c|c|c|c|c|}
\hline 40. Para la resolución de problemas prefiero & in & 交 & $\gtrless$ & z & Z & そ艺 \\
\hline Estudiar individualmente las posibles soluciones. & & & & & & \\
\hline Consensuar con otros distintas alternativas. & & & & & & \\
\hline Confrontar las diferentes propuestas & & & & & & \\
\hline
\end{tabular}

41. Marca el grado de acuerdo con las siguientes afirmaciones:

\begin{tabular}{|c|c|c|c|c|c|c|}
\hline 41. Marca el grado de acuerdo con las siguientes afirmaciones: & E & $\varangle$ & $\overleftarrow{z} \theta$ & D & 旦 & 之 4 \\
\hline $\begin{array}{r}\text { La lectura de los blogs de otros estudiantes es muy enriquecedora para la realización de } \\
\text { mis actividades }\end{array}$ & & & & & & \\
\hline Estoy en contacto en contacto con mis compañeros a través de redes sociales & & & & & & \\
\hline $\begin{array}{r}\text { Las interacciones en los blogs con mis compañeros son enriquecedoras para la realización } \\
\text { de mis actividades }\end{array}$ & & & & & & \\
\hline $\begin{array}{r}\text { Uso con otros compañeros gestores de enlaces para organizar de forma colaborativa los } \\
\text { contenidos de las actividades de aprendizaje }\end{array}$ & & & & & & \\
\hline $\begin{array}{r}\text { Las redes sociales me permiten conectar con grupos de personas relacionadas con mis } \\
\text { metas de aprendizaje }\end{array}$ & & & & & & \\
\hline
\end{tabular}

42. En el trabajo en equipo priorizo

\begin{tabular}{l} 
42. En el trabajo en equipo priorizo \\
\begin{tabular}{|r|}
\hline Interaccionar con otros. \\
\hline
\end{tabular} \\
\hline
\end{tabular}

\begin{tabular}{|c|c|c|c|c|c|}
\hline$\sum_{n}^{n}$ & $\sum$ & 学 & 之 & $\bar{z}_{z}$ & 之艺 \\
\hline & & & & & \\
\hline & & & & & \\
\hline
\end{tabular}


Prendes-Espinosa, Maria Paz; Castañeda-Quintero, Linda; Solano-Fernández, Isabel María; Roig-Vila, Rosabel; Aguiar-Perera, Ma Victoria \& Serrano-Sánchez, José Luis (2016). Validación de un cuestionario sobre hábitos de trabajo y aprendizaje para futuros profesionales: explorar los Entornos Personales de Aprendizaje. RELIEVE, 22(2), art. 6. doi: http://dx.doi.org/10.7203/relieve.22.2.7228

43. He descrito mis conocimientos y mis metas de aprendizaje en una red social profesional como Linkedin, Xing, o en una red social generalista como Facebook o Tuenti

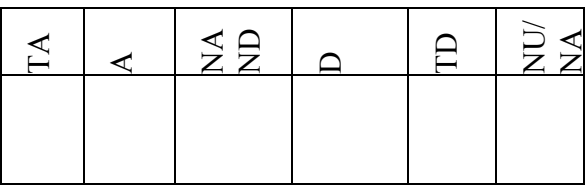

44. Complemento mi formación académica con (Marcar las casillas que correspondan) Cursos en red ofertados por empresas/instituciones. Cursos masivos en red (MOOC). Cursos semipresenciales. Cursos presenciales

\begin{tabular}{ll}
\hline \\
\hline \\
\hline
\end{tabular}
Voluntariado social.
mento mi formación académica No complemento mi formación académica

Prácticas no retribuidas.

45. Cuando envío un trabajo o proyecto para su evaluación, espero...(marca una única respuesta)

Una respuesta donde se subraye especialmente los aspectos positivos de mi trabajo. Una respuesta en la que subraye especialmente orientaciones sobre los aspectos a corregir. Una respuesta con la calificación sin ningún comentario al respecto.

46. Cuando tengo un problema técnico acudo a

47. Cuando tengo una duda de contenido durante el proceso de trabajo acudo a

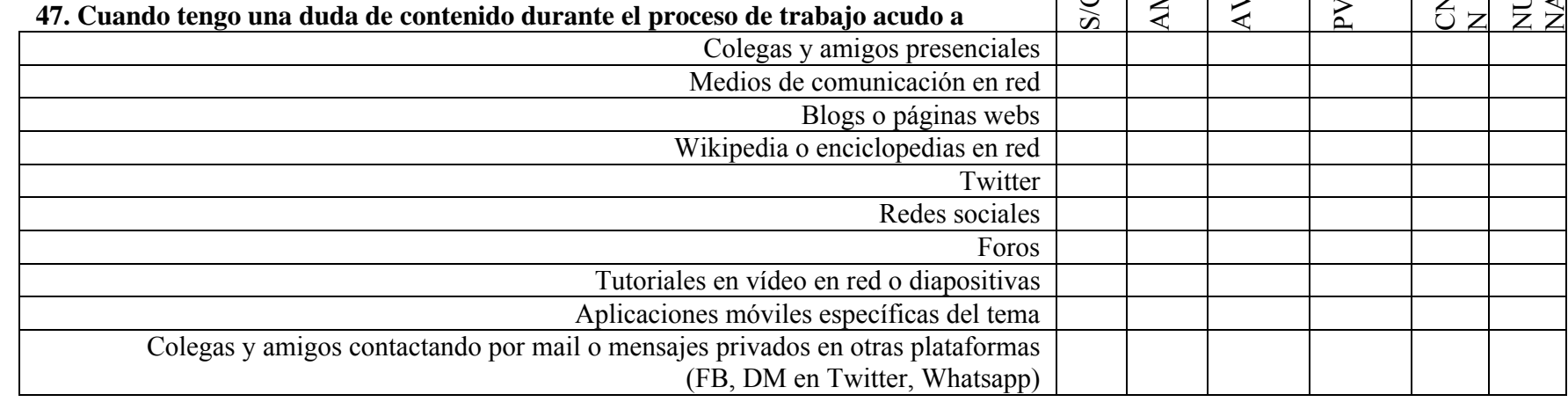

La distribución de las preguntas en las dimensiones definidas inicialmente en el proyecto es la que sigue: 
Prendes-Espinosa, Maria Paz; Castañeda-Quintero, Linda; Solano-Fernández, Isabel María; Roig-Vila, Rosabel; Aguiar-Perera, Ma Victoria \& Serrano-Sánchez, José Luis (2016). Validación de un cuestionario sobre hábitos de trabajo y aprendizaje para futuros profesionales: explorar los Entornos Personales de Aprendizaje. RELIEVE, 22(2), art. 6. doi: http://dx.doi.org/10.7203/relieve.22.2.7228

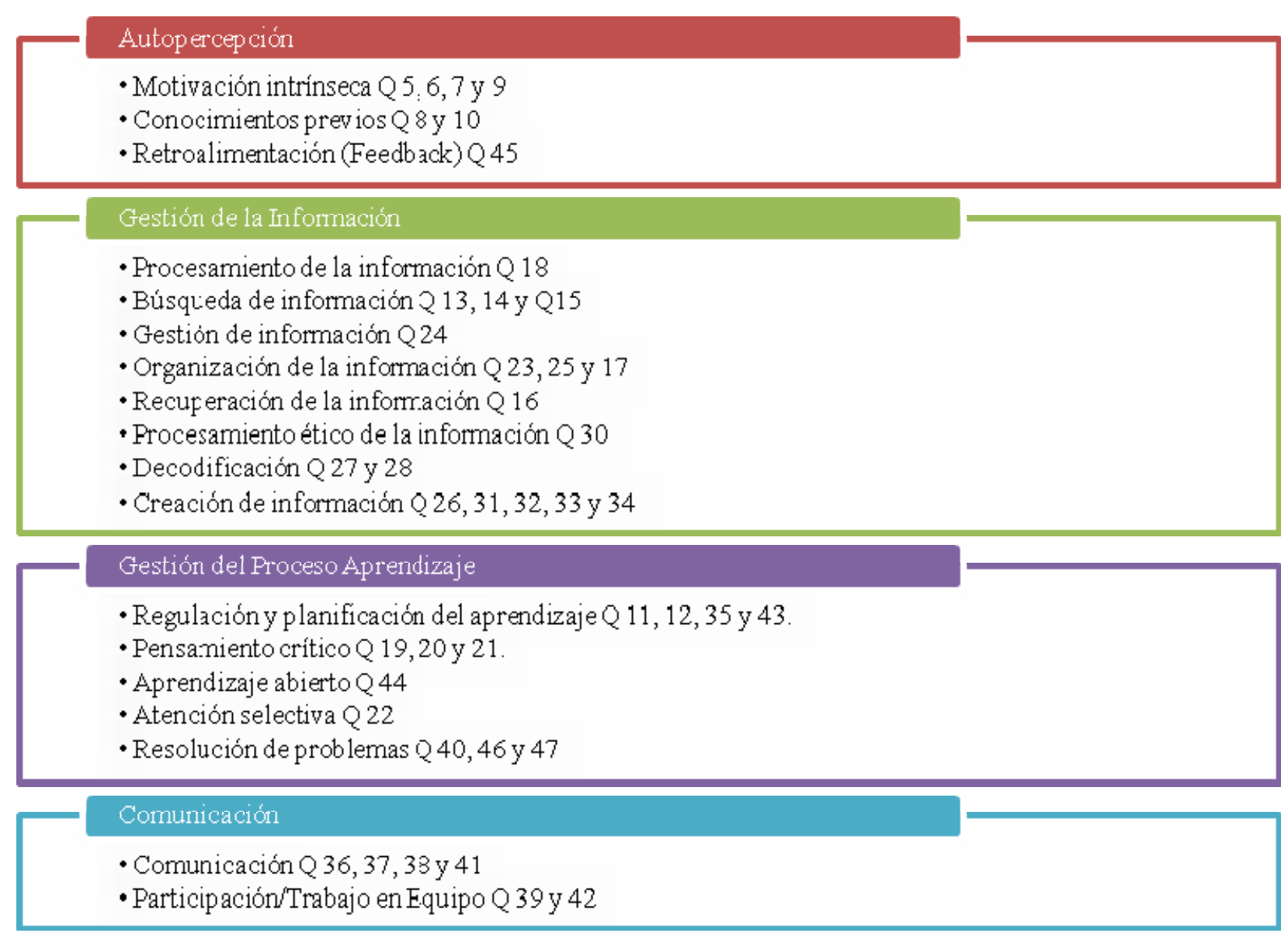

Tabla 6. Composición final del cuestionario CAPPLE respecto de las dimensiones iniciales

Lo recogido en este documento tiene la intención principal de ilustrar un proceso de validación de instrumento variada, con procedimientos cualitativos y cuantitativos $\mathrm{y}$ de exponerla en su complejidad. No obstante, el cuestionario resultante queda a la espera de probar su funcionamiento en el proceso de recogida de datos del proyecto.

En ese paso entendemos que la amplitud del mismo y su complejidad pueden suponer una limitación del cuestionario y obrar en contra de la posibilidad de recoger una mayor cantidad de datos (Krosnick, 1999); sin embargo, se trata del análisis de una realidad compleja y multidimensional, así que el equipo de investigación ha decidido optar por un cuestionario extenso que ofrezca mayor cantidad de información relevante (Stake, 2010).

\section{Referencias}

Adell, J. \& Castañeda, L. (2010). Los Entornos Personales de Aprendizaje (PLEs): una nueva manera de entender el aprendizaje. En R. Roig \& F. Fiorucci (Eds.), Claves para la investigación en innovación y calidad educativas. La integración de las Tecnologías de la Información y la Comunicación y la Interculturalidad en las aulas. Alcoy: Marfil - Roma TRE Universita degli studi. Recuperado de http://digitum.um.es/xmlui/bitstream/10201/1 7247/1/Adell\%26Castañeda 2010.pdf

Attwell, G. (2007). The Personal Learning Environments - the future of eLearning? eLearning Papers, 2(1). Recuperado de http://www.elearningeuropa.info/files/media/ $\underline{\text { media11561.pdf }}$ 
Prendes-Espinosa, Maria Paz; Castañeda-Quintero, Linda; Solano-Fernández, Isabel María; Roig-Vila, Rosabel; Aguiar-Perera, Ma Victoria \& Serrano-Sánchez, José Luis (2016). Validación de un cuestionario sobre hábitos de trabajo y aprendizaje para futuros profesionales: explorar los Entornos Personales de Aprendizaje. RELIEVE, 22(2), art. 6. doi: http://dx.doi.org/10.7203/relieve.22.2.7228

Attwell, G., Castañeda, L. \& Buchem, I. (2013). Guest Editorial Preface: Special Issue from the Personal Learning Environments 2011 Conference. International Journal of Virtual and Personal Learning Environments (IJVPLE), 13(4), 4. Recuperado de: http://www.igiglobal.com/pdf.aspx?tid\%3D102952\%26ptid \%3D71770\%26ctid\%3D15\%26t\%3DSpecial $\%$ 20Issue $\% 20$ from $\% 20$ the $\% 20$ Personal $\% 20$ Learning\%20Environments\%202011\%20Co nference

Best, J. \& Kahn, J. (2006). Research in Education. Boston: Pearson

Buchem, I., Attwell, G. y Torres-Kompen, R. (2011). Understanding Personal Learning Environments: Literature review and synthesis through the Activity Theory lens. pp. 1-33. En Proceedings of the PLE Conference 2011, 10 al 12 de julio de 2011, Southampton, Reino Unido. Recuperado de http://journal.webscience.org/658/

Casquero, O., Portillo, J., Ovelar, R., Romo, J. \& Benito, M. (2008). iGoogle and gadgets as a platform for integrating institutional and external services. En F. Wild, M. Kalz, M. Palmér, Proceedings of the First International Workshop on Mashup Personal Learning Environments (MUPPLE08). Maastricht, The Netherlands. Recuperado de: http://ftp.informatik.rwthaachen.de/Publicati ons/CEUR-WS/Vol-388/casquero.pdf

Castañeda, L. \& Adell, J. (2011). El desarrollo profesional de los docentes en entornos personales de aprendizaje (PLEs). En R. Roig y C. Laneve (Eds.), La práctica educativa en la Sociedad de la Información: Innovación a través de la investigación / La pratica educativa nella Società dell'informazione: L'innovazione attraverso la ricerca. Alcoy: Marfil. (pp. 83-95). Recuperado de: http://digitum.um.es/xmlui/bitstream/10201/2 4647/1/CastanedaAdell2011 preprint.pdf

Castañeda, L., \& Adell, J. (2013). La anatomía de los PLEs. En L. Castañeda \& J. Adell (Eds.), Entornos Personales de Aprendizaje:
Claves para el ecosistema educativo en red (pp. 11-27). Alcoy: Marfil. Recuperado de: http://digitum.um.es/xmlui/bitstream/10201/3 0408/1/capitulo1.pdf

Cohen, J. (1988). Statistical Power Analysis for the Behavioral Sciences. Hillsdale, N.J.: Lawrence Erlbaum. doi: https://doi.org/10.1002/bs.3830330104

Corral, Y. (2009). Validez y confiabilidad de los instrumentos de investigación para la recolección de datos. Revista ciencias de la educación, 19(33), 228-247. Recuperado de: http://servicio.bc.uc.edu.ve/educacion/revista /n33/art12.pdf

Crocker, L. \& Algina, J. (1986). Introduction to classical and modern test theory. Nueva York: Holt, Rinehart and Winston.

Dilman, D. A. (2007). Mail and Internet Surveys. The Tailored Design Method. New Jersey: John Wiley \& Son, Inc.

Escobar-Pérez, J. \& Cuervo-Martínez, A. (2008). Validez de contenido y juicio de expertos: una aproximación a su utilización. Avances en Medición, 6, 27-36. Recuperado de:

http://www.humanas.unal.edu.co/psicometria /files/7113/8574/5708/Articulo3 Juicio_de_e xpertos 27-36.pdf

Gallego-Arrufat, M.J. \& Chaves-Barboza, E. (2014). Tendencias en estudios sobre entornos personales de aprendizaje (Personal Learning Environments -PLE-). EDUTEC, Revista Electrónica de Tecnología Educativa, 49. Recuperado de http://edutec.rediris.es/Revelec2/Revelec49/n 49 Gallego Chaves.html

García, R., Ferrández, R, Sales, Mª . A. \& Moliner, Ma . O. (2006). Elaboración de instrumentos de medida de las actitudes y opiniones del profesorado universitario hacia la ética profesional docente y su papel como transmisor de valores. RELIEVE, 12(1), pp. 129-149.

doi:

http://doi.org/10.7203/relieve.12.1.4247

Jaramillo, S. \& Osses, S. (2012). Validación de un Instrumento sobre Metacognición para 
Prendes-Espinosa, Maria Paz; Castañeda-Quintero, Linda; Solano-Fernández, Isabel María; Roig-Vila, Rosabel; Aguiar-Perera, $\mathrm{M}^{\mathrm{a}}$ Victoria \& Serrano-Sánchez, José Luis (2016). Validación de un cuestionario sobre hábitos de trabajo y aprendizaje para futuros profesionales: explorar los Entornos Personales de Aprendizaje. RELIEVE, 22(2), art. 6. doi: http://dx.doi.org/10.7203/relieve.22.2.7228

Estudiantes de Segundo Ciclo de Educación General Básica. Estudios pedagógicos, Vol. 38(2), 117-131. doi: http://doi.org/10.4067/S0718$\underline{07052012000200008}$

Kline, P. (1994). An Easy Guide to DIMENSIÓN Analysis. Newbury Park: Sage Publications.

Knapp, T. R., \& Mueller, R. O. (2010). Realibility and validity of instruments. In G. R. Hancock \& R. O. Mueller (Eds.), The reviewer guide to quantitative methods in the social sciences (pp. 337-341). New York, NY: Routledge.

Krosnick, J. A. (1999). Survey research. Annual Review of Psychology, 50, 537-567. doi:

http://doi.org/10.1146/annurev.psych.50.1.53 I

Llorente, M. (2013). Assessing Personal Learning Environments (PLEs). An expert evaluation. Journal of New Approaches in Educational Research, 2(1), 39-44. doi: http://doi.org/10.7821/naer.2.1.39-44

Martín, E., García, L.A. Torbay, A. \& Rodríguez, T. (2007). Estructura DIMENSIÓNial y fiabilidad de un cuestionario de estrategias de aprendizaje en universitarios: CEA-U. Anales de psicología, 23, 1-6. Recuperado de: http://www.um.es/analesps/v23/v23 1/0123 1.pdf

Midgley, C., Maehr, M. Hruda, L., Anderman, E., Anderman, L., Freeman, K., Gheen, M., Kaplan, A., Kuman, R., Middleton, M., Nelson, J. Roese, R. \& Urdan, T. (2000). Manual for the Paterrns off Adaptive Learrning Scales. Recuperado de: http://www.umich.edu/ pals/PALS $\% 202000$ V13Word97.pdf

Morales, P. (2012). El tamaño del efecto (effect size): análisis complementarios al contraste de medias. Recuperado de: http://www.upcomillas.es/personal/peter/inve stigacion/Tama $\%$ F1oDelEfecto.pdf
Morales, P. (2013). El Análisis DIMENSIÓNial en la construcción $e$ interpretación de tests, escalas $y$ cuestionarios. Recuperado de: http://www.upcomillas.es/personal/peter/inve stigacion/AnalisisDIMENSIÓNial.pdf

Nunnally, J.C. (1978). Psychometric Theory. Nueva York: McGraw-Hill.

Osborne, J.W. \& Costello, A. (2004). Sample size and subject to item ratio in principal components analysis. Practical Assessment, Research y Evaluation, 9(11). Recuperado de:

http://PAREonline.net/getvn.asp? $\mathrm{v}=9 \mathrm{yn}=11$

Pintrich, P., Smith, D., Garcia, T. \& McKeachie, W. (1991). A Manual for the use of the Motivated strategies for learning questionnaire (MSLQ). Washington, DC: National Center for Research to Improve Postsecondary Teaching and Learning, Ann Arbor, MI. Office of Educational Research and Improvement. Recuperado de: http://files.eric.ed.gov/fulltext/ED338122.pdf

Prendes, M.P. \& Castañeda, L. (2013). PLECentered Education: The Next Boundary. Perceptions and Realities Behind Students Personal Learning Environments. ELA Journal of Educational Leadership in Action, 2(1). Recuperado de: http://www.lindenwood.edu/ela/issue03/casta neda.html

Prendes, M.P., Castañeda, L., Ovelar, R. \& Carrera, X. (2014). Componentes básicos para el análisis de los PLE de los futuros profesionales españoles: en los albores del Proyecto CAPPLE. EDUTEC, Revista Electrónica de Tecnología Educativa, 47. Recuperado de: http://edutec.rediris.es/Revelec2/Revelec47/n 47 Prendes-Castaneda-Ovelar-Carrera.html

Smith, V. \& Molina, M. (2011). Cuaderno Metodológico 5. La entrevista cognitiva: guía para su aplicación en la evaluación y mejoramiento de instrumentos de papel y lápiz. San José, Costa Rica.: Instituto de Investigaciones Psicológicas, Universidad de Costa Rica. Recuperado de: 
Prendes-Espinosa, Maria Paz; Castañeda-Quintero, Linda; Solano-Fernández, Isabel María; Roig-Vila, Rosabel; Aguiar-Perera, Ma Victoria \& Serrano-Sánchez, José Luis (2016). Validación de un cuestionario sobre hábitos de trabajo y aprendizaje para futuros profesionales: explorar los Entornos Personales de Aprendizaje. RELIEVE, 22(2), art. 6. doi: http://dx.doi.org/10.7203/relieve.22.2.7228

http://iip.ucr.ac.cr/sites/default/files/cuaderno smetodologicos/cuamet5.pdf

Snijkers, G. (2002). Cognitive Laboratory Experience: On Pre-testing Compiterised Questionnaires and Data Quality. Tesis Doctoral. Universidad de Utrech. Recuperado de http://dspace.library.uu.n1/bitstream/handle/1 $\underline{874 / 13401 / \text { full.pdf? sequence }=13}$

Stake, R. (2010). Qualitative Research: studying how things work. New York: The Guilford Press.

Utkin, L. V. (2006). A method for processing the unreliable expert judgments about parameters of probability distributions. European Journal of Operational Research, 175(1), 385-398. Doi: https://doi.org/10.1016/j.ejor.2005.04.041

Willis, G.B. (2005). Cognitive interviewing. Thousand Oaks: Sage Publications. doi: https://doi.org/10.4135/9781412983655

Wolley, M.E., Bowen, G.L. \& Bowen, N.K. (2006). The development and evaluation of procedures to assess child self-report item validity. Educational and psychological measurement, 66(4), 687-700. doi: https://doi.org/10.1177/0013164405282467

\section{Nota}

[1] Esta validación forma parte del proyecto "Competencias para el aprendizaje permanente basado en el uso de PLE (entornos personales de aprendizaje): análisis de los futuros profesionales y propuestas de mejora" CAPPLE- (EDU2012-33256), financiado por el Ministerio español de Economía y Competitividad y dirigido por la Dra. $\mathrm{M}^{\mathrm{a}} \mathrm{Paz}$ Prendes Espinosa de la Universidad de Murcia. 
Prendes-Espinosa, Maria Paz; Castañeda-Quintero, Linda; Solano-Fernández, Isabel María; Roig-Vila, Rosabel; Aguiar-Perera, M ${ }^{a}$ Victoria \& Serrano-Sánchez, José Luis (2016). Validación de un cuestionario sobre hábitos de trabajo y aprendizaje para futuros profesionales: explorar los Entornos Personales de Aprendizaje. RELIEVE, 22(2), art. 6. doi: http://dx.doi.org/10.7203/relieve.22.2.7228

\section{ANEXO 1}

\section{Borrador de Cuestionario 1}

Indica tu grado de acuerdo con las siguientes afirmaciones:

\begin{tabular}{|c|c|c|c|c|}
\hline & $\begin{array}{c}\text { Totalmente en } \\
\text { desacuerdo }\end{array}$ & $\begin{array}{l}\text { En } \\
\text { desacuerdo }\end{array}$ & $\begin{array}{c}\text { De } \\
\text { acuerdo }\end{array}$ & $\begin{array}{l}\text { Totalmente de } \\
\text { acuerdo }\end{array}$ \\
\hline $\begin{array}{l}\text { 2. Establecer objetivos me ayuda a aprovechar el tiempo que } \\
\text { dedico a Internet }\end{array}$ & & & & \\
\hline $\begin{array}{l}\text { 4. Valoro la importancia de la tarea que realizo para la } \\
\text { consecución de mis objetivos personales de formación }\end{array}$ & & & & \\
\hline $\begin{array}{l}\text { 7: Analizo mis puntos fuertes y débiles con objeto de valorar el } \\
\text { esfuerzo que necesito para llevar a cabo una tarea }\end{array}$ & & & & \\
\hline $\begin{array}{l}\text { 10: Cuando aprendo en Internet soy una persona que requiere de } \\
\text { una dirección y cierto control externo para tener éxito }\end{array}$ & & & & \\
\hline $\begin{array}{l}\text { 13: He descrito mis conocimientos y mis metas de aprendizaje } \\
\text { en una red social profesional como Linkedin, Xing, o en una } \\
\text { red social generalista como Facebook o Tuenti }\end{array}$ & & & & \\
\hline $\begin{array}{l}\text { 60: Uso un wiki para organizar los contenidos relacionados con } \\
\text { una actividad de aprendizaje }\end{array}$ & & & & \\
\hline $\begin{array}{l}\text { 61: Uso con otros compañeros un wiki para organizar de forma } \\
\text { colaborativa los contenidos de las actividades de aprendizaje }\end{array}$ & & & & \\
\hline $\begin{array}{l}\text { 62: Uso con otros compañeros un servicios de publicación de } \\
\text { contenidos para organizar de forma colaborativa los contenidos } \\
\text { de las actividades de aprendizaje }\end{array}$ & & & & \\
\hline $\begin{array}{l}\text { 80: La lectura de los blogs de otros estudiantes es muy } \\
\text { enriquecedora para la realización de mis actividades }\end{array}$ & & & & \\
\hline $\begin{array}{l}\text { 81: Estoy en contacto con mis compañeros a través de redes } \\
\text { sociales }\end{array}$ & & & & \\
\hline $\begin{array}{l}\text { 82: Las interacciones en los blogs con mis compañeros son } \\
\text { enriquecedoras para la realización de mis actividades }\end{array}$ & & & & \\
\hline $\begin{array}{l}\text { 83: Uso con otros compañeros gestores de enlaces para organizar } \\
\text { de forma colaborativa los contenidos de las actividades de } \\
\text { aprendizaje }\end{array}$ & & & & \\
\hline $\begin{array}{l}\text { 84: Las redes sociales me permiten conectar con comunidades } \\
\text { relacionadas con mis metas de aprendizaje }\end{array}$ & & & & \\
\hline $\begin{array}{l}\text { 112: El reflejo de mi actividad a lo largo del tiempo en las } \\
\text { herramientas Web } 2.0 \text { me permite reflexionar sobre mis } \\
\text { métodos de aprendizaje }\end{array}$ & & & & \\
\hline
\end{tabular}

Indica con qué frecuencia usas o realizas las siguientes acciones

\begin{tabular}{|c|c|c|c|c|c|}
\hline e & $\begin{array}{l}\text { Siempre o } \\
\text { casi siempre }\end{array}$ & $\begin{array}{c}\text { A } \\
\text { menudo }\end{array}$ & \begin{tabular}{c|c} 
A \\
veces
\end{tabular} & $\begin{array}{l}\text { Casi nunca } \\
\text { o nunca }\end{array}$ & $\begin{array}{l}\text { No aplicable } \\
\text { o no lo uso }\end{array}$ \\
\hline \multicolumn{6}{|l|}{$\begin{array}{l}\text { 37: Sé recuperar los contenidos que yo he almacenado en } \\
\text { mi equipo/en la red }\end{array}$} \\
\hline \multicolumn{6}{|l|}{$\begin{array}{l}\text { 37: Sé recuperar los contenidos que otros han } \\
\text { almacenado en su equipo/en la red }\end{array}$} \\
\hline \multicolumn{6}{|l|}{$\begin{array}{l}\text { 37: He desarrollado estrategias para recuperar cualquier } \\
\text { tipo de contenido }\end{array}$} \\
\hline \multicolumn{6}{|l|}{$\begin{array}{l}\text { 42: Creo que no toda la información que hay en } \\
\text { internet tiene el mismo grado de credibilidad }\end{array}$} \\
\hline \multicolumn{6}{|l|}{ 42: Cuando estoy solo no sé qué hacer. } \\
\hline $\begin{array}{l}\text { 42: Soy crítico con la información que encuentro/recibo } \\
\text { y puedo valorar su credibilidad. }\end{array}$ & & & & & \\
\hline
\end{tabular}


Prendes-Espinosa, Maria Paz; Castañeda-Quintero, Linda; Solano-Fernández, Isabel María; Roig-Vila, Rosabel; Aguiar-Perera, M ${ }^{a}$ Victoria \& Serrano-Sánchez, José Luis (2016). Validación de un cuestionario sobre hábitos de trabajo y aprendizaje para futuros profesionales: explorar los Entornos Personales de Aprendizaje. RELIEVE, 22(2), art. 6. doi: http://dx.doi.org/10.7203/relieve.22.2.7228

1: Principalmente, ¿con qué finalidad accedes a Internet?:

\begin{tabular}{|l|c|l|l|l|l|}
\hline & $\begin{array}{c}\text { Siempre o } \\
\text { casi siempre }\end{array}$ & $\begin{array}{l}\text { A } \\
\text { menudo }\end{array}$ & $\begin{array}{c}\text { A } \\
\text { veces }\end{array}$ & $\begin{array}{c}\text { Casi nunca } \\
\text { o nunca }\end{array}$ & $\begin{array}{c}\text { No aplicable } \\
\text { o no lo uso }\end{array}$ \\
\hline Comunicación & & & & & \\
\hline Información & & & & & \\
\hline Trabajo & & & & & \\
\hline Ocio & & & & & \\
\hline Organización & & & & & \\
\hline Formación & & & & & \\
\hline Relaciones Sociales & & & & & \\
\hline
\end{tabular}

3: Que situaciones aumentan mi interés para aprender sobre algo:

\begin{tabular}{|c|c|c|c|c|c|}
\hline & $\begin{array}{c}\text { Siempre o casi } \\
\text { siempre }\end{array}$ & $\begin{array}{l}\text { A } \\
\text { menudo }\end{array}$ & $\begin{array}{l}\text { A } \\
\text { veces }\end{array}$ & $\begin{array}{c}\text { Casi nunca o } \\
\text { nunca }\end{array}$ & $\begin{array}{l}\text { No aplicable o } \\
\text { no lo uso }\end{array}$ \\
\hline Mi asistencia a una clase & & & & & \\
\hline $\begin{array}{l}\text { La lectura o escucha de programas en medios de } \\
\text { comunicación tradicionales (televisión, radio, } \\
\text { periódico, revistas) }\end{array}$ & & & & & \\
\hline $\begin{array}{l}\text { Mi participación como oyente en charlas, } \\
\text { conferencias, jornadas... }\end{array}$ & & & & & \\
\hline La lectura de Noticias que me llegan al correo & & & & & \\
\hline $\begin{array}{l}\text { Mi participación o lectura de temas y } \\
\text { conversaciones en foros en Internet }\end{array}$ & & & & & \\
\hline $\begin{array}{l}\text { La lectura o escucha de programas en Medios de } \\
\text { comunicación en red (podcast, televisión } \\
\text { digital, revistas digitales) }\end{array}$ & & & & & \\
\hline La lectura de Blogs o páginas web & & & & & \\
\hline La lectura de mi Timeline de Twitter & & & & & \\
\hline $\begin{array}{l}\text { Mis conversaciones e intercambios en las redes } \\
\text { sociales (Facebook, Tuenti y Linkedin) }\end{array}$ & & & & & \\
\hline $\begin{array}{l}\text { Visitas a sitios de información multimedia en } \\
\text { red (Youtube, Slidesahe, Flickr, Isuu, prezi, } \\
\text { instagram) }\end{array}$ & & & & & \\
\hline Charlas en Whatsapp o Line (o similares) & & & & & \\
\hline
\end{tabular}

5: Mi motivación en el desempeño de tareas se incrementa si (marca tantos como corresponda):
$\square$ Conozco la finalidad de las mismas.
$\square \mathrm{Me}$ apasiona poder realizarla
$\square$ Conozco las dificultades previsibles
$\square$ Dispongo de los recursos necesarios para desarrollar la tarea
$\square$ Tengo presiones externas que me animan a realizarla

$\square$ Conozco los requerimientos "a priori

6: Cuando aprendes en internet ¿Cómo fijas lo que debes aprender?

\begin{tabular}{|l|c|l|l|l|l|}
\hline $\begin{array}{l}\text { Me ajusto a los objetivos definidos en la } \\
\text { asignatura/el proyecto en el que trabaje }\end{array}$ & $\begin{array}{c}\text { Siempre o } \\
\text { casi siempre }\end{array}$ & $\begin{array}{l}\text { A } \\
\text { menudo }\end{array}$ & $\begin{array}{c}\text { A } \\
\text { veces }\end{array}$ & $\begin{array}{c}\text { Casi nunca } \\
\text { o nunca }\end{array}$ & $\begin{array}{c}\text { No aplicable } \\
\text { o no lo uso }\end{array}$ \\
\hline Me ajusto a los temas que vayan surgiendo & & & & & \\
\hline Me ajusto a las capacidades que tengo & & & & & \\
\hline Me ajusto a las necesidades laborales & & & & & \\
\hline $\begin{array}{l}\text { Me ajusto a lo que creo que mis colegas me } \\
\text { exigirán }\end{array}$ & & & & & \\
\hline
\end{tabular}

12: Cuando envío un trabajo o proyecto para su evaluación, espero...

$\square$ Una respuesta donde se subraye especialmente los aspectos positivos de mi trabajo.

$\square$ Una respuesta en la que subraye especialmente orientaciones sobre los aspectos a corregir.

$\square$ Una respuesta con la calificación sin ningún comentario al respecto. 
Prendes-Espinosa, Maria Paz; Castañeda-Quintero, Linda; Solano-Fernández, Isabel María; Roig-Vila, Rosabel; Aguiar-Perera, M ${ }^{a}$ Victoria \& Serrano-Sánchez, José Luis (2016). Validación de un cuestionario sobre hábitos de trabajo y aprendizaje para futuros profesionales: explorar los Entornos Personales de Aprendizaje. RELIEVE, 22(2), art. 6. doi: http://dx.doi.org/10.7203/relieve.22.2.7228

14: A la hora de planificar mi estudio:

\begin{tabular}{|l|l|l|l|l|l|}
\hline & $\begin{array}{c}\text { Siempre o } \\
\text { casi siempre }\end{array}$ & $\begin{array}{l}\text { A } \\
\text { menudo }\end{array}$ & $\begin{array}{l}\text { A } \\
\text { veces }\end{array}$ & $\begin{array}{c}\text { Casi nunca } \\
\text { o nunca }\end{array}$ & $\begin{array}{c}\text { No aplicable } \\
\text { o no lo uso }\end{array}$ \\
\hline $\begin{array}{l}\text { Organizo mis ideas-tareas en un gestor de tareas } \\
\text { tipo Evernote, remember the milk }\end{array}$ & & & & & \\
\hline $\begin{array}{l}\text { Organizo mis ideas- tareas en un folio, libreta o } \\
\text { agenda }\end{array}$ & & & & & \\
\hline No organizo mis ideas-tareas por escrito. & & & & & \\
\hline
\end{tabular}

19: A la hora de organizar mí tiempo y recursos en cuanto a trabajos y tareas

\begin{tabular}{|l|c|c|c|c|c|}
\hline & $\begin{array}{c}\text { Siempre o } \\
\text { casi siempre }\end{array}$ & $\begin{array}{c}\text { A } \\
\text { menudo }\end{array}$ & $\begin{array}{c}\text { A } \\
\text { veces }\end{array}$ & $\begin{array}{c}\text { Casi nunca } \\
\text { o nunca }\end{array}$ & $\begin{array}{c}\text { No aplicable } \\
\text { o no lo uso }\end{array}$ \\
\hline Utilizo una agenda en papel. & & & & & \\
\hline Utilizo un calendario en red. & & & & & \\
\hline $\begin{array}{l}\text { Utilizo algún tipo de herramienta agregador } \\
\text { para organizar mis recursos y herramientas en } \\
\text { red tipo Symbaloo, netvibes }\end{array}$ & & & & & \\
\hline $\begin{array}{l}\text { Utilizo algún contador de tiempo de aprendizaje } \\
\text { para organizar mis tiempos en red (Tipo } \\
\text { "pomodoro" }\end{array}$ & & & & & \\
\hline No suelo organizar mi tiempo y recursos & & & & & \\
\hline
\end{tabular}

22: Me planteo realizar actividades que, a través de la red, supongan

\begin{tabular}{|l|c|c|c|c|c|}
\hline & $\begin{array}{c}\text { Siempre o } \\
\text { casi siempre }\end{array}$ & $\begin{array}{c}\text { A } \\
\text { menudo }\end{array}$ & $\begin{array}{c}\text { A } \\
\text { veces }\end{array}$ & $\begin{array}{c}\text { Casi nunca } \\
\text { o nunca }\end{array}$ & $\begin{array}{c}\text { No aplicable } \\
\text { o no lo uso }\end{array}$ \\
\hline Resolver problemas. & & & & & \\
\hline Investigar e indagar. & & & & & \\
\hline Analizar contenidos e informaciones. & & & & & \\
\hline Desarrollar proyectos. & & & & & \\
\hline Elaborar creaciones. & & & & & \\
\hline Ejercitar tareas repetitivas. & & & & & \\
\hline
\end{tabular}

24: Cuando quiero aprender algo nuevo acudo a:

24: Cuando quiero aprender algo nuevo acudo a:
\begin{tabular}{|l|c|c|c|c|c|}
\hline Colegas y amigos presenciales & $\begin{array}{c}\text { Siempre o } \\
\text { casi siempre }\end{array}$ & $\begin{array}{c}\text { A } \\
\text { menudo }\end{array}$ & $\begin{array}{c}\text { A } \\
\text { veces }\end{array}$ & $\begin{array}{c}\text { Casi nunca } \\
\text { o nunca }\end{array}$ & $\begin{array}{c}\text { No aplicable } \\
\text { o no lo uso }\end{array}$ \\
\hline Libros & & & & & \\
\hline Profesores y otras figuras & & & & & \\
\hline Medios de comunicación en red & & & & & \\
\hline Blogs o páginas webs & & & & & \\
\hline Wikipedia o enciclopedias en red & & & & & \\
\hline Twitter & & & & & \\
\hline Redes sociales & & & & & \\
\hline Foros & & & & \\
\hline Tutoriales en vídeo en red o diapositivas & & & & & \\
\hline Aplicaciones móviles específicas del tema & & & & & \\
\hline $\begin{array}{l}\text { Colegas y amigos contactando por mail o } \\
\text { mensajes privados en otras plataformas (FB, } \\
\text { DM en Twitter, Whatsapp) }\end{array}$ & & & & & \\
\hline Otros & & & & & \\
\hline
\end{tabular}

25: Cuando busco información lo hago en:
$\square$ Un único motor de búsqueda generalista (google, yahoo...)
$\square$ Varios buscadores generalistas.
๑ Buscadores temáticos, especializados.
$\square$ Motores de búsqueda específicos, temáticos.
$\square$ Bibliotecas y bases de datos en red.
$\square$ Redes sociales $\square$ Foros de debate
$\square \quad$ En otros espacios en red (di cuáles). 
Prendes-Espinosa, Maria Paz; Castañeda-Quintero, Linda; Solano-Fernández, Isabel María; Roig-Vila, Rosabel; Aguiar-Perera, M ${ }^{\mathrm{a}}$ Victoria \& Serrano-Sánchez, José Luis (2016). Validación de un cuestionario sobre hábitos de trabajo y aprendizaje para futuros profesionales: explorar los Entornos Personales de Aprendizaje. RELIEVE, 22(2), art. 6. doi: http://dx.doi.org/10.7203/relieve.22.2.7228

27: Para acceder a la información realizo... $\square$ Búsquedas "de tanteo" en manuales, libros de texto, enciclopedias

口 Búsquedas "de tanteo" en buscadores web.

$\square$ Busquedas sistematizadas en revistas especializadas

$\square$ Busquedas en base de datos concretas.

$\square$ Búsquedas en sitios y portales Web especializados.

$\square$ Busqueda por autores de referencia.

$\square$ Otro tipo de búsquedas. ¿Cuáles?

29: Complemento mi formación académica con

$\square$ Cursos en red ofertados por empresas/instituciones

$\square$ Cursos masivos en red (MOOC).

$\square$ Cursos semipresenciales.

$\square$ Cursos presenciales.

口 Prácticas no retribuidas.

$\square$ Voluntariado social.

๑ Otro tipo de búsquedas. ¿Cuáles?

31: Suelo guardar la información:

\begin{tabular}{|l|c|c|c|c|c|}
\hline & $\begin{array}{c}\text { Siempre o } \\
\text { casi siempre }\end{array}$ & $\begin{array}{c}\text { A } \\
\text { menudo }\end{array}$ & $\begin{array}{c}\text { A } \\
\text { veces }\end{array}$ & $\begin{array}{c}\text { Casi nunca } \\
\text { o nunca }\end{array}$ & $\begin{array}{c}\text { No aplicable } \\
\text { o no lo uso }\end{array}$ \\
\hline En modo local en mi ordenador & & & & & \\
\hline En mi ordenador y en la nube. & & & & & \\
\hline Sólo en la nube & & & & & \\
\hline
\end{tabular}

33: Cuándo abordo un nueva información, considero necesario...

\begin{tabular}{|l|c|c|c|c|c|}
\hline & $\begin{array}{c}\text { Siempre o } \\
\text { casi siempre }\end{array}$ & $\begin{array}{c}\text { A } \\
\text { menudo }\end{array}$ & $\begin{array}{c}\text { A } \\
\text { veces }\end{array}$ & $\begin{array}{c}\text { Casi nunca } \\
\text { o nunca }\end{array}$ & $\begin{array}{c}\text { No aplicable } \\
\text { o no lo uso }\end{array}$ \\
\hline Vincularla a mis conocimientos previos. & & & & & \\
\hline $\begin{array}{l}\text { Establecer una conexión y/asociación } \\
\text { entre los diferentes conceptos }\end{array}$ & & & & & \\
\hline $\begin{array}{l}\text { Determinar una jerarquía entre los } \\
\text { diferentes elementos que componen el } \\
\text { nuevo contenido }\end{array}$ & & & & & \\
\hline
\end{tabular}

35: Para organizar y gestionar la información prefiero:

\begin{tabular}{|l|c|c|c|c|c|}
\hline & $\begin{array}{c}\text { Siempre o } \\
\text { casi siempre }\end{array}$ & $\begin{array}{c}\text { A } \\
\text { menudo }\end{array}$ & $\begin{array}{c}\text { A } \\
\text { veces }\end{array}$ & $\begin{array}{c}\text { Casi nunca } \\
\text { o nunca }\end{array}$ & $\begin{array}{c}\text { No aplicable } \\
\text { o no lo uso }\end{array}$ \\
\hline Marcadores sociales (Diigo, delicious...) & & & & & \\
\hline Wikis & & & & & \\
\hline Blogs & & & & & \\
\hline Redes sociales (Twitter, facebook...) & & & & & \\
\hline Otras herramientas en red. ¿Cuáles? & & & & & \\
\hline
\end{tabular}

36: Cuando organizo mis contenidos utilizo:

\begin{tabular}{|l|c|c|c|c|c|}
\hline & $\begin{array}{c}\text { Siempre o } \\
\text { casi siempre }\end{array}$ & $\begin{array}{c}\text { A } \\
\text { menudo }\end{array}$ & $\begin{array}{c}\text { A } \\
\text { veces }\end{array}$ & $\begin{array}{c}\text { Casi nunca } \\
\text { o nunca }\end{array}$ & $\begin{array}{c}\text { No aplicable } \\
\text { o no lo uso }\end{array}$ \\
\hline Carpetas (jerárquicas) & & & & & \\
\hline Una línea de tiempo & & & & & \\
\hline $\begin{array}{l}\text { Una organización basada en mis intereses } \\
\text { personales y académicos }\end{array}$ & & & & \\
\hline
\end{tabular}

38: Cuando quiero aprender algo nuevo acudo a:

\begin{tabular}{|l|c|c|c|c|c|}
\hline & $\begin{array}{c}\text { Siempre o } \\
\text { casi siempre }\end{array}$ & $\begin{array}{c}\text { A } \\
\text { menudo }\end{array}$ & A veces & $\begin{array}{c}\text { Casi nunca } \\
\text { o nunca }\end{array}$ & $\begin{array}{c}\text { No aplicable o } \\
\text { no lo uso }\end{array}$ \\
\hline Me vienen a la mente espontáneamente & & & & & \\
\hline Llego a ellos a través de otras ideas, conocimientos & & & & & \\
\hline Hablo mentalmente & & & & & \\
\hline Hablo en voz baja conmigo mismo & & & & & \\
\hline $\begin{array}{c}\text { Utilizo un papel para escribir o representar las ideas o } \\
\text { los conocimientos }\end{array}$ & & & & & \\
\hline Recurro a materiales que he elaborado y que tienen & & & & & \\
\hline
\end{tabular}


Prendes-Espinosa, Maria Paz; Castañeda-Quintero, Linda; Solano-Fernández, Isabel María; Roig-Vila, Rosabel; Aguiar-Perera, M ${ }^{\mathrm{a}}$ Victoria \& Serrano-Sánchez, José Luis (2016). Validación de un cuestionario sobre hábitos de trabajo y aprendizaje para futuros profesionales: explorar los Entornos Personales de Aprendizaje. RELIEVE, 22(2), art. 6. doi: http://dx.doi.org/10.7203/relieve.22.2.7228

\begin{tabular}{|l|l|l|l|l|}
\hline relación directa con dichos conocimientos & & & & \\
\hline $\begin{array}{l}\text { Tengo la información categorizada para su } \\
\text { recuperación }\end{array}$ & & & & \\
\hline $\begin{array}{l}\text { Utilizo otras estrategias de acceso al conocimiento (di } \\
\text { cuáles) }\end{array}$ & & & & \\
\hline
\end{tabular}

39: Cuando necesito acceder a informaciones que tengo almacenadas en la red:

\begin{tabular}{|l|c|c|c|c|}
\hline \multicolumn{1}{|c|}{$\begin{array}{c}\text { Siempre o } \\
\text { casi siempre }\end{array}$} & $\begin{array}{c}\text { A } \\
\text { menudo }\end{array}$ & $\begin{array}{c}\text { A } \\
\text { veces }\end{array}$ & $\begin{array}{c}\text { Casi nunca } \\
\text { o nunca }\end{array}$ & $\begin{array}{c}\text { No aplicable } \\
\text { o no lo uso }\end{array}$ \\
\hline Accedo a ella instintivamente & & & & \\
\hline Antes valoro si realmente necesito consultarla & & & & \\
\hline La consulto y la descargo & & & & \\
\hline $\begin{array}{l}\text { Tras consultarla accedo a otras } \\
\text { informaciones atengo almacenadas }\end{array}$ & & & & \\
\hline $\begin{array}{l}\text { Tras consultarla accedo a otras fuentes de } \\
\text { Internet }\end{array}$ & & & & \\
\hline $\begin{array}{l}\text { Tras consultarla accedo a fuentes de } \\
\text { información off-line }\end{array}$ & & & & \\
\hline $\begin{array}{l}\text { Tras consultarla hablo de ella con } \\
\text { compañeros o amigos a través de la red }\end{array}$ & & & & \\
\hline $\begin{array}{l}\text { Tras consultarla hablo de ella con } \\
\text { compañeros o amigos cara a cara }\end{array}$ & & & & \\
\hline Actúo de otras maneras (di cuáles) & & & & \\
\hline
\end{tabular}

40: Cuando necesito acceder a informaciones que he elaborado:

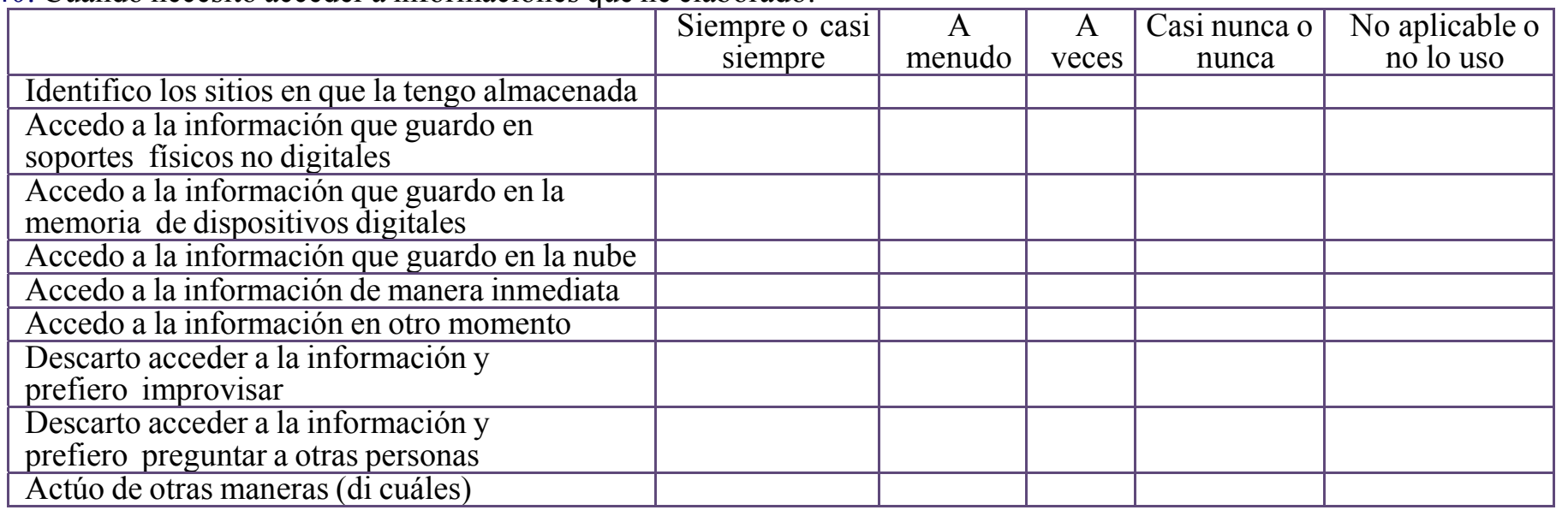

41: Cuestiono la información que recibo de...:

\begin{tabular}{|l|l|l|l|l|l|}
\hline & $\begin{array}{c}\text { Siempre o } \\
\text { casi siempre }\end{array}$ & $\begin{array}{l}\text { A } \\
\text { menudo }\end{array}$ & $\begin{array}{c}\text { A } \\
\text { veces }\end{array}$ & $\begin{array}{c}\text { Casi nunca } \\
\text { o nunca }\end{array}$ & $\begin{array}{c}\text { No aplicable } \\
\text { o no lo uso }\end{array}$ \\
\hline De mis profesores & & & & & \\
\hline De mis amigos y familiares & & & & & \\
\hline Medios de comunicación tradicionales & & & & & \\
\hline Medios de comunicación en red & & & & & \\
\hline Blogs y páginas web & & & & & \\
\hline Twitter & & & & \\
\hline Redes sociales & & & & \\
\hline Foros & & & & \\
\hline Tutoriales & & & & \\
\hline Aplicaciones móviles específicas & & & & \\
\hline Noticias que me llegan al correo & & & & \\
\hline De expertos u otros profesionales del área & & & & & \\
\hline
\end{tabular}

43: ¿Qué añade credibilidad a la información que recibo?

Que venga de una institución oficial

Que aparezca en varios medios de comunicación

\begin{tabular}{|c|c|c|c|c|}
$\begin{array}{c}\text { Siempre o } \\
\text { casi siempre }\end{array}$ & $\begin{array}{c}\text { A } \\
\text { menudo }\end{array}$ & $\begin{array}{c}\text { A } \\
\text { veces }\end{array}$ & $\begin{array}{r}\text { Casi nunca } \\
\text { o nunca }\end{array}$ & $\begin{array}{c}\text { No aplicable } \\
\text { o no lo uso }\end{array}$ \\
\hline & & & & \\
\hline & & & & \\
\hline
\end{tabular}


Prendes-Espinosa, Maria Paz; Castañeda-Quintero, Linda; Solano-Fernández, Isabel María; Roig-Vila, Rosabel; Aguiar-Perera, M ${ }^{\mathrm{a}}$ Victoria \& Serrano-Sánchez, José Luis (2016). Validación de un cuestionario sobre hábitos de trabajo y aprendizaje para futuros profesionales: explorar los Entornos Personales de Aprendizaje. RELIEVE, 22(2), art. 6. doi: http://dx.doi.org/10.7203/relieve.22.2.7228

\begin{tabular}{|l|l|l|l|l|}
\hline Que me lo recomiende el profesor & & & & \\
\hline $\begin{array}{l}\text { Que me lo recomienden mis colegas, } \\
\text { amigos y familiares. }\end{array}$ & & & & \\
\hline Que sea recomendado en las redes sociales & & & & \\
\hline $\begin{array}{l}\text { Que aparezca en un sistema de recomendación } \\
\text { en red ("meneame", "tripavisor") }\end{array}$ & & & & \\
\hline $\begin{array}{l}\text { Que sea una de las primeras posiciones } \\
\text { de la búsqueda en google }\end{array}$ & & & & \\
\hline Que sea trending topic en twitter & & & \\
\hline $\begin{array}{l}\text { Que aparezca en varios recursos (artículos, } \\
\text { libros, vídeos) en red }\end{array}$ & & & & \\
\hline Que lo recomiende un experto & & & & \\
\hline
\end{tabular}

44: Ante la información que recibo:

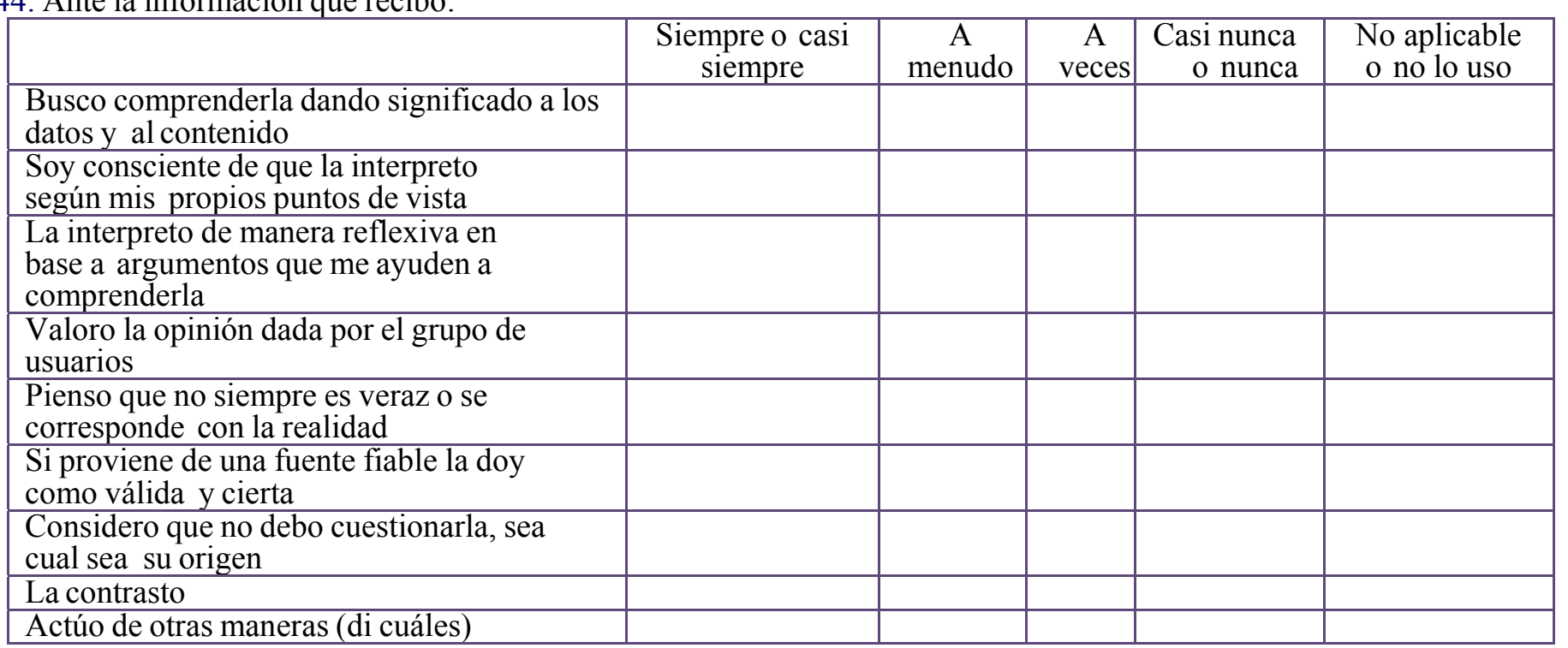

47 Para sistematizar la selección de la información, en primer lugar...

$\square$ Identifico los conceptos importantes que describen la información a buscar.

$\square$ Delimito las palabras clave en otros idiomas.

$\square$ Establezco una franja temporal de los documentos (años concretos).

$\square$ Utilizo otras estrategias (di cuáles).

49: Cuando trabajo con información, para comprenderla mejor, prefiero que sea:

\begin{tabular}{|l|c|c|c|c|c|}
\hline & $\begin{array}{c}\text { Siempre o } \\
\text { casi siempre }\end{array}$ & $\begin{array}{c}\text { A } \\
\text { menudo }\end{array}$ & $\begin{array}{c}\text { A } \\
\text { veces }\end{array}$ & $\begin{array}{c}\text { Casi nunca } \\
\text { o nunca }\end{array}$ & $\begin{array}{c}\text { No aplicable } \\
\text { o no lo uso }\end{array}$ \\
\hline texto & & & & & \\
\hline Icónica (fotografía o imágenes) & & & & & \\
\hline Vídeo & & & & & \\
\hline Audio & & & & & \\
\hline Multimedia & & & & & \\
\hline Hipermedia & & & & & \\
\hline De otro tipo (dí cuáles) & & & & \\
\hline
\end{tabular}

51: De la información que localizo, selecciono:

\begin{tabular}{|c|c|c|c|c|c|}
\hline & $\begin{array}{c}\text { Siempre o } \\
\text { casi siempre }\end{array}$ & $\begin{array}{c}\mathrm{A} \\
\text { menudo }\end{array}$ & $\begin{array}{c}\text { A } \\
\text { veces }\end{array}$ & $\begin{array}{l}\text { Casi nunca } \\
\text { o nunca }\end{array}$ & $\begin{array}{c}\text { No aplicable } \\
\text { o no lo uso }\end{array}$ \\
\hline \multicolumn{6}{|c|}{ La que es estéticamente más atractiva } \\
\hline \multicolumn{6}{|c|}{ La que es más actual } \\
\hline \multicolumn{6}{|c|}{ La que utilice un lenguaje más sencillo } \\
\hline \multicolumn{6}{|c|}{ La que utiliza formato audiovisual } \\
\hline \multicolumn{6}{|l|}{ La que parte de un esquema claro } \\
\hline \multicolumn{6}{|l|}{ La que más me han recomendado } \\
\hline La que es obligatorio que revise & & & & & \\
\hline
\end{tabular}


Prendes-Espinosa, Maria Paz; Castañeda-Quintero, Linda; Solano-Fernández, Isabel María; Roig-Vila, Rosabel; Aguiar-Perera, M ${ }^{\mathrm{a}}$ Victoria \& Serrano-Sánchez, José Luis (2016). Validación de un cuestionario sobre hábitos de trabajo y aprendizaje para futuros profesionales: explorar los Entornos Personales de Aprendizaje. RELIEVE, 22(2), art.

6. doi: http://dx.doi.org/10.7203/relieve.22.2.7228

\section{2: Cuando utilizo información de terceros lo hago:}

\begin{tabular}{|l|c|c|c|c|c|}
\hline $\begin{array}{l}\text { Responsablemente, respetando los } \\
\text { derechos de autor }\end{array}$ & $\begin{array}{c}\text { Siempre o } \\
\text { casi siempre }\end{array}$ & $\begin{array}{c}\text { A } \\
\text { menudo }\end{array}$ & $\begin{array}{c}\text { A } \\
\text { veces }\end{array}$ & $\begin{array}{c}\text { Casi nunca } \\
\text { o nunca }\end{array}$ & $\begin{array}{c}\text { No aplicable } \\
\text { o no lo uso }\end{array}$ \\
\hline $\begin{array}{l}\text { Respetando el tipo de licencia con que } \\
\text { está protegida }\end{array}$ & & & & \\
\hline Sin mencionar las fuentes y/o autores & & & & \\
\hline Citando los fuentes y/o autores & & & & & \\
\hline
\end{tabular}

56 Cuando encuentro un documento interesante...

\begin{tabular}{|c|c|c|c|c|c|}
\hline & \begin{tabular}{|c|} 
Siempre o \\
casi siempre
\end{tabular} & $\begin{array}{c}\text { A } \\
\text { menudo }\end{array}$ & $\begin{array}{c}\text { A } \\
\text { veces }\end{array}$ & $\begin{array}{l}\text { Casi nunca } \\
\text { o nunca }\end{array}$ & $\begin{array}{l}\text { No aplicable o } \\
\text { no lo uso }\end{array}$ \\
\hline $\begin{array}{l}\text { Lo leo en red y tomo notas en una herramienta } \\
\text { online específica (tipo diigo) }\end{array}$ & & & & & \\
\hline $\begin{array}{l}\text { Lo incluyo en una herramienta específica de gestión } \\
\text { de bibliografía (tipo mendeley, RefWorks) y tomo } \\
\text { notas del mismo en esa misma herramienta }\end{array}$ & & & & & \\
\hline $\begin{array}{l}\text { Me bajo el documento a mi ordenador y tomo notas } \\
\text { en una herramienta específica mientras lo leo en } \\
\text { pantalla. }\end{array}$ & & & & & \\
\hline $\begin{array}{l}\text { Uso metadatos para incorporarlo en mis propios } \\
\text { recursos }\end{array}$ & & & & & \\
\hline $\begin{array}{l}\text { Lo leo impreso en papel, lo subrayo y tomo notas en } \\
\text { el mismo papel, las notas las paso a un documento } \\
\text { de texto para guardarlas }\end{array}$ & & & & & \\
\hline $\begin{array}{l}\text { Lo leo impreso en papel, lo subrayo y tomo notas en } \\
\text { el mismo papel }\end{array}$ & & & & & \\
\hline Adopto otras estrategias (dí cuáles) & & & & & \\
\hline
\end{tabular}

57: Cuando encuentro un vídeo o un audio interesante...

\begin{tabular}{|l|l|l|l|l|l|}
\hline & $\begin{array}{c}\text { Siempre o } \\
\text { casi } \\
\text { siempre }\end{array}$ & $\begin{array}{l}\text { A } \\
\text { menudo }\end{array}$ & $\begin{array}{c}\text { A } \\
\text { veces }\end{array}$ & $\begin{array}{c}\text { Casi nunca } \\
\text { o nunca }\end{array}$ & $\begin{array}{c}\text { No aplicable } \\
\text { o no lo uso }\end{array}$ \\
\hline Solo veo/escucho las veces que me hagan falta & & & & & \\
\hline Lo escucho/veo en red y tomo notas en papel & & & & \\
\hline $\begin{array}{c}\text { Lo escucho/veo en red y tomo notas en un } \\
\text { documento de texto }\end{array}$ & & & & \\
\hline $\begin{array}{c}\text { Lo escucho/veo en red y tomo notas en un } \\
\text { programa específico para ello }\end{array}$ & & & & \\
\hline Adopto otras estrategias (dí cuáles) & & & & & \\
\hline
\end{tabular}

58: Cuando encuentro un vídeo o un audio interesante...

\begin{tabular}{|l|c|c|c|c|c|}
\hline La analizo & $\begin{array}{c}\text { Siempre o } \\
\text { casi siempre }\end{array}$ & $\begin{array}{c}\text { A } \\
\text { menudo }\end{array}$ & $\begin{array}{c}\text { A } \\
\text { veces }\end{array}$ & $\begin{array}{c}\text { Casi nunca } \\
\text { o nunca }\end{array}$ & $\begin{array}{c}\text { No aplicable } \\
\text { o no lo uso }\end{array}$ \\
\hline La interpreto & & & & & \\
\hline La contrasto con lo que sé & & & & & \\
\hline La relaciono con lo que sé & & & & & \\
\hline Me surgen preguntas / dudas & & & & & \\
\hline Busco contrastarla con otras fuentes & & & & & \\
\hline Realizo otras actuaciones (di cuáles) & & & & & \\
\hline
\end{tabular}

64: Que hago con mis notas/información relevante que he encontrado

\begin{tabular}{|c|c|c|c|c|c|}
\hline & $\begin{array}{c}\text { Siempre o } \\
\text { casi siempre }\end{array}$ & $\begin{array}{c}\mathrm{A} \\
\text { menudo }\end{array}$ & $\begin{array}{c}\text { A } \\
\text { veces }\end{array}$ & $\begin{array}{r}\text { Casi nunca } \\
\text { o nunca }\end{array}$ & $\begin{array}{l}\text { No aplicable } \\
\text { o no lo uso }\end{array}$ \\
\hline La guardo cuidadosamente & & & & & \\
\hline $\begin{array}{l}\text { Hago un esquema/mapa conceptual para } \\
\text { relacionarla: en papel/en un documento de } \\
\text { texto/en una herramienta específica en red/ }\end{array}$ & & & & & \\
\hline $\begin{array}{l}\text { Me hago un resumen: en papel/en un documento } \\
\text { de texto/en una entrada en mi página } \\
\text { personal/en una entrada que comparto en mi }\end{array}$ & & & & & \\
\hline
\end{tabular}


Prendes-Espinosa, Maria Paz; Castañeda-Quintero, Linda; Solano-Fernández, Isabel María; Roig-Vila, Rosabel; Aguiar-Perera, M ${ }^{\mathrm{a}}$ Victoria \& Serrano-Sánchez, José Luis (2016). Validación de un cuestionario sobre hábitos de trabajo y aprendizaje para futuros profesionales: explorar los Entornos Personales de Aprendizaje. RELIEVE, 22(2), art. 6. doi: http://dx.doi.org/10.7203/relieve.22.2.7228

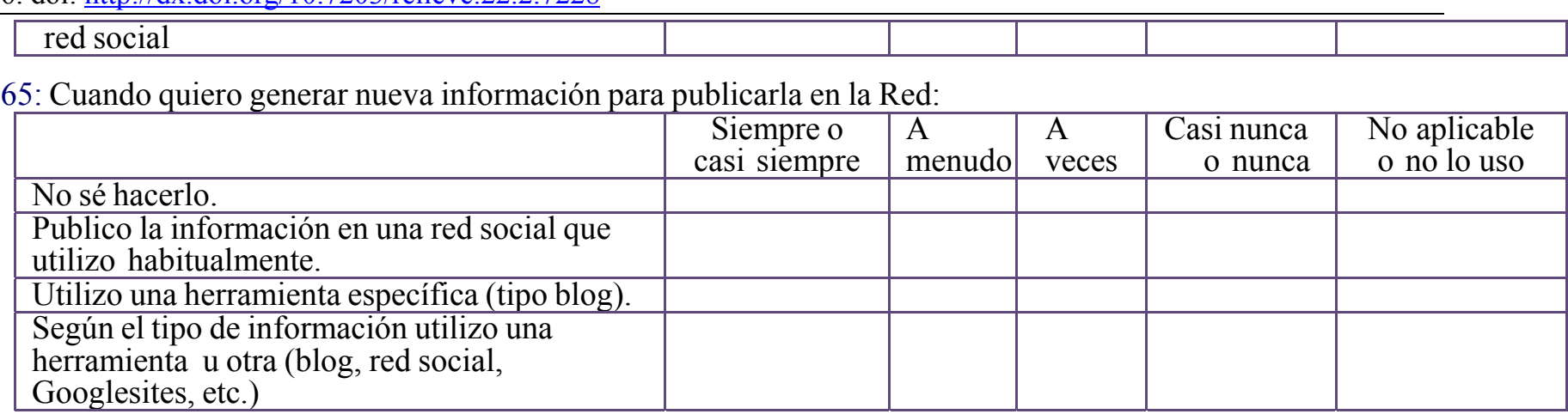

66: Los contenidos digitales que produzco para compartir en red son

\begin{tabular}{|l|l|l|l|l|l|}
\hline & $\begin{array}{c}\text { Siempre o } \\
\text { casi siempre }\end{array}$ & $\begin{array}{l}\text { A } \\
\text { menudo }\end{array}$ & $\begin{array}{c}\text { A } \\
\text { veces }\end{array}$ & $\begin{array}{c}\text { Casi nunca } \\
\text { o nunca }\end{array}$ & $\begin{array}{c}\text { No aplicable } \\
\text { o no lo uso }\end{array}$ \\
\hline Texto & & & & & \\
\hline Icónica (fotografía o imágenes) & & & & & \\
\hline Vídeo & & & & & \\
\hline Audio & & & & & \\
\hline Multimedia & & & & & \\
\hline Hipermedia & & & & & \\
\hline De otro tipo (dí cuáles) & & & & & \\
\hline
\end{tabular}

69: Para crear recursos u objetos de aprendizaje prefiero soportes:
$\square$ Textuales (wikis, blog)
$\square$ Visuales (Flick, Picasa...)
$\square$ Audiovisuales (podcats, Youtube...)
$\square$ Sonoros (podcast)
$\square$ Gráficos de representación mental (mapas conceptuales, líneas de tiempo)
$\square$ Cualquier soporte
$\square$ Otros soportes (dí cuáles)

70: Cuando quiero hacer algo creativo y nuevo:

\begin{tabular}{|c|c|c|c|c|c|}
\hline & $\begin{array}{l}\text { Siempre o } \\
\text { casi siempre }\end{array}$ & $\begin{array}{l}\text { A } \\
\text { menudo }\end{array}$ & $\begin{array}{l}\text { A } \\
\text { veces }\end{array}$ & $\begin{array}{r}\text { Casi nunca } \\
\text { o nunca }\end{array}$ & $\begin{array}{l}\text { No aplicable } \\
\text { o no lo uso }\end{array}$ \\
\hline $\begin{array}{l}\text { Busco información en sitios web y a partir } \\
\text { de esa información genero algo un poco } \\
\text { diferente. }\end{array}$ & & & & & \\
\hline $\begin{array}{l}\text { Selecciono información que considero } \\
\text { relevante y a partir de ahí creo algo nuevo. }\end{array}$ & & & & & \\
\hline Creo algo nuevo sin buscar referentes. & & & & & \\
\hline Actúo de otra forma (di cómo) & & & & & \\
\hline
\end{tabular}

72: Para elaborar informaciones que deseo alojar en la red me ayudo de:

\begin{tabular}{|l|l|l|l|l|l|}
\hline & $\begin{array}{c}\text { Siempre o } \\
\text { casi siempre }\end{array}$ & $\begin{array}{l}\text { A } \\
\text { menudo }\end{array}$ & $\begin{array}{c}\text { A } \\
\text { veces }\end{array}$ & $\begin{array}{c}\text { Casi nunca } \\
\text { o nunca }\end{array}$ & $\begin{array}{c}\text { No aplicable } \\
\text { o no lo uso }\end{array}$ \\
\hline Borradores elaborados en papel & & & & & \\
\hline Borradores elaborados en soporte digital & & & & & \\
\hline $\begin{array}{l}\text { Compañeros, con quienes hablo sobre lo que } \\
\text { estoy elaborando }\end{array}$ & & & & \\
\hline $\begin{array}{c}\text { Compañeros, quienes revisan lo que } \\
\text { estoy elaborando antes de publicarlo }\end{array}$ & & & & & \\
\hline $\begin{array}{l}\text { No utilizo ayudas, edito y publico } \\
\text { directamente la información }\end{array}$ & & & & & \\
\hline Otro tipo de ayudas (di cuáles) & & & & & \\
\hline
\end{tabular}

73: Considero que las líneas del tiempo, los mapas conceptuales y/o mapas mentales:

\begin{tabular}{|l|l|l|l|c|}
\hline & $\begin{array}{c}\text { Totalmente en } \\
\text { desacuerdo }\end{array}$ & $\begin{array}{c}\text { En } \\
\text { desacuerdo }\end{array}$ & $\begin{array}{c}\text { De } \\
\text { acuerdo }\end{array}$ & $\begin{array}{c}\text { Totalmente de } \\
\text { acuerdo }\end{array}$ \\
\hline Permiten conocer de modo intuitivo la información. & & & & \\
\hline
\end{tabular}


Prendes-Espinosa, Maria Paz; Castañeda-Quintero, Linda; Solano-Fernández, Isabel María; Roig-Vila, Rosabel; Aguiar-Perera, M ${ }^{\mathrm{a}}$ Victoria \& Serrano-Sánchez, José Luis (2016). Validación de un cuestionario sobre hábitos de trabajo y aprendizaje para futuros profesionales: explorar los Entornos Personales de Aprendizaje. RELIEVE, 22(2), art. 6. doi: http://dx.doi.org/10.7203/relieve.22.2.7228

\begin{tabular}{|l|l|l|l|}
\hline $\begin{array}{l}\text { Permite determinar a priori las relaciones y jerarquias que } \\
\text { se establecen entre los diferentes conceptos. }\end{array}$ & & & \\
\hline Simplifican demasiado la información. & & & \\
\hline Dificultan la comprensión de la información & & & \\
\hline Permiten conocer de modo intuitivo la información. & & & \\
\hline
\end{tabular}

74: A la hora de comunicarme...

$\square$ Me comunico usando una única herramienta

$\square$ Me comunico usando una única herramienta usando distintos tipo de herramienta en función de la situación

$\square$ Conozco un amplio rango de herramientas y servicios que utilizo en función de cada situación

76: Cuando necesito comunicarme a través de la Red:

\begin{tabular}{|l|c|c|c|c|c|}
\hline & $\begin{array}{c}\text { Siempre o } \\
\text { casi siempre }\end{array}$ & $\begin{array}{c}\text { A } \\
\text { menudo }\end{array}$ & A veces & $\begin{array}{c}\text { Casi nunca o } \\
\text { nunca }\end{array}$ & $\begin{array}{c}\text { No aplicable } \\
\text { o no lo uso }\end{array}$ \\
\hline Apenas me comunico. & & & & & \\
\hline Utilizo herramientas básicas (correo electrónico) & & & & & \\
\hline Utilizo redes sociales (Facebbok, Twitter) & & & & & \\
\hline
\end{tabular}

78: ¿Valoras las aportaciones y críticas de los usuarios?
$\square$ Siempre o casi siempre
$\square$ Casi nunca o nunca
$\square$ A menudo
$\square$ No aplicable o no lo uso
$\square$ A veces

79: Para favorecer la colaboración e interacción con otros prefiero:
$\square$ Redes sociales (Twitter, Facebook...)
$\square$ Correo electrónico Chats
Videoconferencias.
$\square$ Mensajería (Whattsapp, Line, Skype, etc.)
$\square$ Otros (dí cuáles)
$\square$ Utilizo otras estrategias (dí cuáles).

86: Para realizar proyectos colaborativos prefiero utilizar:
$\square$ Google doc
$\square$ Wikis Blogs
$\square$ Redes sociales (Twitter, Facebook...)

$\square$ Entornos virtuales como Moodle, Sakai, etc.

$\square$ Otros (dí cuáles)

89: En el trabajo en equipo priorizo:

\begin{tabular}{|l|c|c|c|c|c|}
\hline & $\begin{array}{c}\text { Siempre o } \\
\text { casi siempre }\end{array}$ & $\begin{array}{c}\text { A } \\
\text { menudo }\end{array}$ & $\begin{array}{c}\text { A } \\
\text { veces }\end{array}$ & $\begin{array}{c}\text { Casi nunca } \\
\text { o nunca }\end{array}$ & $\begin{array}{c}\text { No aplicable } \\
\text { o no lo uso }\end{array}$ \\
\hline Compartirrecursos. & & & & & \\
\hline Interaccionar con otros. & & & & & \\
\hline Construir de forma conjunta & & & & & \\
\hline Actúo con otras prioridades (dí cuáles) & & & & & \\
\hline
\end{tabular}

92: Para realizar proyectos colaborativos prefiero utilizar:

$\checkmark$ Grado de implicación exigido.

$\square$ Todos

$\square$ Grado de libertad ofrecido.

$\square$ Grado de cohesión con los demás.

$\square$ Otro (dí cuáles)

100: Cuando tengo un problema técnico acudo a:

\begin{tabular}{|l|c|c|c|c|c|}
\hline & $\begin{array}{c}\text { Siempre o } \\
\text { casi siempre }\end{array}$ & $\begin{array}{c}\text { A } \\
\text { menudo }\end{array}$ & $\begin{array}{c}\text { A } \\
\text { veces }\end{array}$ & $\begin{array}{c}\text { Casi nunca } \\
\text { o nunca }\end{array}$ & $\begin{array}{c}\text { No aplicable } \\
\text { o no lo uso }\end{array}$ \\
\hline Colegas y amigos presenciales & & & & & \\
\hline Libros & & & & & \\
\hline Profesores y otras figuras & & & & & \\
\hline Medios de comunicación en red & & & & & \\
\hline Blogs o páginas webs & & & & & \\
\hline Wikipedia o enciclopedias en red & & & & & \\
\hline Twitter & & & & & \\
\hline Redes sociales & & & & & \\
\hline Foros & & & & & \\
\hline Tutoriales en vídeo en red o diapositivas & & & & \\
\hline Aplicaciones móviles específicas del tema & & & & \\
\hline $\begin{array}{l}\text { Colegas y amigos contactando por mail o } \\
\text { mensajes privados en otras plataformas (FB, } \\
\text { DM en Twitter, whatsapp) }\end{array}$ & & & & & \\
\hline
\end{tabular}


Prendes-Espinosa, Maria Paz; Castañeda-Quintero, Linda; Solano-Fernández, Isabel María; Roig-Vila, Rosabel; Aguiar-Perera, M ${ }^{\mathrm{a}}$ Victoria \& Serrano-Sánchez, José Luis (2016). Validación de un cuestionario sobre hábitos de trabajo y aprendizaje para futuros profesionales: explorar los Entornos Personales de Aprendizaje. RELIEVE, 22(2), art. 6. doi: http://dx.doi.org/10.7203/relieve.22.2.7228

101: Cuando tengo una duda de contenido durante el proceso de trabajo acudo a:

\begin{tabular}{|l|l|l|l|l|l|}
\hline & $\begin{array}{c}\text { Siempre o } \\
\text { casi siempre }\end{array}$ & $\begin{array}{l}\text { A } \\
\text { menudo }\end{array}$ & $\begin{array}{c}\text { A } \\
\text { veces }\end{array}$ & $\begin{array}{c}\text { Casi nunca } \\
\text { o nunca }\end{array}$ & $\begin{array}{c}\text { No aplicable } \\
\text { o no lo uso }\end{array}$ \\
\hline Colegas y amigos presenciales & & & & & \\
\hline Libros & & & & & \\
\hline Profesores y otras figuras & & & & & \\
\hline Medios de comunicación en red & & & & & \\
\hline Blogs o páginas webs & & & & & \\
\hline Wikipedia o enciclopedias en red & & & & & \\
\hline Twitter & & & & & \\
\hline Redes sociales & & & & & \\
\hline Foros & & & & & \\
\hline Tutoriales en vídeo en red o diapositivas & & & & & \\
\hline Aplicaciones móviles específicas del tema & & & & & \\
\hline $\begin{array}{l}\text { Colegas y amigos contactando por mail o } \\
\text { mensajes privados en otras plataformas (FB, } \\
\text { DM en Twitter, whatsapp) }\end{array}$ & & & & & \\
\hline
\end{tabular}

105: Para la resolución de problemas prefiero:

\begin{tabular}{|l|l|l|l|l|l|}
\hline $\begin{array}{l}\text { Estudiar individualmente las posibles } \\
\text { soluciones. }\end{array}$ & $\begin{array}{c}\text { Siempre o } \\
\text { casi siempre }\end{array}$ & $\begin{array}{l}\text { A } \\
\text { menudo }\end{array}$ & $\begin{array}{l}\text { A } \\
\text { veces }\end{array}$ & $\begin{array}{l}\text { Casi nunca } \\
\text { o nunca }\end{array}$ & $\begin{array}{c}\text { No aplicable } \\
\text { o no lo uso }\end{array}$ \\
\hline Consensuar con otros distintas alternativas. & & & & & \\
\hline Confrontar las diferentes propuestas & & & & & \\
\hline
\end{tabular}

108: Ajusto la cantidad y variedad de herramientas en red que utilizo para aprender en función de:

\begin{tabular}{|l|c|c|c|c|c|}
\hline & $\begin{array}{c}\text { Siempre o } \\
\text { casi siempre }\end{array}$ & $\begin{array}{c}\text { A } \\
\text { menudo }\end{array}$ & $\begin{array}{c}\text { A } \\
\text { veces }\end{array}$ & $\begin{array}{c}\text { Casi nunca } \\
\text { o nunca }\end{array}$ & $\begin{array}{c}\text { No aplicable } \\
\text { o no lo uso }\end{array}$ \\
\hline La importancia que doy a un aprendizaje & & & & & \\
\hline El tiempo que tengo para ese aprendizaje & & & & & \\
\hline La valoración que va a tener ese aprendizaje & & & & & \\
\hline En el impacto que tendrá en mi prestigio en red & & & & & \\
\hline
\end{tabular}

110: Suelo reflejar la reflexión sobre lo que voy aprendiendo

\begin{tabular}{|l|c|l|l|l|l|}
\hline & $\begin{array}{c}\text { Siempre o } \\
\text { casi siempre }\end{array}$ & $\begin{array}{l}\text { A } \\
\text { menudo }\end{array}$ & $\begin{array}{l}\text { A } \\
\text { veces }\end{array}$ & $\begin{array}{l}\text { Casi nunca } \\
\text { o nunca }\end{array}$ & $\begin{array}{c}\text { No aplicable } \\
\text { o no lo uso }\end{array}$ \\
\hline En un blog personal & & & & & \\
\hline En un documento Word & & & & & \\
\hline En mi calendario electrónico & & & & & \\
\hline En una hoja de papel o mi diario & & & & & \\
\hline Otras (di cuáles) & & & & & \\
\hline
\end{tabular}

\section{ANEXO 2}

\section{PROTOCOLO DE ENTREVISTA COGNITIVA}

La entrevista cognitiva es una técnica de validación de instrumentos de evaluación comúnmente utilizada en el ámbito científico, sobre todo en disciplinas de Ciencias de la salud, y específicamente en la construcción cuestionarios psicométricos. Consiste en la administración de un borrador de instrumento, que no tiene por qué contener todas las preguntas incluidas en el mismo, y en la recopilación simultáneamente de información verbal sobre cómo han llegado a responder las preguntas planteadas. La información verbal se debe recoger en formato audio y/o vídeo mediante una grabación. En análisis de la información recogida permitirá evaluar la 
Prendes-Espinosa, Maria Paz; Castañeda-Quintero, Linda; Solano-Fernández, Isabel María; Roig-Vila, Rosabel; Aguiar-Perera, Ma Victoria \& Serrano-Sánchez, José Luis (2016). Validación de un cuestionario sobre hábitos de trabajo y aprendizaje para futuros profesionales: explorar los Entornos Personales de Aprendizaje. RELIEVE, 22(2), art. 6. doi: http://dx.doi.org/10.7203/relieve.22.2.7228

calidad del ítem formulado, su adecuación en la encuesta y sobre todo, permitirá saber si se obtiene la información que el investigador esperaba.

El objetivo de la entrevista cognitiva que hemos diseñado para el proyecto CAPPLE es conocer cómo responden e interpretan los alumnos de último curso de titulación a preguntas sobre su proceso de aprendizaje, así como el uso de herramientas y estrategias de lectura, reflexión y relación que utilizan para llevar a cabo este proceso de aprendizaje. Para ello, hemos seleccionado 10 preguntas target, que serán las que, junto con un reducido número de preguntas sociodemográficas, conformen el cuestionario que le vamos a pasar a los alumnos.

El tipo de entrevista cognitiva que vamos a emplear en este estudio es la entrevista cognitiva concurrente, que consiste en solicitarle a los alumnos que vayan respondiendo en voz alta a las preguntas que les planteemos, manifestando en ese momento sus dudas, problemas o inquietudes. Simultáneamente les iremos planteando una serie de preguntas, que llamaremos en este protocolo "pruebas", para obtener más información sobre la forma en la que se está respondiendo a las preguntas. Con el objetivo de ser lo más precisos posible, elaboraremos pruebas generales y pruebas específicas.

En el desarrollo de esta técnica, resulta fundamental que el entrevistador sea muy riguroso tanto en el desarrollo de la entrevista como en el proceso de recogida de información, ya que de lo contrario, la prueba puede quedar invalidada.

\section{Instrucciones para el grupo entrevistador}

- Tendréis que recoger 5 entrevistas de alumnos de último curso (grado o licenciatura) de titulación. El total de entrevistas quedará conformado por 1 alumno de cada rama de especialización: Ciencias sociales y jurídicas; Ciencias de la Salud; Ciencias; Arquitectura e Ingeniería; Artes y Humanidades.

- Todas las entrevistas tienen que ser grabadas en formato audio. Si alguna entrevista no fuera grabada, no se podrá utilizar, de ahí la importancia de que prestéis mucha atención a este paso.

- Una vez grabadas las entrevistas, tendrán que ser transcritas. La transcripción y el audio deberá ser enviado antes del XXXX a la dirección XXXXXXXX

- Ten en cuenta a la hora de realizar la entrevista que no nos interesan las respuestas que cada alumno da a los items del cuestionario, lo importante es obtener la mayor cantidad de información sobre cómo han llegado a esa respuesta, si resulta confusa, si es fácilmente entendible por el alumno, y faltan opciones de respuesta, etc. Se trata de una discusión informal en la que debes insistir en que necesitamos respuestas sinceras y que nos muestren el significado que dan a las preguntas y en qué se fundamentan para responderlas.

- Es importante que no condiciones a los alumnos en sus respuestas. No respondas a sus dudas, y pídeles que verbalicen sus inquietudes con la pregunta. Si no entienden la formulación o alguna pregunta, pídeles que te expliquen de la manera más detallada posible el motivo. Finalmente el alumno tendrá que responder a la pregunta, o en su defecto dejarla en blanco, pero verbalizando sus inquietudes y problemas para entender la pregunta o responder en función de las opciones que se indican.

- Para asegurarnos de que han entendido bien el proceso a seguir, les pedirás que respondan en 
Prendes-Espinosa, Maria Paz; Castañeda-Quintero, Linda; Solano-Fernández, Isabel María; Roig-Vila, Rosabel; Aguiar-Perera, Ma Victoria \& Serrano-Sánchez, José Luis (2016). Validación de un cuestionario sobre hábitos de trabajo y aprendizaje para futuros profesionales: explorar los Entornos Personales de Aprendizaje. RELIEVE, 22(2), art. 6. doi: http://dx.doi.org/10.7203/relieve.22.2.7228

voz alta a las preguntas sociodemográficas que hay en el cuestionario. Indícales que este es el momento preciso para plantear las dudas que tengan.

- Para todas las preguntas del cuestionario, les pediremos a los alumnos que respondan a estas tres preguntas básicas (o pruebas generales):

- ¿Podrías repetir la pregunta con tus propias palabras?

- ¿En qué piensas a la hora de contestarla?

-¿Qué dudas te surgen a la hora de contestar, si es que te surge alguna?

- Asegúrate de que han entendido bien el proceso, y comienza la entrevista leyendo las instruccions al entrevistado que tienes a continuación:

\section{Instrucciones para el entrevistado}

Antes de comenzar la entrevista, tendrás que leer estas instrucciones a los alumnos entrevistados. Es importante que no olvides ninguno de los enunciados que aquí te indicamos.

- En primer lugar, gracias por participar en este estudio.

- Este estudio está enmarcado dentro de un proyecto Nacional del Ministerio de Economía y Competividad de España.

- En el proyecto, vamos a pasar un cuestionario a alumnos que, como tu, están en su último año de titulación.

- Antes de pasar este cuestionario, necesitamos realizar una serie de pruebas para ver cómo funciona.

- Te voy a dar el cuestionario para que lo cumplimentes; pero como lo que nos interesa es saber cómo funciona este cuestionario, te voy a pedir que, conforme vayas respondiendo a las preguntas, las vayas diciendo en voz alta, así como todo lo que te viene a la cabeza para responderlas.

- Ten en cuenta que no estamos tan interesados en tus respuestas como en cómo has llegado a esas respuestas. Por ello, en relación con cada item del cuestionario, te iré haciendo algunas preguntas para completar la información sobre las mismas. Esto puede resultar en ocasiones un poco repetitivo, pero es fundamental para que nos cuentes en qué has pensado para responder las preguntas del cuestionario.

- Ten en cuenta que nuestro objetivo con esta entrevista es elaborar un cuestionario claro y que funcione, de ahí que te pidamos encarecidamente que nos indiques todo lo que te parezca confuso, o que pueda ser mejorado.

- $\quad$ Esta entrevista va a durar alrededor de 30 minutos.

- Antes de comenzar, ¿tienes alguna pregunta? 


\section{CUESTIONARIO ENTREVISTAS COGNITIVAS}

I. Datos del Entrevistado

Antes empezar te voy a pedir que realizamos una prueba respondiendo a las preguntas iniciales referidas a tus datos que aparecen en el cuestionario.

P.1. ¿Qué edad tienes?

P.2. ¿En qué ciudad estudias?

P. 3. ¿Qué titulación has estudiado?

II. Núcleo de la entrevista

Comenzamos con la entrevista. Lee todas las preguntas en voz y responde reflexionando sobre las respuestas que das.

\section{PREGUNTA 4}

4: ¿Que situaciones aumentan mi interés para aprender sobre algo?

\begin{tabular}{|l|l|c|c|c|c|}
\hline & $\begin{array}{c}\text { Siempre o } \\
\text { casi siempre }\end{array}$ & $\begin{array}{c}\text { A } \\
\text { menudo }\end{array}$ & $\begin{array}{c}\text { A } \\
\text { veces }\end{array}$ & $\begin{array}{c}\text { Casi nunca } \\
\text { o nunca }\end{array}$ & $\begin{array}{c}\text { No aplicable } \\
\text { o no lo uso }\end{array}$ \\
\hline $\begin{array}{l}\text { Mi asistencia a una clase } \\
\text { medios de comunicación tradicionales } \\
\text { (televisión, radio, periódico, revistas) }\end{array}$ & & & & & \\
\hline $\begin{array}{l}\text { Mi participación como oyente en charlas, } \\
\text { conferencias, jornadas... }\end{array}$ & & & & & \\
\hline $\begin{array}{l}\text { La lectura de Noticias que me llegan al } \\
\text { correo }\end{array}$ & & & & & \\
\hline $\begin{array}{l}\text { Mi participación o lectura de temas y } \\
\text { conversaciones en foros en Internet }\end{array}$ & & & & \\
\hline $\begin{array}{l}\text { La lectura o escucha de programas en } \\
\text { Medios de comunicación en red (podcast, } \\
\text { televisión digital, revistas digitales) }\end{array}$ & & & & \\
\hline $\begin{array}{l}\text { La lectura de Blogs o páginas web } \\
\text { La lectura de mi Timeline de Twitter }\end{array}$ & & & & \\
\hline $\begin{array}{l}\text { Mis conversaciones e intercambios en las } \\
\text { redes sociales (Facebook, Tuenti y } \\
\text { Linkedin) }\end{array}$ & & & & \\
\hline $\begin{array}{l}\text { Visitas a sitios de información multimedia } \\
\text { en red (Youtube, Slidesahe, Flickr, Isuu, } \\
\text { prezi, instagram) }\end{array}$ & & & & \\
\hline \begin{tabular}{l} 
Charlas en Whatsapp o Line (o similares) \\
\hline
\end{tabular} & & & & & \\
\hline
\end{tabular}

\section{Prueba general:}

- ¿Podrías repetir la pregunta con tus propias palabras?

- ¿En qué piensas a la hora de contestarla?

- ¿Qué dudas te surgen a la hora de contestar, si es que te surge alguna?

Prueba específica:

¿¿Qué entiendes por "información multimedia en red”?

- ¿Desde qué curso -año de tu carrera has tenido que remontarte para responder a la pregunta para responder? 
Prendes-Espinosa, Maria Paz; Castañeda-Quintero, Linda; Solano-Fernández, Isabel María; Roig-Vila, Rosabel; Aguiar-Perera, Ma Victoria \& Serrano-Sánchez, José Luis (2016). Validación de un cuestionario sobre hábitos de trabajo y aprendizaje para futuros profesionales: explorar los Entornos Personales de Aprendizaje. RELIEVE, 22(2), art. 6. doi: http://dx.doi.org/10.7203/relieve.22.2.7228

\section{PREGUNTA 5}

\section{5: Cuando aprendes en internet ¿Cómo fijas lo que debes aprender?}

\begin{tabular}{|l|c|c|c|c|c|}
\hline & $\begin{array}{c}\text { Siempre o } \\
\text { casi siempre }\end{array}$ & $\begin{array}{c}\text { A } \\
\text { menudo }\end{array}$ & A veces & $\begin{array}{c}\text { Casi nunca } \\
\text { o nunca }\end{array}$ & $\begin{array}{c}\text { No aplicable } \\
\text { o no lo uso }\end{array}$ \\
\hline $\begin{array}{c}\text { Me ajusto a los objetivos definidos en la } \\
\text { asignatura/el proyecto en el que trabaje }\end{array}$ & & & & & \\
\hline $\begin{array}{l}\text { Me ajusto a los temas que vayan surgiendo } \\
\text { Me ajusto a las capacidades que tengo }\end{array}$ & & & & & \\
\hline $\begin{array}{l}\text { Me ajusto a las necesidades laborales } \\
\begin{array}{c}\text { Me ajusto a lo que creo que mis colegas } \\
\text { me exigirán }\end{array}\end{array}$ & & & & & \\
\hline
\end{tabular}

Prueba general:

- ¿Podrías repetir la pregunta con tus propias palabras?

- ¿En qué piensas a la hora de contestarla?

-¿Qué dudas te surgen a la hora de contestar, si es que te surge alguna?

Prueba específica:

- ¿Consideras que todas las posibles opciones de respuestas están contempladas en la pregunta? En caso negativo, ¿cuál faltaría?

• ¿Consideras que sobraría alguna opción de respuesta? En caso afirmativo indica cuál.

\section{PREGUNTA 6}

\section{6: A la hora de organizar mí tiempo y recursos en cuanto a trabajos y tareas}

\begin{tabular}{|c|c|c|c|c|c|}
\hline & $\begin{array}{c}\text { Siempre o } \\
\text { casi siempre }\end{array}$ & $\begin{array}{c}\mathrm{A} \\
\text { menudo }\end{array}$ & A veces & $\begin{array}{l}\text { Casi nunca } \\
\text { o nunca }\end{array}$ & $\begin{array}{l}\text { No aplicable } \\
\text { o no lo uso }\end{array}$ \\
\hline Utilizo una agenda en papel. & & & & & \\
\hline Utilizo un calendario en red. & & & & & \\
\hline $\begin{array}{l}\text { Utilizo algún tipo de herramienta agregador } \\
\text { para organizar mis recursos y herramientas } \\
\text { en red tipo Symbaloo, netvibes }\end{array}$ & & & & & \\
\hline $\begin{array}{l}\text { Utilizo algún contador de tiempo de } \\
\text { aprendizaje para organizar mis tiempos en } \\
\text { red (Tipo "pomodoro") }\end{array}$ & & & & & \\
\hline No suelo organizar mi tiempo y recursos & & & & & \\
\hline
\end{tabular}

Prueba general:

- ¿Podrías repetir la pregunta con tus propias palabras?

- ¿En qué piensas a la hora de contestarla?

- ¿Qué dudas te surgen a la hora de contestar, si es que te surge alguna?

Prueba específica:

¿¿Qué entiendes por "herramienta agregador”?

- ¿Consideras que falta alguna opción de respuesta? En caso afirmativo, indica cuál.

\section{PREGUNTA 7}

\section{7: Para acceder a la información realizo...}

$\square$ Búsquedas "de tanteo" en manuales, libros de texto, enciclopedias 
$\square$ Búsquedas "de tanteo" en buscadores web.

$\square$ Busquedas sistematizadas en revistas especializadas.

$\square$ Busquedas en base de datos concretas.

$\square$ Búsquedas en sitios y portales Web especializados.

$\square$ Busqueda por autores de referencia.

口 Otro tipo de búsquedas. ¿Cuáles?

Prueba general:

- ¿Podrías repetir la pregunta con tus propias palabras?

- ¿En qué piensas a la hora de contestarla?

- ¿Qué dudas te surgen a la hora de contestar, si es que te surge alguna?

Prueba específica:

¿¿Qué entiendes por “"búsquedas de tanteo”?

- Cuando buscas información en la red, ¿sueles encontrar lo que buscas?

\section{PREGUNTA 8}

\section{8: Cuando quiero aprender algo nuevo acudo a:}

\begin{tabular}{|l|l|l|l|l|l|}
\hline & $\begin{array}{c}\text { Siempre o } \\
\text { casi siempre }\end{array}$ & A menudo & A veces & $\begin{array}{c}\text { Casi nunca } \\
\text { o nunca }\end{array}$ & $\begin{array}{c}\text { No aplicable } \\
\text { o no lo uso }\end{array}$ \\
\hline $\begin{array}{l}\text { Me vienen a la mente espontáneamente } \\
\text { conocimientos }\end{array}$ & & & & & \\
\hline $\begin{array}{l}\text { Hablo mentalmente } \\
\text { Hablo en voz baja conmigo mismo }\end{array}$ & & & & & \\
\hline $\begin{array}{l}\text { Utilizo un papel para escribir o } \\
\text { representar las ideas o los } \\
\text { conocimientos }\end{array}$ & & & & \\
\hline $\begin{array}{l}\text { Recurro a materiales que he elaborado y } \\
\text { que tienen relación directa con dichos } \\
\text { conocimientos }\end{array}$ & & & & & \\
\hline $\begin{array}{c}\text { Tengo la información categorizada para } \\
\text { su recuperación }\end{array}$ & & & & & \\
\hline $\begin{array}{c}\text { Utilizo otras estrategias de acceso al } \\
\text { conocimiento (di cuáles) }\end{array}$ & & & & & \\
\hline
\end{tabular}

\section{Prueba general:}

- ¿Podrías repetir la pregunta con tus propias palabras?

- ¿En qué piensas a la hora de contestarla? ¿Has tenido que pensar en situaciones concretas para responder a la pregunta? Comenta brevemente alguna de ellas.

-¿Qué dudas te surgen a la hora de contestar, si es que te surge alguna?

Prueba específica:

- ¿Entiendes todas las opciones que se plantean en la pregunta? En caso negativo, indica cuál y por qué.

\section{PREGUNTA 9}




\section{9: Cuando quiero hacer algo creativo y nuevo:}

\begin{tabular}{|l|l|l|l|l|l|}
\hline & $\begin{array}{c}\text { Siempre o } \\
\text { casi siempre }\end{array}$ & $\begin{array}{c}\text { A } \\
\text { menudo }\end{array}$ & A veces & $\begin{array}{c}\text { Casi nunca } \\
\text { o nunca }\end{array}$ & $\begin{array}{c}\text { No } \\
\text { aplicable o } \\
\text { no lo uso }\end{array}$ \\
\hline $\begin{array}{l}\text { Busco información en sitios web y a partir } \\
\text { de esa información genero algo un poco } \\
\text { diferente. }\end{array}$ & & & & & \\
\hline $\begin{array}{l}\text { Selecciono información que considero } \\
\text { relevante y a partir de ahí creo algo nuevo. }\end{array}$ & & & & & \\
\hline Creo algo nuevo sin buscar referentes. & & & & & \\
\hline Actúo de otra forma (di cómo) & & & & & \\
\hline
\end{tabular}

Prueba general:

- ¿Podrías repetir la pregunta con tus propias palabras?

- ¿En qué piensas a la hora de contestarla? ¿Has tenido que pensar en situaciones concretas para responder a la pregunta? Comenta brevemente alguna de ellas.

-¿Qué dudas te surgen a la hora de contestar, si es que te surge alguna?

Prueba específica:

• ¿Consideras que falta alguna opción de respuesta? En caso afirmativo, indica cuál.

\section{PREGUNTA 10}

10: Para elaborar informaciones que deseo alojar en la red me ayudo de:

\begin{tabular}{|l|c|c|c|c|c|}
\hline & $\begin{array}{c}\text { Siempre o } \\
\text { casi siempre }\end{array}$ & $\begin{array}{c}\text { A } \\
\text { menudo }\end{array}$ & A veces & $\begin{array}{c}\text { Casi nunca } \\
\text { o nunca }\end{array}$ & $\begin{array}{c}\text { No aplicable } \\
\text { o no lo uso }\end{array}$ \\
\hline Borradores elaborados en papel & & & & \\
\hline $\begin{array}{c}\text { Borradores elaborados en soporte digital } \\
\begin{array}{c}\text { Compañeros, con quienes hablo sobre lo } \\
\text { que estoy elaborando }\end{array}\end{array}$ & & & & & \\
\hline $\begin{array}{c}\text { Compañeros, quienes revisan lo que estoy } \\
\text { elaborando antes de publicarlo }\end{array}$ & & & & & \\
\hline $\begin{array}{c}\text { No utilizo ayudas, edito y publico } \\
\text { directamente la información }\end{array}$ & & & & & \\
\hline Otro tipo de ayudas (di cuáles) & & & & & \\
\hline
\end{tabular}

Prueba general:

- ¿Podrías repetir la pregunta con tus propias palabras?

- ¿En qué piensas a la hora de contestarla?

- ¿Qué dudas te surgen a la hora de contestar, si es que te surge alguna?

Prueba específica:

• ¿Consideras que sobra alguna opción de respuesta? En caso afirmativo, indica cuál.

\section{PREGUNTA 11}

\section{1: Para favorecer la colaboración e interacción con otros prefiero:}

$\square$ Redes sociales (Twitter, Facebook...) Correo electrónico

$\square$ Chats Videoconferencias.

$\square$ Mensajería (Whattsapp, Line, Skype, etc.) Otros (dí cuáles) 
Prendes-Espinosa, Maria Paz; Castañeda-Quintero, Linda; Solano-Fernández, Isabel María; Roig-Vila, Rosabel; Aguiar-Perera, Ma Victoria \& Serrano-Sánchez, José Luis (2016). Validación de un cuestionario sobre hábitos de trabajo y aprendizaje para futuros profesionales: explorar los Entornos Personales de Aprendizaje. RELIEVE, 22(2), art. 6. doi: http://dx.doi.org/10.7203/relieve.22.2.7228

๑ Utilizo otras estrategias (dí cuáles).

Prueba general:

- ¿Podrías repetir la pregunta con tus propias palabras?

- ¿En qué piensas a la hora de contestarla?

- ¿Qué dudas te surgen a la hora de contestar, si es que te surge alguna?

Prueba específica:

-¿Qué entiendes por "estrategias"?

- Al responder a esta pregunta ¿has pensado en el contexto educativo de la titulación que has cursado o en un contexto personal y de ocio?

\section{PREGUNTA 12}

\section{2: Para realizar proyectos colaborativos prefiero utilizar:}

$\square$ Grado de implicación exigido.

$\square$ Grado de libertad ofrecido.

$\square$ Todos.

$\square$ Grado de cohesión con los demás.

Prueba general:

- ¿Podrías repetir la pregunta con tus propias palabras?

- ¿En qué piensas a la hora de contestarla?

-¿Qué dudas te surgen a la hora de contestar, si es que te surge alguna?

Prueba específica:

¿¿Qué entiendes por "proyectos colaborativos”?

•¿Con qué seguridad afirmas (la opción/es que elijan)...?

\section{PREGUNTA 13}

\section{3: Ajusto la cantidad y variedad de herramientas en red que utilizo para aprender en función de:}

\begin{tabular}{|l|c|c|c|c|c|}
\hline & $\begin{array}{c}\text { Siempre o } \\
\text { casi siempre }\end{array}$ & $\begin{array}{c}\text { A } \\
\text { menudo }\end{array}$ & A veces & $\begin{array}{c}\text { Casi nunca } \\
\text { o nunca }\end{array}$ & $\begin{array}{c}\text { No aplicable } \\
\text { o no lo uso }\end{array}$ \\
\hline La importancia que doy a un aprendizaje & & & & & \\
\hline $\begin{array}{l}\text { El tiempo que tengo para ese aprendizaje } \\
\text { aprendizaje que va a tener ese }\end{array}$ & & & & & \\
\hline $\begin{array}{l}\text { En el impacto que tendrá en mi prestigio } \\
\text { en red }\end{array}$ & & & & & \\
\hline
\end{tabular}

Prueba general:

- ¿Podrías repetir la pregunta con tus propias palabras?

- ¿En qué piensas a la hora de contestarla?

- ¿Qué dudas te surgen a la hora de contestar, si es que te surge alguna?

Prueba específica:

- ¿Entiendes todas las opciones que se plantean en la pregunta? En caso negativo, indica cuál y por qué.

•¿Consideras que falta alguna opción de respuesta? En caso afirmativo, indica cuál.

Hemos terminado con la entrevista. Muchas gracias por tu colaboración. 
Prendes-Espinosa, Maria Paz; Castañeda-Quintero, Linda; Solano-Fernández, Isabel María; Roig-Vila, Rosabel; Aguiar-Perera, Ma Victoria \& Serrano-Sánchez, José Luis (2016). Validación de un cuestionario sobre hábitos de trabajo y aprendizaje para futuros profesionales: explorar los Entornos Personales de Aprendizaje. RELIEVE, 22(2), art. 6. doi: http://dx.doi.org/10.7203/relieve.22.2.7228

\section{ANNEX 3}

Por favor Marca con una X en cada caso, indicando si SÍ considera que los enunciados se corresponden, o si NO, o si propone otra enunciación

\begin{tabular}{|c|c|c|c|c|c|}
\hline \multicolumn{2}{|l|}{ Tipo de información a recopilar } & \multirow[b]{2}{*}{ COD } & \multirow{2}{*}{ "๘ } & \multirow[b]{2}{*}{$\stackrel{?}{\mathbf{Z}}$} & \multirow{2}{*}{$\begin{array}{c}\text { Objeciones o Enunciación } \\
\text { alternativa }\end{array}$} \\
\hline NOMBRE original & Propuesta & & & & \\
\hline $\begin{array}{l}\text { Para qué emplea internet y si la usa } \\
\text { con conciencia formativa }\end{array}$ & Finalidad del uso deinternet & 1 & & & \\
\hline Creación de objetivos & $\begin{array}{l}\text { Uso de internet en base a unos } \\
\text { objetivos }\end{array}$ & 2 & & & \\
\hline ¿Qué situaciones le motivan? & $\begin{array}{l}\text { Situaciones motivadoras para el } \\
\text { aprendizaje }\end{array}$ & 3 & & & \\
\hline $\begin{array}{l}\text { Reflexión sobre motivación } \\
\text { intrínseca }\end{array}$ & \multirow{2}{*}{$\begin{array}{l}\text { Reflexión sobre motivación intrínseca } \\
\text { Factores que inciden en la motivación }\end{array}$} & 4 & & & \\
\hline $\begin{array}{l}\text { ¿Qué factores inciden en mi } \\
\text { motivación? }\end{array}$ & & 5 & & & \\
\hline $\begin{array}{l}\text { Capacidad para identificar sus } \\
\text { necesidad de aprendizaje apoyadas } \\
\text { en internet }\end{array}$ & $\begin{array}{l}\text { Adaptación al proceso de aprendizaje } \\
\text { en internet }\end{array}$ & 6 & & & \\
\hline $\begin{array}{l}\text { Reflexión sobre conocimientos } \\
\text { previos }\end{array}$ & \multirow{2}{*}{$\begin{array}{l}\text { Valoración previa del esfuerzo a } \\
\text { realizar } \\
\text { Imagen personal en el aprendizaje en } \\
\text { red }\end{array}$} & 7 & & & \\
\hline $\begin{array}{l}\text { Cuál es la imagen que tiene la } \\
\text { persona que aprende usando la red. }\end{array}$ & & 10 & & & \\
\hline $\begin{array}{l}\text { Comunicación a través de } \\
\text { herramientas digital }\end{array}$ & Perspectiva sobre la evaluación & 12 & & & \\
\hline $\begin{array}{l}\text { Uso de redes sociales para } \\
\text { establecer objetivos a larga plazo }\end{array}$ & $\begin{array}{l}\text { Uso de redes sociales para establecer } \\
\text { objetivos a larga plazo }\end{array}$ & 13 & & & \\
\hline $\begin{array}{l}\text { ¿Cómo organizas y planificas tu } \\
\text { aprendizaje? }\end{array}$ & Organización del estudio & 14 & & & \\
\hline $\begin{array}{l}\text { ¿Dónde organiza su tiempo de } \\
\text { trabajo, }\end{array}$ & $\begin{array}{l}\text { Recursos para la organización del } \\
\text { trabajo }\end{array}$ & 19 & & & \\
\hline $\begin{array}{l}\text { ¿Cómo se facilitaría la asimilación } \\
\text { de los contenidos? }\end{array}$ & $\begin{array}{l}\text { Recursos para la asimilación de } \\
\text { contenidos }\end{array}$ & 22 & & & \\
\hline $\begin{array}{l}\text { ¿Dónde busca ayuda cuando quiere } \\
\text { aprender algo sobre una herramienta } \\
\text { o aplicación nueva? }\end{array}$ & $\begin{array}{l}\text { Localización de recursos de ayuda } \\
\text { para un nuevo aprendizaje }\end{array}$ & 24 & & & \\
\hline $\begin{array}{l}\text { ¿Cómo buscas la información que } \\
\text { necesitas? }\end{array}$ & $\begin{array}{l}\text { Herramienta de búsqueda de } \\
\text { información }\end{array}$ & 25 & & & \\
\hline $\begin{array}{l}\text { ¿Qué mecanismo arbitra, en primer } \\
\text { lugar, para buscar información? }\end{array}$ & $\begin{array}{l}\text { Mecanismos para la búsqueda de } \\
\text { información }\end{array}$ & 27 & & & \\
\hline $\begin{array}{l}\text { ¿Utiliza herramientas de formación } \\
\text { online no institucionales? }\end{array}$ & Formación complemetaria & 29 & & & \\
\hline \multirow[t]{2}{*}{$\begin{array}{l}\text { ¿Cómo ordena y reordena } \\
\text { internamente la información? } \\
\text { ¿Cómo organiza la información } \\
\text { fuera de la red? } \\
\text { ¿Cómo organiza la información en } \\
\text { la red? }\end{array}$} & $\begin{array}{l}\text { Herramientas o recursos para el } \\
\text { almacenamiento de información }\end{array}$ & 31 & & & \\
\hline & & 32 & & & \\
\hline $\begin{array}{l}\text { ¿Cómo gestiono el tratamiento de la } \\
\text { información? }\end{array}$ & $\begin{array}{l}\text { Gestión del tratamiento de la } \\
\text { información }\end{array}$ & 33 & & & \\
\hline $\begin{array}{l}\text { Wikis, Blogs, aplicaciones en } \\
\text { línea, ... }\end{array}$ & $\begin{array}{l}\text { Herramientas de gestión } \\
\text { y organización de la información }\end{array}$ & 35 & & & \\
\hline $\begin{array}{l}\text { ¿Cómo se organiza los contenidos el } \\
\text { alumno? } \\
\text { ¿Cómo relaciona los contenidos? }\end{array}$ & $\begin{array}{l}\text { Criterios para la organización de la } \\
\text { información }\end{array}$ & 36 & & & \\
\hline $\begin{array}{l}\text { Relación entre wikis y fase } 1 \text { del } \\
\text { ciclo SRL de } \\
\text { (Planificación) }\end{array}$ & $\begin{array}{l}\text { Uso de wikis para la organización de } \\
\text { la información }\end{array}$ & 60 & & & \\
\hline
\end{tabular}


Prendes-Espinosa, Maria Paz; Castañeda-Quintero, Linda; Solano-Fernández, Isabel María; Roig-Vila, Rosabel; Aguiar-Perera, Ma Victoria \& Serrano-Sánchez, José Luis (2016). Validación de un cuestionario sobre hábitos de trabajo y aprendizaje para futuros profesionales: explorar los Entornos Personales de Aprendizaje. RELIEVE, 22(2), art.

6. doi: http://dx.doi.org/10.7203/relieve.22.2.7228

\section{Tipo de información a recopilar} NOMBRE original

Negociación de significados, relacionado con la fase 2 del ciclo SRL de Zimmerman

Negociación de significados, relacionado con la fase 2 del ciclo SRL de Zimmerman

¿Cómo prefieres que se te presente la información?

Recuperar información

¿Cómo accede a conocimientos integrados e informaciones conocidas?

Cómo accede a conocimientos integrados e informaciones conocidas?

Cómo accede a conocimientos integrados e informaciones conocidas?

¿cuestiona la información que le Ilega?

Evaluación de la información

¿qué hace que le dé más importancia a alguna información?

¿Cómo se posiciona ante la

información recibida?

¿Cómo la contrasta?

¿Cómo se lleva a cabo el proceso de selección de la información relevante?

¿Qué le lleva a coger una información y no otra?

Gestión de la Propiedad Intelectual

¿Qué hace con un documento que le parece interesante?

¿Qué hace con los vídeos o audios que les parece interesante?

¿Cómo visualiza internamente las informaciones?

¿Cómo construye y re- construye internamente el conocimiento?

¿Qué hace con la información relevante?

¿Cómo genera nueva

información a partir del

conocimiento adquirido?

Producción

Youtube, Podcast, Albumenes Web,

¿Cómo innovo al usar las TIC?

¿Cómo construye la información para comunicarla?

¿Qué tipo de lenguajes emplea para elaborarla?

Líneas del tiempo. Mapas conceptuales. Mapas mentales.

Canales de comunicación

¿Cómo se comunica?

Aceptación y consideración de otros usuarios.

\section{Propuesta}

Uso de wikis para organizar el contenido de forma colaborativa

Uso de servicios de publicación para organizar el contenido de forma colaborativa

Preferencias sobre la presentación de la información

Recuperación de la información

Mecanismos de acceso a conocimientos integrados

Mecanismos de acceso a información almacenada en red

Mecanismos de acceso a información elaborada

Cuestionamiento de la información recibida

Evaluación de la información

Criterios de credibilidad de la información

Contraste la información recibida

Proceso de selección de la información relevante

Criterios de selección de la información

Gestión de la Propiedad Intelectual

Actuación ante documentos relevantes

Actuación ante vídeos o audios relevantes

Visualización interna de la información

Actuación ante información relevante encontrada

Proceso de generación

de información en red a partir del conocimiento adquirido

Tipo de información que se produce para compartir en red

Tipo de soportes para la creación de recursos u objetos de aprendizaje Innovación en el uso de las TIC

Modo de construcción de la información para su posterior comunicación

Percepciones sobre las líneas del tiempo, mapas conceptuales y mapas mentales.

Canales de comunicación

Herramientas para la comunicación red

Aceptación y consideración de otros usuarios

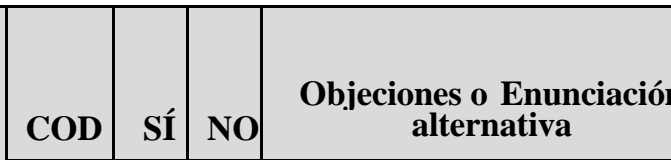
alternativa

37

38

39

42

43

44

47

51

52

56

57

58

64

65

66

69

70

72

73

74

76

78 
Prendes-Espinosa, Maria Paz; Castañeda-Quintero, Linda; Solano-Fernández, Isabel María; Roig-Vila, Rosabel; Aguiar-Perera, Ma Victoria \& Serrano-Sánchez, José Luis (2016). Validación de un cuestionario sobre hábitos de trabajo y aprendizaje para futuros profesionales: explorar los Entornos Personales de Aprendizaje. RELIEVE, 22(2), art. 6. doi: http://dx.doi.org/10.7203/relieve.22.2.7228

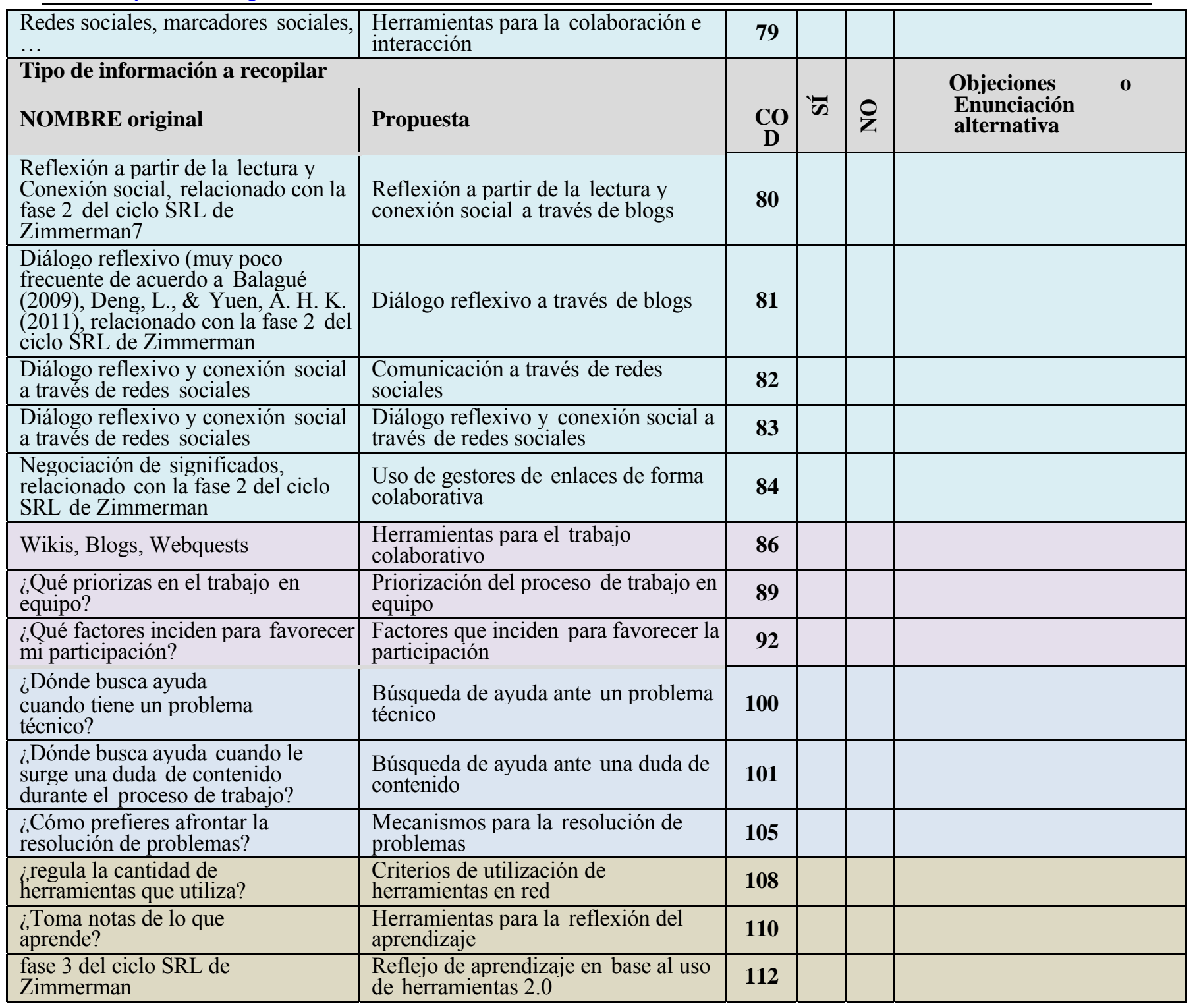


Prendes-Espinosa, Maria Paz; Castañeda-Quintero, Linda; Solano-Fernández, Isabel María; Roig-Vila, Rosabel; Aguiar-Perera, Ma Victoria \& Serrano-Sánchez, José Luis (2016). Validación de un cuestionario sobre hábitos de trabajo y aprendizaje para futuros profesionales: explorar los Entornos Personales de Aprendizaje. RELIEVE, 22(2), art. 6. doi: http://dx.doi.org/10.7203/relieve.22.2.7228

\begin{tabular}{l} 
Autores / Authors \\
\hline Prendes-Espinosa, María Paz (pazprend@um.es) \\
Pedagoga, Doctora en Pedagogía por la Universidad de Murcia, profesora del \\
Departamento de Didáctica y Organización Escolar de la Universidad de Murcia y \\
directora del Grupo de Investigación de Tecnología Educativa de la misma \\
institución. Directora de varios proyectos nacionales e internacionales de \\
implementación de TIC en contextos educativos e Investigadora Principal del \\
proyecto CAPPLE. Su dirección postal es Dpto. de Didáctica y Organización \\
Escolar, Facultad de Educación. Campus de Espinardo - Universidad de Murcia. \\
30100-Murcia (España)
\end{tabular}

\section{Castañeda-Quintero, Linda (lindacq@um.es)}

Pedagoga, Doctora en Tecnología Educativa por la Universitat de les Illes Balears. Profesora del Departamento de Didáctica y Organización Escolar de la Universidad de Murcia y miembro del Grupo de Investigación de Tecnología Educativa de la Universidad de Murcia Su dirección postal es Dpto. de Didáctica y Organización Escolar, Facultad de Educación. Campus de Espinardo - Universidad de Murcia. 30100-Murcia (España)

To know more / Saber más

$\underline{0000-0001-8375-5983}$

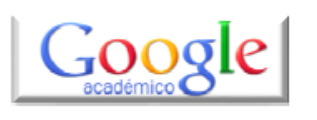

ResearchGate

academia.edu

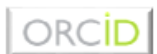

$\underline{0000-0002-1055-924}$

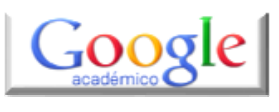

ResearchGate

academia.edu

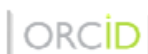

$\underline{0000-0003-3760-8899}$

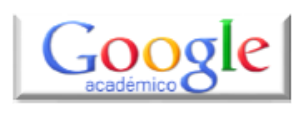

\section{Solano-Fernández, Isabel María (imsolano@um.es)}

Pedagoga, Doctora en Pedagogía por la Universidad de Murcia y Profesora del Departamento de Didáctica y Organización Escolar de la Universidad de Murcia y miembro del Grupo de Investigación de Tecnología Educativa de la Universidad de Murcia. Su dirección postal es Dpto. de Didáctica y Organización Escolar, Facultad de Educación. Campus de Espinardo - Universidad de Murcia. 30100-Murcia (España)

\section{Roig-Vila, Rosabel (rosabel.roig@ua.es)}

Doctora en Pedagogía por la Universidad de Alicante y profesora titular del Área de Didáctica y Organización Escolar en el Departamento de Didáctica General y Didácticas Específicas de esta misma Universidad. Editora la revista científica del campo de las ciencias de la educación Journal of New Approaches in the Educational Research y directora del Máster en Educación y Tecnologías de la Información y la Comunicación de la Universidad de Alicante. Su dirección postal es Universidad de Alicante, Apdo. de correos 99, 03080-Alicante (España).

ORCID

$\underline{0000-0002-9731-430 X}$

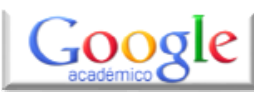

ResearchGate

academia.edu

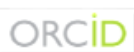

0000-0003-0017-9058

Doctora en Psicopedagogía por la Universidad de Las Palmas de Gran Canaria y Profesora Titular de Universidad impartiendo docencia en Nuevas Tecnologías aplicadas a la educación desde el curso 1993. Su dirección postal es Calle Juana de Arco, 1. ES35004 - Las Palmas de Gran Canaria (España)

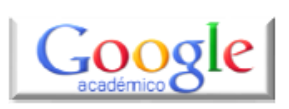

ORCID $\underline{0000-0003-2359-959 X}$

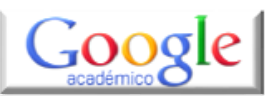

ResearchGate de Educación. Campus de Espinardo - Universidad de Murcia. 30100-Murcia (España) 
Prendes-Espinosa, Maria Paz; Castañeda-Quintero, Linda; Solano-Fernández, Isabel María; Roig-Vila, Rosabel; Aguiar-Perera, Ma Victoria \& Serrano-Sánchez, José Luis (2016). Validación de un cuestionario sobre hábitos de trabajo y aprendizaje para futuros profesionales: explorar los Entornos Personales de Aprendizaje. RELIEVE, 22(2), art. 6. doi: http://dx.doi.org/10.7203/relieve.22.2.7228

\section{RELIEVE}

\section{Revista ELectrónica de Investigación y $\mathbf{E V}$ aluación Educativa E-Journal of Educational Research, Assessment and Evaluation}

[ISSN: 1134-4032]

(C) Copyright, RELIEVE. Reproduction and distribution of this articles it is authorized if the content is no modified and their origin is indicated (RELIEVE Journal, volume, number and electronic address of the document).

(C) Copyright, RELIEVE. Se autoriza la reproducción y distribución de este artículo siempre que no se modifique el contenido y se indique su origen (RELIEVE, volumen, número y dirección electrónica del documento). 